Universidade de São Paulo

Faculdade de Filosofia, Letras e Ciências Humanas

Departamento de Linguística

Programa de Pós-graduação em Semiótica e Linguística Geral

\title{
Tipologia e uso dos pronomes independentes na língua lakota
}

\author{
Roger Buono
}

Dissertação apresentada à faculdade de Filosofia, Letras e Ciências Humanas da Universidade de São Paulo para a obtenção do título de mestre em letras no Programa de Pósgraduação em Semiótica e Linguística geral.

Orientação: Prof. Dr. Paulo Chagas de Souza 
Autorizo a reprodução e divulgação total ou parcial deste trabalho, por qualquer meio convencional ou eletrônico, para fins de estudo e pesquisa, desde que citada a fonte.

Catalogação na Publicação

Serviço de Biblioteca e Documentação

Faculdade de Filosofia, Letras e Ciências Humanas da Universidade de São Paulo

B943t Buono, Roger

Tipologia e uso dos pronomes independentes na

língua lakota / Roger Buono ; orientador Paulo chagas Souza. - São Paulo, 2017.

$147 \mathrm{f}$.

Dissertação (Mestrado) - Faculdade de Filosofia, Letras e Ciências Humanas da Universidade de São

Paulo. Departamento de Linguística. Área de

concentração: Semiótica e Lingüística Geral.

1. lakota. 2. morfossintaxe. 3. funcionalismo. I. Souza, Paulo chagas, orient. II. Título. 
Nome: $\quad$ BUONO, Roger

Título: $\quad$ Tipologia e uso dos pronomes independentes na língua lakota

Dissertação apresentada à faculdade de Filosofia, Letras e Ciências Humanas da Universidade de São Paulo para obtenção do título de mestre.

Aprovado em:

Banca examinadora:

Prof. Dr.

Instituição:

Julgamento: Assinatura:

Prof. Dr. Instituição: Julgamento: Assinatura:

Prof. Dr. Instituição: Julgamento: Assinatura: 



\section{Agradecimentos}

Agradeço profundamente a todo o conhecimento e sabedoria que pude aprender do povo lakota neste pouco tempo e à sua luta pela sobrevivência e pela manutenção de sua língua/tradição.

Agradeço à Universidade de São Paulo, à sua Faculdade de Filosofia, Letras e Ciências Humanas e ao Departamento de Linguística pelo acolhimento e pela oportunidade de realizar este trabalho.

Ao Prof. Dr. Paulo Chagas de Souza, pela orientação, pelo incentivo e por ter depositado confiança em meu trabalho.

À profa. Dra. Ana Paula Scher e ao prof. Dr. Paulo Roberto Gonçalves Segundo, que participaram do meu exame de qualificação e contribuíram com ótimas sugestões e questionamentos.

À CAPES, pela bolsa de estudos que, durante dois anos, foi minha principal fonte de renda.

Agradeço ainda a todos aqueles sem os quais eu não estaria aqui, em especial meus pais e avós, aos demais familiares e amigos, que muito me ajudaram, ainda que indiretamente com sua paciência.

Por último, agradeço a meu orí, por me apoiar e não me abandonar nos momentos mais confusos. 



\section{Resumo}

O lakota é uma língua do tipo head-marking falada no centro dos Estados Unidos, principalmente nos estados de Dakota do Norte e Dakota do Sul. O presente trabalho visa analisar e demonstrar um aspecto da língua ainda pouco explorado: a morfologia da classe de palavras tradicionalmente conhecida como pronome. Há nesta língua evidências de que tal classe é composta de uma raiz verbal precedida por morfemas pessoais, os mesmos usados nos verbos regulares, e seu uso dentro de uma sentença é similar ao da clivagem. Da mesma forma que os pronomes pessoais, os substantivos, os números e os pronomes interrogativos também podem receber os mesmos morfemas em determinados contextos e, assim, exercer função de núcleo do predicado. $O$ modelo teórico adotado para a análise da língua é a Gramatica de Papel e Referência (Van Valin \& Lapolla, 1998), um modelo funcionalista que busca compreender a manifestação de estruturas gramaticais levando em consideração seus aspectos semânticos e pragmáticos. Suas principais motivações são como desenvolver um modelo teórico baseando-se em línguas de tipologias diversas, especialmente aquelas de estruturas diferentes das do inglês ou de outras línguas europeias e de que modo a interação entre sintaxe, semântica e pragmática pode ser melhor descrita em sistemas linguísticos diferentes. A metodologia consiste em extrair e analisar as sentenças pertinentes de duas das maiores obras em língua lakota atualmente disponíveis: os livros Dakota Texts (Deloria, 1932) e New Lakota Dictionary (Ullrich, 2008). As sentenças serão analisadas de acordo com sua estrutura morfológica e sintática, bem como pelo uso que é feito das ocorrências. Além disso, será necessário apresentar também o uso das marcas de pessoa nos verbos, em especial aqueles usados na identificação e categorização de entidades, a fim de estabelecer paralelos entre as duas ocorrências.

\section{Palavras-chave: lakota, morfossintaxe, funcionalismo}





\begin{abstract}
Lakota is a head-marking language, spoken in the Midwest Region of the United States, mainly in the states of North Dakota and South Dakota. This work aims to analyze and demonstrate one aspect of the language that has been little explored: the morphology of the part of speech traditionally known as independent pronoun. In this language, there is evidence that such part of speech is composed of a verbal root preceded by personal morphemes, the same ones used in regular verbs, and its usage within a sentence is similar to that of the cleft sentence. As well as personal pronouns, nouns, numbers and interrogative pronouns may also have the same morphemes in certain contexts and, then, are able to perform the function of core of the predicate. The theoretical model adopted to analyze the language is Role and Reference Grammar (Van Valin \& Lapolla, 1998), a functionalist model that seeks to understand the manifestation of grammatical structures, considering their semantic and pragmatic aspects. Its main motivations are how to develop a theoretical model based on languages of different typologies, especially those whose structures are different from the English ones and other European languages, and how syntax, semantics and pragmatics can best be described in different linguistic systems. The methodology consists of extracting and analyzing relevant sentences from two of the greatest works in Lakota language that are currently available: Dakota Texts (Deloria, 1932) and New Lakota Dictionary (Ullrich, 2008). The sentences will be analyzed according to their morphological and syntactic structures, as well as the usage made of the occurrences. In addition, it is also necessary to present the usage of personal marks in verbs, especially those used in the identification and categorization of entities, in order to draw parallels between the two occurrences.
\end{abstract}

Keywords: Lakota, morphosyntax, functionalism 

Siglas utilizadas:

$\begin{array}{ll}\text { 1sg } & \text { primeira pessoa do singular } \\ \text { 1d } & \text { primeira pessoa do dual } \\ 2 \text { sg } & \text { segunda pessoa do singular } \\ 3 \text { sg } & \text { terceira pessoa do singular } \\ 3 \mathrm{pl} & \text { terceira pessoa do plural } \\ \text { A } & \text { actor } \\ \text { ARG } & \text { argumento } \\ \text { ART } & \text { artigo } \\ \text { ASP } & \text { aspecto } \\ \text { CAUS } & \text { causativo } \\ \text { CON } & \text { contraste } \\ \text { CONJ } & \text { conjunção } \\ \text { DEF } & \text { artigo definido } \\ \text { DEIC } & \text { deitico } \\ \text { DUR } & \text { durativo } \\ \text { DT } & \text { Dakota Texts } \\ \text { ENC } & \text { enclítico } \\ \text { EVID } & \text { partícula de evidencialidade } \\ \text { FUT } & \text { futuro } \\ \text { IF } & \text { illocutionary force } \\ \text { IMPER } & \text { imperativo } \\ \text { IND } & \text { artigo indefinido } \\ \text { INT } & \text { interrogativo } \\ \text { INTERJ } & \text { interjeição } \\ \text { LOC } & \text { locativo } \\ \text { NEG } & \text { negativo } \\ \text { NLD } & \text { New Lakota Dictionary } \\ \text { NUC } & \end{array}$




$\begin{array}{ll}\text { PER } & \text { periphery } \\ \text { PL } & \text { plural } \\ \text { POS } & \text { possessivo } \\ \text { POSP } & \text { posposição } \\ \text { REDUP } & \text { reduplicação } \\ \text { RP } & \text { reference phrase } \\ \text { STEM } & \text { parte da raiz da palavra que recebe infixo } \\ \text { TNS } & \text { tempo } \\ U & \text { Undergoer }\end{array}$




\section{Índice}

Trajetória da graduação à pós graduação 1

Introdução $\quad 3$

Capítulo 1 A língua lakota, seus falantes e sua história $\quad 7$

$\begin{array}{lll}1.0 & \text { Introdução } & 7\end{array}$

$\begin{array}{lll}1.1 & \text { Os lakotas e sua língua } & 7\end{array}$

1.2 A presença da escrita na língua lakota: origens e fins 9

$\begin{array}{lll}1.3 & \text { A tradição oral } & 10\end{array}$

$1.4 \quad$ Estruturas recorrentes nas narrativas orais em lakota 13

Capítulo 2 O sistema verbal e os morfemas pessoais 17

$\begin{array}{ll}2.0 & \text { Introdução } \\ \end{array}$

$\begin{array}{lll}2.1 & \text { O complexo verbal } & 17\end{array}$

2.2 A flexão de pessoa e número 20

2.3 A conjugação dupla 24

$\begin{array}{lll}\text { Capítulo } 3 & \text { Os pronomes independentes } & 28\end{array}$

$\begin{array}{lll}3.0 & \text { Introdução } & 28\end{array}$

3.1 A estrutura da sentença segundo a Gramática de Papel e Referência 28

3.2 Os pronomes independentes 37

3.3 iyé 38

3.3.1 iyé como argumento de um verbo 45 
3.4 Pronomes interrogativos, negativos e substantivos 50

3.5 iyé em conjunto com posposições 68

$\begin{array}{lll}3.6 & \text { iyéš } & 73\end{array}$

$\begin{array}{lll}3.7 \text { íň } & 75\end{array}$

3.7.1 Estrutura morfológica $\quad 76$

$\begin{array}{ll}\text { 3.7.2 Ocorrências e usos } & 76\end{array}$

$\begin{array}{ll}\text { 3.7.3 Análise sintática } & 80\end{array}$

3.7 .4 ịš-eyá $\quad 88$

3.8 ínš iyé 90

Capítulo 4 Pronomes independentes nas narrativas orais 97

$\begin{array}{lll}4.0 & \text { Introdução } & 97\end{array}$

$\begin{array}{lll}4.1 & \text { Estruturas de foco } & 97\end{array}$

4.2 Marcas de pessoa e estrutura de foco 100

4.3 Padrões derivados do narrow focus 103

$\begin{array}{ll}\text { Considerações finais } & 111\end{array}$

$\begin{array}{lr}\text { Apêndice } & 114\end{array}$

$\begin{array}{ll}\text { Referências bibliográficas } & 125\end{array}$ 


\section{Trajetória da graduação à pós-graduação}

A ideia de estudar a língua lakota foi fruto de um longo processo que começou durante meu intercâmbio no Japão, realizado entre setembro de 2011 e agosto de 2012. Ao ter acesso à cultura e a um falante da língua ainu, etnia minoritária que vive na ilha de Hokkaido, interessei-me por sua estrutura linguística (a chamada língua polissintética) e seus aspectos culturais. Durante um tempo considerável, cogitei a possibilidade de estudá-la no mestrado, mas, enquanto isso, achei que seria interessante conhecer outras línguas com características similares. Descobri então que haviam muitas distribuídas ao longo da América e, ao voltar para o Brasil, comecei a frequentar os cursos de tupi e de guarani, oferecidos pela FFLCH a fim de testar as famosas semelhanças com o a língua japonesa ${ }^{1}$. Passei também a procurar materiais de outros povos nativos da América e a me sensibilizar com a complexidade de suas culturas e de suas narrativas. Das línguas norte americanas, estudei durante alguns meses o inuktitut e o navajo, duas da línguas mais faladas atualmente e com maiores chances de sobrevivência. Este tempo foi importante pois pude entender ao longo do processo de aprendizagem alguns dos mecanismos linguísticos recorrentes nas línguas head-marking, como a incorporação nominal, o extenso sistema de afixos pessoais que podem indicar sujeito/agente e objeto/paciente ao mesmo tempo, voz anti-passiva, transitividade cindida dentre outros.

A dificuldade de acessar os poucos materiais didáticos e pesquisas existentes e a qualidade variada dos que podem ser mais facilmente encontrados nas livrarias limitam as línguas que são realmente viáveis de se aprender a distância. Os diversos projetos de revitalização linguística e cultural, desenvolvidos pelas comunidades interessadas e universidades, embora sejam direcionados para as suas respectivas etnias, foram o principal caminho que me levou ao estudo do lakota: ONGs como Lakota Language Consortium e The

\footnotetext{
${ }^{1}$ Em junho de 2013 apresentei um trabalho sobre este tema no I Seminário de Tupi, organizado pelo Prof. Dr. Eduardo de Almeida Navarro e pelo Centro Angel Rama. Analisando a obra Tupi: língua oriental (xcafdfsfvs), levantei evidências linguísticas e históricas que apontam inúmeros erros na comparação entre o vocabulário da língua japonesa e do tupi.
} 
Language Conservancy têm se preocupado em desenvolver materiais didáticos para todas as faixas etárias e oferecer cursos de formação de professores, além de disponibilizarem sua tecnologia para outras etnias que tiverem interesse em preservar sua língua. Os inúmeros estudos históricos, antropológicos e linguísticos sobre este povo e as gramáticas e coletâneas de textos já publicadas proporcionaram também maior segurança no meu processo de aprendizagem. Para complementar minha formação e me preparar para analisar a língua lakota no mestrado, cursei ainda as matérias Fonologia e Morfologia em 2014 com meu atual orientador, Prof. Dr. Paulo Chagas de Souza.

A leitura de textos antropológicos e históricos, as discussões sobre multiculturalismo e etnocentrismo, a leitura dos textos produzidos por nativos e, principalmente, a leitura do corpus introduziu ainda um outro elemento a ser levado em consideração: a tradição oral. Esta, bastante desenvolvida nos povos ágrafos ou nos povos que assimilaram uma escrita apenas em tempos mais recentes, como os lakota e os yorubá, conecta diversas áreas acadêmicas a etnias, minoritárias ou não, oferecendo a possibilidade de estudos interdisciplinares. Assim, tenho buscado também estudar e incorporar à minha pesquisa os fatores relevantes da tradição oral na língua lakota. 


\section{Introdução}

Esta dissertação de mestrado visa apresentar uma descrição e análise dos pronomes independentes na língua lakota. Estes pronomes, ainda pouco explorados nos trabalhos acadêmicos, apresentam peculiaridades quanto sua forma e usos. Uma vez que a proposta é abarcar seu uso em um contexto mais amplo, serão apresentadas também ocorrências dentro das narrativas orais coletadas da obra Dakota Texts (DELORIA,1932), de onde foi retirado o corpus. Desta forma, pretendemos abarcar as marcas de pessoa em dois níveis: (1) sua estrutura morfológica e sintática, levando em consideração seus aspectos tipológicos, e (2) seu uso dentro da narrativa oral, como forma articular os tópicos e as informações novas.

A escolha da obra Dakota Texts (DELORIA,1932) para extrair o corpus da pesquisa foi motivada primeiramente pela sua relevância cultural e histórica. Foi um dos poucos estudos acadêmicos realizados por uma mulher da própria etnia, que apresenta seu povo não apenas como objeto de estudo mas também como sujeito complexo e capaz de articular sua tradição dentro das narrativas. Além de ser a maior coletânea de narrativas orais em língua lakota já publicada, tem servido de base para várias pesquisas, inclusive para a seleção de exemplos de uso do New Lakota Dictionary (ULLRICH, 2011). A precisão da ortografia adotada, o trabalho meticuloso na coleta dos textos e as várias notas de rodapé com explicações culturais e linguísticas conferem credibilidade à obra.

Outra fonte de marcas de pessoa utilizada na pesquisa foi o próprio dicionário e seus exemplos de uso para cada verbete. Desenvolvido a partir de 2008 pela Lakota Language Consortium, apresenta apenas usos atestados por falantes nativos e comporta um grande número de ocorrências. Deu-se preferência, no entanto, para os termos colhidos nas narrativas, uma vez que um dos objetivos da pesquisa é estudar também as estruturas de foco e, para isso, é mais adequado manter o exemplo dentro do contexto.

Para indicar a fonte do exemplo, será incluído após a tradução para o português uma referência ao corpus com a seguinte formatação: Para as sentenças de Dakota Texts (DT) indicaremos a página e, para as sentenças de 
New Lakota Dictionary (NLD), indicaremos tanto a página quanto o verbete que a inclui.

O processo de recolhimento e análise das sentenças deu-se da seguinte forma:

Primeiro, os 63 textos foram lidos em lakota e em inglês, para que seu sentido geral fosse compreendido. Quando necessário, aspectos culturais e mitológicos foram pesquisados principalmente nas obras The Sioux (HASSRICK, 1964), The sons of the Wind (DOOGLING, 1984) e Lakota Myth (WALKER, 1983). Em seguida, foram pesquisadas no dicionário e nos materiais didáticos todas as estruturas e vocabulários não compreendidos. Parte deles ocorreram devido à antiguidade do texto e o uso de termos arcaicos. Para solucionar este problema, usei como referência a indicação de termo arcaico ou obsoleto apresentados pelo New Lakota Dictionary (ULLRICH, 2011) e evitei usar tais sentenças na análise. Cumprida esta etapa, procurei todas as ocorrências de pronomes independentes e interrogativos e as separei de acordo com a posição da palavra dentro da oração (núcleo verbal, periphery ou reference phrase) e de acordo com o tipo de estrutura apresentada, juntando o máximo de exemplos possíveis para cada morfema.

A análise foi feita seguindo os mecanismos oferecidos pela Gramática de Papel e Referência (VAN VALIN, 1997). Este modelo possui uma abordagem funcionalista e procura explicar os fenômenos linguísticos levando em consideração aspectos semânticos e pragmáticos. Assim, diferente das teorias formalistas, rejeita a autonomia da sintaxe. Van Valin (1997) esclarece:

The motivating questions for RRG were, "what would a linguistic theory look like if it were based on the analysis of languages with diverse structures, such as Lakhota, Tagalog, Dyirbal and Barai (Papua New Guinea), rather than on the analysis of English?', and 'how can the interaction of syntax, semantics and pragmatics in different grammatical systems best be captured and explained?' These two questions contain both theoretical and descriptive content. On the one hand, they both emphasize the importance of taking account of typologically diverse languages in the formulation of a linguistic theory, and on the other, they indicate that the 
resulting theory will be one in which semantics and pragmatics play significant roles.

O modelo teórico não postula nenhum tipo de estrutura subjacente ou morfema nulo. Assim, o corpus foi analisado sempre como é apresentado. Outra característica importante do modelo teórico é sua orientação tipológica. Há uma preocupação em respeitar as especificidades estruturais da língua lakota e um dos objetivos deste critério é analisar uma língua do tipo head-marking tomando cuidado para não classificá-la segundo padrões aplicáveis às línguas dependentmarking se não houver evidências morfossintáticas para isso. Esta abordagem se fará importante principalmente na discussão dos pronomes independentes, onde postularei questões sobre terminologia e apresentarei exemplos que demonstrem os limites de sua aplicação.

A Gramática de Papel e Referência postula também um modelo de análise das estruturas de foco da sentença, aproximando questões morfológicas e sintáticas de seu uso pragmático. Sendo este também um dos objetivos da pesquisa, buscaremos classificar os usos dos afixos pessoais e pronomes independentes dentro dos padrões de foco e topicalização apresentados na narrativa. Os mecanismos utilizados pelo modelo teórico e exemplos de aplicação usando a própria língua descrita serão introduzidos ao longo dos capítulos, de acordo com a relevância para a análise.

A dissertação está estruturada da seguinte maneira:

No capítulo 1 apresentaremos a etnia lakota, parte de sua história linguística e sua tradição oral. Serão apresentadas também algumas das estruturas e morfemas mais comuns nestas narrativas.

No capítulo 2 serão introduzidos os elementos básicos para a compreensão da estrutura verbal em lakota como as possibilidades de afixos pessoais e as classes verbais.

No capítulo 3 serão analisadas segundo a Gramática de Papel e Referência (VAN VALIN, 1997) as duas classes de pronomes independentes e algumas de suas formas derivadas, buscando entender sua estrutura morfológica e sintática, bem como seu uso dentro das sentenças. Serão feitas 
também comparações com algumas outras classes de palavras, como substantivos e verbos.

No capítulo 4 apresentaremos os mesmos grupos de pronomes/verbos, desta vez analisando seus usos enquanto estrutura de foco da sentença. Comentaremos também seu emprego dentro das narrativas estudadas.

Para fins de apreciação e referência, transcrevi com a ortografia moderna uma das narrativas compiladas por Deloria (1932) e acrescentei uma tradução parcial para o português. 


\section{Capítulo 1 O lakota, sua língua e suas histórias}

\subsection{Introdução}

Neste capítulo trataremos da língua lakota enquanto seu aspecto histórico e social. Em 1.1, faremos uma distinção entre a língua lakota e dakota, apresentando o problema da terminologia. Em 1.2 trataremos da introdução da cultura escrita e das diversas ortografias. Em 1.3, comentaremos as características e a importância da tradição oral para a língua lakota. Por fim, veremos em 1.4 algumas das estruturas recorrentes nas narrativas estudadas.

\subsection{Os lakotas e sua língua}

Os lakota (Lakȟ́ta), também chamados de teton (Thítȟunwan) na literatura, compreendem vários grupos politicamente estruturados que vivem em sua maior parte nos estados de Dakota do Sul, Dakota do Norte e Nebrasca, dentro e fora das reservas. Atualmente possuem cerca de 100000 integrantes, formando uma das maiores etnias dos EUA. São sete as suas subdivisões: Oglala (Oglála), Sicangu (Sičhánğu), Hunkpapa (Hunkpáph̆a), Mnikowoju (Mnikȟówožu), Sihasapa (Sihásapa), Oohenunpa (Oóhenunpa) e Itazipco (Itázipčho), e encontram-se distribuídas principalmente nas reservas Standing Rock, Cheyenne River, Pine Ridge e Rosebud.

Integram ainda um conjunto maior de povos, os dakotas, que possuem mais seis subdivisões. Um dos nomes usados para designar todas estas nações enquanto unidade é Očhéthi šakówin "As sete fogueiras", mas é considerado um termo arcaico. Provavelmente o termo mais difundido para designá-los é sioux², que por vezes incluiu ainda os Assiniboine $^{3}$ do Canadá. Sioux é uma abreviação do francês Naduesiu, que por sua vez é uma aproximação de nadowe-is-iw-ug, termo usado pelos ojibwe para designar os dakotas. A tradução literal é "inimigo

\footnotetext{
${ }^{2} \mathrm{O}$ termo sioux também deu origem ao nome da família linguística a qual o lakota pertence.

3 Powers (1982) conta que os Assiniboines ou Nakotas foram bandos yanktonais que se aliaram com a nação Cree e migraram para a região que atualmente pertence ao Canadá.
} 
menor". A falta de consistência no uso do termo sioux e a amplitude de seu conceito exigem que o pesquisador tenha cautela na seleção das informações a serem consideradas, a fim de não atribuir a todas essas nações as características de um grupo específico. O próprio nome dakota apresenta o mesmo problema uma vez que durante muito tempo foi aplicado também aos lakotas. As variantes yankton-yanktonai do Dakota são conhecidos também por nakota ${ }^{4}$, mas este nome parte da generalização de uma regra fonológica feita no século passado e é evitado pelos membros da comunidade. Atualmente, o termo nakota é usado para designar a nação assiniboine.

Personalidades como Touro Sentado (Tȟatȟánka ĺyotake), Cavalo Doido (Tȟašúnke Witkó), Nuvem Vermelha (Maȟpíya Lúta) e Alce Negro (Heȟáka Sápa), líderes políticos e espirituais que viveram no século XIX, atestam a força e a coerência política desses povos além de sua importância para um estudo crítico da expansão da cultura eurocêntrica nos Estados Unidos. Assim como a maioria dos outros povos nativos, opuseram-se não apenas ao avanço territorial e ao domínio político dos brancos, mas também a muitos dos padrões de vida. As etnografias Neihardt (1932), Black Elk speaks, Brown (1953), Black Elk's the Sacred Pipe, e Canku (2013), The Dakota Prisoner of War Letters, e Deloria (1932), Dakota Texts, são importantes obras de referência para compreender estes povos enquanto sujeitos da história.

A língua lakota é falada nos Estados Unidos e em partes do Canadá pelo pelas nações Lakotas. Concentra-se nas reservas Rosebud, Pine Ridge, Cheyenne River e Standing Rock. Apesar de ocupar uma área relativamente extensa, sua fonologia e morfologia são bastante homogêneas e assemelhamse também à língua Dakota ${ }^{5}$ falada nos mesmos estados e em Minnesota.

\footnotetext{
4 A equivalente sonora de / $\mathrm{t} /$ no começo e no meio das palavras é /d/ nas variantes Santee-Sisseton e Yankton-Yanktonai, mas pronuncia-se /I/ em lakota. Daí surge a diferença no nome dos povos [dakhota] e [lak ${ }^{\mathrm{x}}$ ota]. No entanto, há algumas palavras em Yankton-Yanktonai que começam com / $\mathrm{n} /$ onde nos demais começariam com /d/ ou /l/. Generalizando esta regra, muitos missionários acreditaram que Yankton-Yanktonai usavam sempre /n/ onde os demais diziam /d/ e /l/ e este povo passou a ser chamado de Nakota.

${ }^{5}$ A língua Dakota divide-se em quatro dialetos principais: Santee, Sisseton, Yankton e Yankonai. Quando o lakota não é interpretado como língua independente, frequentemente é chamado pelo nome Teton e constitui o quinto dialeto. As variantes Yankton e Yanktonai tem o sistema fonológico mais próximo do Santee e Sisseton, mas possui mais cognatos comuns com o Teton, formando assim uma ponte entre os dois extremos.
} 
Atualmente existem cerca de 5.000 falantes, sendo a maior parte acima de 60 anos.

O lakota faz parte da família Siouan, que compreende também outras 13 línguas: dakota, nakota (assiniboine), stoney, kanza, osage, quapaw, omaha, ponca $^{6}$, winnebago, chiwere, hidatsa, mandan e crow. O lakota e o dakota são mutuamente inteligíveis e podem ser consideradas dialetos de uma mesma língua e, na prática, os falantes e materiais didáticos oscilam entre as duas definições. Já as línguas nakoda e stoney, apesar de terem se desenvolvido a partir do subgrupo yankton, dos Dakotas há cerca de 400 anos, não são compreendidas com facilidade pelos falantes nem de lakota nem de dakota, por isso são consideradas línguas diferentes.

\subsection{A presença da escrita na língua lakota: origens e fins}

Sendo uma sociedade baseada na tradição oral, documentos escritos nas línguas sioux or nativos só foram produzidos com certa regularidade a partir do século XIX. A alfabetização dos povos nativos se deu, em sua maior parte, pelos trabalhos missionários dos padres e pastores cristãos, que criavam cartilhas e "ajudavam" as pessoas na transição para a chamada "vida civilizada". Além destes, temos ainda as gramáticas, dicionários e bíblias feitas para familiarizar o religioso com a língua da nação a ser convertida, constituindo as primeiras tentativas formais de estudo linguístico e de escrita da língua.

Assim como no restante da América, além da conversão ao cristianismo, a postura das igrejas e dos governos frequentemente era incentivar/obrigar o uso das línguas europeias, consideradas pela lógica racionalista e positivista da época sinônimo de superioridade. Dessa forma, para sobreviver à condição a que estavam submetidas, muitas famílias deixaram de ensinar a seus filhos suas tradições e línguas ancestrais. Houve então um movimento de negação de identidade que culminou na extinção de diversas línguas. A língua lakota, apesar

\footnotetext{
${ }^{6} \mathrm{O}$ mesmo problema de interpretação do Lakota e Dakota como línguas independentes ou dialetos de uma mesma língua ocorre com as línguas Osage, Ponca, Kanza, Omaha e Quapaw. Estas, quando são consideradas uma unidade, são chamadas de Dhegiha.
} 
de ter sofrido diversos atos de repressão, é uma das línguas nativas mais bem documentadas até o momento. Diversos documentos sobreviveram ao tempo e, por ser um dos povos mais fortes politicamente e por terem resistido por tanto tempo, atraíram o interesse de diversos antropólogos. Além dos materiais divulgados pelos missionários, há diversos documentos escritos por nativos, como o jornal Dakota Tawaxikitu kin, com notícias em lakota e em dakota, e cartas pessoais. A obra The Dakota Prisoner of War Letters (2013), reúne cinquenta destas cartas escritas no século XIX, com a transcrição do texto original em dakota e a tradução para inglês, oferecendo a possibilidade de conhecermos diversos aspectos da vida na prisão, a história e a opinião de muitos dakotas presos durante as guerras.

Uma outra característica da história da escrita na língua lakota foi a variedade de alfabetos empregados nos documentos. Os principais sistemas foram os empregados por Williamson (século XIX), Riggs (século XIX), Buechel (século $X I X$ ), Boas (século $X X$ ) e Taylor (século $X X$ ). Um sistema não se extinguiu com o surgimento de outro, mas coexistiram e foram produtivos por diferentes períodos de tempo. Ainda hoje há pessoas que escrevem usando alguma variedade dos modelos citados e não houve até o momento uma atualização da ortografia das obras históricas. Este fato dificulta bastante 0 acesso dos estudiosos e dos demais interessados, principalmente os próprios lakotas, já que algumas das escritas contém diacríticos incomuns e necessita de prática para acostumar-se a tantas variações. A ortografia empregada neste trabalho é a desenvolvida por Rood e Taylor, da Universidade de Colorado, e atualmente a mais difundida entre os lakotas. É usada nas principais obras de referência, como o New Lakota Dictionary (ULRICH, 2011), e nos livros didáticos mais recentes.

\subsection{A tradição oral}

Até meados do século XIX, a cultura lakota era baseada quase que exclusivamente na tradição oral. A oralidade desempenha funções no desenvolvimento da comunidade ágrafa que não podem ser ignoradas. Como os 
lakotas eram tradicionalmente nômades e não produziam ou acumulavam muitos documentos $^{7}$, a maior parte do conhecimento histórico, ritualístico e científico, bem como seus valores morais e seu imaginário coletivo, era transmitido através das narrativas e da vida prática.

Uma vez que na tradição oral não costuma haver autoria sobre as narrativas, os lakotas contavam as histórias sempre mantendo a consciência de que foi ouvida de outra pessoa através de morfemas evidenciais como škhé e kéye, traduzidos como "dizem" e que indicam a antiguidade da narrativa.

Um dos aspectos mais importantes da tradição oral é a singularidade de cada performance. Ainda que o narrador contasse a mesma história inúmeras vezes, sua habilidade e desenvoltura, sua memória em relação aos detalhes, sua própria contribuição pessoal para o enredo dentre outros fatores atribuem à narrativa uma capacidade imensa de transformação. Embora sempre houvesse o objetivo de se preservar o sentido geral e os detalhes mais importantes, principalmente nas narrativas míticas e nas cerimônias religiosas, surgiram inúmeras variantes, mais ou menos conhecidas de acordo com sua popularidade e preservação.

A manutenção do conhecimento e a troca de experiências dependia da interação entre as pessoas da comunidade e entre as diversas comunidades. Franz Boas (1938), ao comentar sobre o fluxo de ideias e de tecnologias, diz:

Ideias e invenções passavam de um povo a outro; e, embora a comunicação recíproca fosse lenta, cada povo que participou no desenvolvimento antigo trouxe sua contribuição para o progresso geral. Inúmeras provas encontradas demonstram que as ideias se difundiam cada vez que um povo entrava em contato com outro. Nem raça, nem idioma limitam sua propagação. A hostilidade e um tímido isolamento em relação aos vizinhos não conseguem impedir o fluxo das ideias de uma tribo a outra e elas se infiltram em territórios que ficam a milhares de milhas de distância.

\footnotetext{
${ }^{7}$ Os povos das planícies documentavam alguns acontecimentos marcantes como a morte de um líder famoso ou algum fenômeno natural incomum em peças de couro de búfalo, chamados "winter count" (waníyetu iyáwapi). Uma vez que os anos não eram numerados, esta documentação servia como referência e era herdado pelas gerações seguintes a fim de preservar a memória histórica.
} 
Um claro exemplo desse fluxo de ideias e da riqueza de variantes na tradição é a história "Iktómi e os faisões", coletada por Deloria (1932). Nesta narrativa, a personagem mítica Iktómi encontra um grupo de faisões e arma uma armadilha para matá-los e comê-los: convida-os para uma dança em que todos precisam fechar os olhos e, enquanto os faisões inocentemente se divertem, iktómi seleciona aqueles que tinham o peito com mais carne e os mata. Quando uma das aves estranha o evento e descobre a matança, grita e foge com as que sobreviveram. Iktómi recolhe então os corpos e os prepara para comer. As árvores, que assistiam o acontecimento, tramam um castigo para iktómi e o aprisionam enquanto tempos depois surgem lobos e raposas e comem sua comida já pronta.

Uma narrativa semelhante é compartilhada também pelos assiniboine, mas com algumas algumas alterações no enredo: em vez de faisões, os pássaros mortos por Iktómi ${ }^{8}$ são patos. Outra alteração é a inexistência da ação das árvores no enredo. Nesta versão, o trickster dorme e tem seus alimentos consumidos por lobos, coiotes e raposas.

Uma terceira variação está presente na obra Comanche ${ }^{9}$ Texts (CANONGE, 1958): nela a personagem principal não é Iktómi, mas um coiote que, ao chegar em um grupo de cães da pradaria que dançavam, convida-se para cantar desde que todos vendassem os olhos. Então, com um pedaço de pau, mata o máximo de vítimas que consegue. Nesta variante, não há consequência para a ação do coiote e este assa e come todos os animais que matou. A passagem de Iktómi para um coiote não é coincidência. $O$ coiote representa para muitos povos da América do Norte, o animal que prega peças nos outros, embora frequentemente falhe na tarefa ou acabe se colocando em situação humilhante. A própria personagem Iktómi, que desempenha o mesmo papel em suas narrativas, também aparece por vezes encarnada em um coiote.

\footnotetext{
${ }^{8}$ Os assiniboine mantiveram a personagem Iktómi em seu imaginário coletivo apesar do distanciamento do grupo de origem e sua rivalidade.

${ }^{9}$ Os comanches, também conhecidos como Shoshoni, são uma etnia que viviam na região de Colorado e New Mexico. Eram inimigos dos lakotas.
} 
A tradição oral e as narrativas são também muito importantes para a manutenção da língua. Diversas coletâneas foram feitas ao longo dos dois últimos séculos, sendo a maior delas a de Ella Deloria, filha de yanktons (um dos subgrupos dos Dakotas) mestiços. Sua publicação mais conhecida é Dakota Texts (1932), que, apesar do nome, reúne 63 narrativas em lakota e uma em Dakota. Escreveu ainda junto com Boas uma gramática da língua Dakota. Por serem os dois trabalhos mais meticulosos e completos da época, são ainda hoje duas referências indispensáveis nos estudos linguísticos. Apesar da antiguidade dos textos (foram coletados entre 1928 e 1931), trata-se de uma das maiores fontes de vocabulário e de estruturas. A obra New Lakota Dictionary (ULRICH, 2011), o dicionário da língua lakota mais completo feito até hoje, retirou grande parte de suas entradas e sentenças de exemplo da obra de Deloria, preocupando-se, no entanto, em separar as palavras ainda usadas dos termos arcaicos.

Deloria (1932) mostra ainda a classificação tradicional que os lakotas faziam de suas narrativas. O primeiro tipo é chamado Ohúnkakan e compreende as narrativas mais antigas que se conhecem além dos mitos de criação. Histórias com as personagens Iktómi, lya e Anúng Ité e outros seres do imaginário coletivo incluem-se neste grupo. O segundo tipo de narrativas é chamado wóyakapi e compreendem relatos mais recentes sobre grandes feitos dos lakotas e de outros povos. Em geral são tidos como reais ou ao menos possíveis, apesar de algumas vezes incluírem algum detalhe místico. Este segundo grupo de histórias é especifico de cada comunidade e muitas não são conhecidas em outras reservas.

\subsection{Estruturas recorrentes nas narrativas orais em lakota}

Neste tópico serão apresentadas algumas das estruturas e termos recorrentes no corpus selecionado. Estas estruturas, embora não exclusivas ao gênero textual, constituem ferramentas muito úteis para a narrativa, uma vez que criam nuances e podem contribuir para a performance do narrador, tendo sido encontradas em todas as narrativas consultadas. 
A primeira delas é a marca de evidencialidade. São dois os enclíticos utilizados em lakota: kéyapi/kéye e škhé. Através destes, o narrador salienta que a narrativa não é de sua autoria e que ouviu de terceiros. Segundo Deloria (1932), as forma kéyapi/kéye (literalmente "eles dizem") é preferida entre os yanktons (Dakota), pois o enclítico škhé é por demais vago e muito útil na divulgação de fofocas. Conforme o que foi observado ao longo das narrativas, os dois enclíticos parecem ser utilizados indistintamente, muitas vezes alternados ou repetidos por longos trechos.

Em relação às conjunções, embora o lakota disponha de diversas possibilidades de escolha, as mais recorrentes foram apenas quatro conjunções coordenativas: yunkh̆án, čhanké (čhankhé), na (na nakún) e k’éyaš (kȟéš). Uma vez que as narrativas eram transmitidas oralmente, não eram raros períodos longos que envolvessem mais de uma dessas conjunções ou até mesmo repetições.

Yunkh̆án é uma conjunção usada para indicar um evento que o narrador considera inesperado para o ouvinte, geralmente introduzindo algum acontecimento importante para o desenvolvimento do enredo. Nesta dissertação foi traduzida como "e então".

Cȟankȟé é uma conjunção que indica a consequência de algum estado ou acontecimento. Pode ser traduzida como "e assim" ou "e por isso".

Na nakún é usada para enumerar qualidades e entidades do mundo da mesma forma como a conjunção "e" do português. Quando usada entre orações, pode indicar uma sequência temporal de eventos.

K'éyas/khéš corresponde à conjunção adversativa "mas" do português. Khéš pode ainda indicar que a relação adversativa entre as duas orações é recorrente, sendo traduzida como "mas sempre."

O trecho abaixo ilustra o uso dos marcadores de evidência e das conjunções apresentadas neste tópico: 
$\begin{array}{llllll}\text { Oyáte wan thípi } & \text { yunkhán él } & \text { wikȟóškalaka wan wínyan } \\ \text { Povo um acampava e então lá } & \text { jovem } & \text { uma mulher }\end{array}$

wašté čha líla waštékilapi škhé. Waúnšila na nakún

bela que muito amada dizem. Gentil e

ksápa čhanké wičháša kin iyúha čhantíheyapi na

inteligente portanto homens os todos desejavam $\mathbf{e}$

yúzapi kta čhínpi kheš wičála šni škhé.

casar (FUT) queriam mas aceitava não dizem.

"Contam que um povo estava acampando e que lá havia uma jovem que era muito bela e amada. Dizem que era gentil e inteligente, por isso todos os rapazes a desejavam e queriam casar com ela, mas ela nunca aceitava." (DT: 46)

O trecho apresentado é o início do conto "Duas Faces engana a jovem." Nele, a conjunção yunkhán segue a ambientação do enredo (um acampamento) e é usada para introduzir uma das protagonistas. No segundo período estão presentes as outras três conjunções descritas. $\mathrm{Na}$ enumera as qualidades da personagem (gentil e inteligente) e chanké transforma a oração em explicação para a oração seguinte (os homens a desejavam e a cortejavam). Por fim, a conjunção khéš introduz uma oração adversativa que apresenta a reação da protagonista ao comportamento dos homens (não aceitava os pedidos de casamento). Nota-se ainda nesta última sentença da narrativa que khéš introduz uma reação repetitiva da protagonista.

A língua lakota possui também alguma variedade de artigos definidos e indefinidos, todos eles recorrentes. No entanto, o artigo definido k'un merece 
uma menção especial neste tópico. Este morfema é empregado para reintroduzir na narrativa algum elemento que já foi citado e que o falante julgou necessário retomar. Deloria (1932) traduz o termo na glossa como "the-past," se referindo tanto à capacidade de definir quanto fato de ter sido citado. Na obra New Lakhota Dictionary (2011), consta também a definição "the aforesaid." Observe o exemplo retirado do desfecho mesma narrativa:

Čhápala k'un hé theȟ́lapi na tanyán yuhápila (...) Marmota DEF esta foi amada e bem mantida (...) "Esta marmota foi amada e bem cuidada (...)" (DT: 49)

Neste mito que conta como uma jovem moça foi sequestrada por um monstro, mas conseguiu escapar com a ajuda de seu animal de estimação, o narrador diz que a marmota de estimação foi mantida e oficializada como um pequeno morador, um mascote da aldeia. Por ser uma personagem citada apenas em poucos trechos da história, sua reintrodução é feita algumas vezes usando o artigo k'un. Com isso, o ouvinte deve entender que não se trata de uma marmota qualquer, e sim aquela que a moça cuidava como animal de estimação. 


\section{Capítulo $2 \quad 0$ sistema verbal e os afixos pessoais}

\subsection{Introdução}

O objetivo deste capitulo é introduzir o leitor ao sistema verbal da língua lakota de acordo com suas flexões. Em 2.1 será dada uma breve explanação sobre a constituição do complexo verbal e os tipos de morfema que podem ser incluídos. Em 2.2 apresentaremos a variedade de morfemas, seus alomorfes e o caso particular dos verbos que recebem mais de uma marca com a mesma função.

\section{1 complexo verbal}

Nichols (1986) classifica a língua lakota como head-marking, ou seja, um tipo de língua em que os verbos recebem uma infinidade de afixos e enclíticos para construir o sentido da oração, acumulando funções que geralmente são expressas nas línguas do tipo dependent-marking através de sintagmas separados. Uma das consequências é que uma palavra somente pode ter a função de uma sentença completa com sujeito, verbo, objeto etc.

Mni-má-ya-k'u

Água-1sgU-2sgA-dar

Você me deu água.

Mni-wíčha-un-k'u-pi

Água-3plAnimU-1dA-dar-PL

Nós demos água para eles. 
O primeiro exemplo é composto pelo núcleo verbal k'ú "dar", que teve o substantivo mní "água" incorporado, formando o verbo mnik'ú "dar água" 10. Depois, foram incluídos os afixos ya "você" (enquanto actor, A) e ma "eu" (enquanto undergoer, $\mathrm{U}$ ) para indicar quem deu e quem recebeu a água. $\mathrm{O}$ exemplo seguinte é formado pelo mesmo núcleo e substantivo incorporado, mas acrescentou-se os morfemas un "você e eu" (actor), wičha "eles" (undergoer) e o sufixo pi, que neste caso transforma a primeira pessoa do dual em primeira pessoa do plural.

A raiz verbal pode ser modificada por diversos tipos de afixos. Estes servem para indicar pessoa, para aumentar a valência do verbo, para indicar número, direção da ação, instrumento ou para nominalizar os verbos. A tabela na página seguinte ${ }^{11}$ mostra a posição mais comum para as classes de afixos em relação à raiz e cita alguns deles:

\footnotetext{
${ }^{10}$ Este exemplo foi escolhido propositalmente para apresentar o máximo de argumentos dentro de um verbo. No entanto, a incorporação nominal não é produtiva em lakota e restam apenas alguns resquícios de sua existência.

${ }^{11}$ Adaptada do livro: RANKIN, Robert L. Kanza Languages for Families and Communities. Kaw City: Kanza Language Project, 2007
} 


\begin{tabular}{|c|c|c|c|}
\hline $\begin{array}{l}\text { Natureza } \\
\text { do } \\
\text { morfema }\end{array}$ & Categoria & Morfemas & Significado \\
\hline \multirow[t]{5}{*}{ Prefixo } & Indefinido & wa- & $\begin{array}{l}\text { Serve para tornar o objeto } \\
\text { do verbo indefinido. Usado } \\
\text { para diminuir a valência do } \\
\text { verbo }\end{array}$ \\
\hline & $\begin{array}{l}1^{\circ} \text { pessoa do dual } \\
\text { inclusivo }\end{array}$ & $U \eta(k)-$ & $\begin{array}{l}\text { Significa "você e eu". Com o } \\
\text { acréscimo do sufixo pi, } \\
\text { passa a significar "nós", } \\
\text { tanto inclusivo quanto } \\
\text { exclusivo. Usado em todas } \\
\text { as classes de verbos, } \\
\text { inclusive os estáticos. }\end{array}$ \\
\hline & Locativo & $a^{\prime-}, i^{-}, i_{-}, o^{-}$ & $\begin{array}{l}\text { Criam novos argumentos } \\
\text { para o verbo. Significam } \\
\text { respectivamente: "sobre", } \\
\text { "com", "para" e "dentro de" }\end{array}$ \\
\hline & Undergoer & $\begin{array}{l}\text { ma-, ni-, čhi-, } \\
\text { wičha- etc }\end{array}$ & $\begin{array}{l}\text { Usados para formar a meta, } \\
\text { o receptor e o cliente nos } \\
\text { verbos transitivos. A } \\
\text { terceira pessoa só é } \\
\text { marcada no plural de seres } \\
\text { animados. }\end{array}$ \\
\hline & Actor & $\begin{array}{l}\text { wa-, bl-, ya, l- } \\
\text { etc }\end{array}$ & $\begin{array}{l}\text { Usado para formar as duas } \\
\text { primeiras pessoas nos } \\
\text { verbos ativos. Indica } \\
\text { agência. A terceira pessoa, } \\
\text { como será visto mais } \\
\text { adiante, é marcada pela } \\
\text { ausência de morfema. }\end{array}$ \\
\hline
\end{tabular}




\begin{tabular}{|l|l|l|l|}
\hline & $\begin{array}{l}\text { Prefixos } \\
\text { derivativos }\end{array}$ & $\begin{array}{l}k i-, \quad i c ̌ ' i-, \quad k i c ̌ i-, \\
k i c ̌ h i-, g l-\text { etc }\end{array}$ & $\begin{array}{l}\text { São usados para construir } \\
\text { verbos dativos, reflexivos, } \\
\text { benefactivos, recíprocos e } \\
\text { possessivos. }\end{array}$ \\
\hline & Instrumental & $\begin{array}{l}k a-, \quad n a-, \quad p a-, \\
w a-, \text { wo-, ya-, } \\
y u-\end{array}$ & $\begin{array}{l}\text { Indicam o modo como a } \\
\text { ação acontece ou o } \\
\text { instrumento usado. O } \\
\text { morfema na-, por exemplo, } \\
\text { indica que a ação foi feita } \\
\text { com os pés. }\end{array}$ \\
\hline Raiz & Núcleo do verbo & (raiz verbal) & $\begin{array}{l}\text { Pode ser um verbo ativo ou } \\
\text { estativo }\end{array}$ \\
\hline Sufixo & Distributivo & $P i$ & Forma o plural dos verbos \\
\hline
\end{tabular}

\subsection{A flexão de pessoa e número}

A flexão dos verbos em lakota é formada por morfemas ora infixados ora prefixados, dependendo da natureza do verbo (se é formado só por uma raiz, por mais de uma, por uma raiz e outros prefixos, etc). A língua possui no total de sete pessoas: 1sg, 2sg, 3sg (independente do gênero), 1 Dual inclusivo, $1 \mathrm{pl}^{12}$, $2 \mathrm{pl} \mathrm{e} 3 \mathrm{pl}$. Os morfemas podem indicar no verbo o papel de actor (marcado na glossa pela sigla A) ou undergoer (U). Os verbos transitivos frequentemente usam mais de um morfema pessoal, dada a característica das línguas siouan de marcá-los junto à raiz verbal.

${ }^{12}$ Note na tabela abaixo que a primeira pessoa do plural é formada a partir do dual e não da primeira do singular. 
Seguem abaixo a lista dos morfemas possíveis na marcação de pessoa e número dos verbos:

$\begin{array}{ll}\text { /Ø-/ } & \text { 3sgA ou 3sgU } \\ \text { /wa-/, /bl-/ e /m-/ } & 1 \mathrm{sgA} \\ / \text { ma-/ } & 1 \mathrm{sgU} \\ / \text { ya-/, /l-/ e /n-/ } & 2 \mathrm{sgA} \\ / \text { ni-/ } & 2 \mathrm{sgU} \\ / \text { čhi// } & 2 \mathrm{sgU}+1 \mathrm{sgA} \\ \text { /un-/ } & 1 \mathrm{dU} \text { ou 1dA } \\ \text { /wičha-/ } & 3 p / \text { Anim } \\ \text { /-pi/ } & \mathrm{PL}\end{array}$

Com exceção do afixo wíchha, apresentado acima, a terceira pessoa será sempre marcada com o símbolo $\varnothing$. No entanto, esta marca não deve ser confundida com o morfema nulo usado em alguns modelos teóricos. Nesta dissertação, $\varnothing$ deve ser compreendido como a ausência de morfema que caracteriza a terceira pessoa do singular em lakota. A representação desta ausência nos indicará a posição em que determinada raiz normalmente receberia um afixo pessoal, e, portanto, onde está presente o argumento do núcleo verbal. Optou-se ainda por indicar a terceira pessoa do singular na glossa com a finalidade de apresentar a quantidade de argumentos que determinado verbo possui. Entretanto, por não considerar a existência de um morfema ocupando aquela posição, a terceira pessoa estará sempre entre parênteses. 
A tabela abaixo ${ }^{13}$ apresenta as possíveis combinações de afixos que indicam ator/sujeito (escritos em negrito) e paciente/objeto (sublinhado) em suas respectivas posições em relação à raiz verbal (indicada pelas reticências).

\begin{tabular}{|c|c|c|c|c|c|c|c|}
\hline & $1 \mathrm{sgU}$ & $2 \mathrm{sgU}$ & $\begin{array}{l}\text { 3sgU } \\
\text { 3pllnan } \\
U\end{array}$ & $1 \mathrm{dU}$ & $1 \mathrm{plU}$ & $2 p l U$ & 3plAnim \\
\hline $1 \mathrm{sgA}$ & & $\underline{\text { Čhi... }}$ & $\begin{array}{l}\text { Wa- } \underline{\varnothing} . . \\
\text { BI- } \underline{\varnothing} \ldots \\
\text { m- } \underline{\varnothing} \ldots\end{array}$ & & & Čhi...pi & $\begin{array}{l}\text { Wičha-wa... } \\
\text { Wičha-bl... } \\
\text { Wičha-m... }\end{array}$ \\
\hline $2 \mathrm{sgA}$ & $\begin{array}{l}\text { Ma-ya... } \\
\text { Ma-ya-I... } \\
\text { Ma-ya-n... }\end{array}$ & & $\begin{array}{l}\text { Ya- } \underline{\varnothing . . .} \\
\mathrm{I}-\underline{\varnothing} \ldots \\
\mathrm{n}-\underline{\varnothing} \ldots\end{array}$ & & $\begin{array}{l}\text { Un-ya...pi } \\
\text { Un-ya-I...pi } \\
\text { Un-ya-n...pi }\end{array}$ & & $\begin{array}{l}\text { Wičha-ya... } \\
\text { Wičha-ya-I... } \\
\text { Wičha-ya-n... }\end{array}$ \\
\hline $3 \mathrm{sgA}$ & Ma-ø... & Ni-ø... & $\underline{\varnothing}-\varnothing \ldots$ & $\frac{\text { Unø... }}{14}$ & $\underline{\text { Un-ø...pi }}$ & Ni-ø...pi & Wičha-ø... \\
\hline $1 \mathrm{dA}$ & & & Un-Øַ... & & & & Wičha-un... \\
\hline $1 \mathrm{plA}$ & & Un-ni...pi & $\begin{array}{l}\text { Un- } \\
\underline{\varnothing . . . p i ~}\end{array}$ & & & Un-ni...pi & Wičha-un...pi \\
\hline $2 \mathrm{plA}$ & $\begin{array}{l}\text { Ma-ya...pi } \\
\text { Ma-ya-I...pi } \\
\text { Ma-ya- } \\
\text { n...pi }\end{array}$ & & $\begin{array}{l}\text { Ya-ø....pi } \\
\text { I-ø....pi } \\
\text { n-Ø̋...pi }\end{array}$ & & $\begin{array}{l}\text { Un-ya...pi } \\
\text { Un-ya-I...pi } \\
\text { Un-ya-n...pi }\end{array}$ & & $\begin{array}{l}\text { Wičha-ya...pi } \\
\text { Wičha-ya-I...pi } \\
\text { Wičha-ya- } \\
\text { n...pi }\end{array}$ \\
\hline $3 p \mid A$ & Ma-ø...pi & Ni-ø...pi & $\underline{\varnothing-\ldots . . p i}$ & & $\underline{\text { Un-ø...pi }}$ & Ni-ø...pi & Wičha-ø...pi \\
\hline
\end{tabular}

Antes de apresentar alguns exemplos de paradigma, é necessário apontar algumas características da língua:

A) Nota-se na tabela acima que algumas combinações de sujeito e objeto apresentam três alomorfes. Estes são empregados da seguinte maneira: a segunda linha (que apresentam os morfemas bl- e l-) é usada exclusivamente como flexão dos verbos que começam com os prefixos ya- ou yu-. A terceira linha (com os morfemas $m$-e $n$-) é usada

\footnotetext{
${ }^{13}$ Adaptada de: ULLRICH, Jan F. New Lakota Dictionary. Bloomington: Lakota Language Consortium, 2008. Pag. 771.

${ }^{14} \mathrm{O}$ dual só é usado nos verbos transitivos quando marca sujeito/ator. Nos demais casos, usa-se o plural com - pi. A forma aqui destacada é usada somente com verbos intransitivos.
} 
quando o verbo é iniciado com uma vogal nasal. Os demais casos são marcados com o morfema default, wa-e ya-

B) A terceira pessoa do singular e a terceira do plutal inanimado são marcadas pela ausência de morfema no verbo. Para formar o plural, basta acrescentar o sufixo $-p i$ à raiz verbal. Quando o objeto na terceira é plural e animado, utiliza-se o prefixo Wičha-. A ausência do morfema de terceira pessoa será indicada pelo sinal de vazio, mas sua interpretação constará entre parênteses na glossa.

C) A língua lakota apresenta intransitividade cindida, ou seja, alguns verbos intransitivos (como ištínme, "dormir") marcam o argumento com os prefixos de undergoer e outros (como lowán, "cantar"), o fazem com os prefixos para actor. Na tabela acima, a linha cinza representa os verbos intransitivos do primeiro tipo e a coluna cinza, os do segundo.

D) A estrutura verbal não admite a repetição do morfema de plural pi-. Uma das consequências é que este pode se referir tanto ao sujeito no plural quanto ao objeto, criando formas ambíguas que podem ser compreendidas apenas dentro de um contexto.

Os exemplos abaixo ilustram algumas possibilidades de flexão da raiz hí "vir", k'u "dar" e t'a "morrer", usando os itens de vocabulário apresentados:

$\begin{array}{lll}\text { Ø-hí } & \text { (3sgA)-vir } & \text { ele vem } \\ \text { Ya-hí } & \text { 2sgA-vir } & \text { você vem } \\ \text { Wa-hí } & \text { 1sgA-vir } & \text { eu venho } \\ \text { Ma-ya-k'u } & \text { 1sgU-2sgA-dar } & \text { você me dá } \\ \text { Ya-k'ú-pi } & (3 s g U) \text {-2sgA-dar-PL } & \text { Vocês dão (isso) } \\ \text { T'á-pi } & \text { (3sgU)-morrer-PL } & \text { eles morrem. }\end{array}$


No caso de verbos em que o afixo pessoal é infixado, optou-se por indicar a tradução apenas na última parte da raiz. Todas as outras serão indicadas com a notação STEM. O verbo nah̆'ún "ouvir" abaixo nos serve de exemplo:

$(2.4)^{15}$

$\begin{array}{lll}\text { Na-Ø-h̆'ún } & \text { STEM-(3sgA)-ouvir } & \text { ele ouve } \\ \text { Na-yá-h̆'un-pi } & \text { STEM-2sgA-ouvir-PL } & \text { vocês ouvem } \\ \text { Na-wá-ȟ'un } & \text { STEM-1sgA-ouvir } & \text { eu ouço }\end{array}$

\subsection{Conjugação dupla}

Uma característica marcante das línguas siouan, presente em pequena escala nas línguas dakota, lakota, assiniboine, mas bastante produtiva nas línguas kanza, osage, ponka e omaha, é a marcação de pessoa com mais de um morfema. Os verbos abaixo exemplificam marcação repetida em lakota:

\begin{tabular}{|c|c|c|}
\hline$\varnothing$ - $\varnothing$-yu-wášte & (3sgU)-(3sgA)-INST-bom & ele corrige isto \\
\hline Ø-bl-u-wášte & (3sgU)-1sgA-INST-bom & eu corrijo isto \\
\hline Ø-I-u-wášte & (3sgU)-2sgA-INST-bom & você corrige isto \\
\hline ma-yá-I-u-wašte & 1sgU-2sgA-2sgA-INST-bom & você me corrige \\
\hline ma-yá-I-u-wašta-pi & 1sgU-2sgA-2sgA-INST-bom-PL & vocês me corrigem \\
\hline un-yá-I-u-wašta-pi & 1dU-2sgA-2sgA-INST-bom-PL & você nos corrige/ \\
\hline
\end{tabular}

${ }^{15}$ O paradigma dos verbos será sempre apresentado na ordem: terceira pessoa (singular e plural), segunda pessoa (singular e plural), primeira pessoa (dual e plural) e primeira pessoa (singular). A cisão na primeira pessoa ocorre, pois o dual e o plural possuem um prefixo próprio. 
Sendo o verbo acima formado a partir da raíz wašté "ser bom" com o prefixo instrumental $y u$ - "fazer algo utilizando as mãos", os morfemas pessoais acoplados aos verbos são bl- para a primeira pessoa e l-para a segunda, como foi descrito anteriormente e pode ser visto nos três primeiros casos acima.

No entanto, ao acrescentarmos os morfema de objeto ma-, un-, wičha-, o verbo ganha mais uma marca de segunda pessoa logo antes da marca anterior, embora utilize um dos alomorfes e não a reduplicação desta.

É importante notar também que esta marcação dupla está restrita à segunda pessoa do singular e do plural, não aparecendo com as demais combinações de morfemas nesse contexto.

A marcação múltipla de pessoa pode acontecer ainda em mais alguns verbos:

$\begin{array}{lll}\varnothing \text {-ín- } \varnothing \text {-yanke } & \text { (3sgA)-STEM-(3sgA)-correr } & \text { ele corre } \\ \text { ya-ín-n-anke } & \text { 2sgA-STEM-2sgA-correr } & \text { você corre } \\ \text { wa-ín-mn16-anke } & \text { 1sgA-STEM-1sgA-correr } & \text { eu corro }\end{array}$

Ø-hi-Ø-yá-Ø-ye (3ssgA)-STEM-(3sgA)-STEM-(3sgA)-passar

Ele passa

Ya-hí---a-I-e

2sgA-STEM-2sgA-STEM-2sgA-passar

Você passa

Wa-hí-bl-a-bl-e 1sgA-STEM-1sgA-STEM-1sgA-passar

Eu passo

\footnotetext{
${ }^{16} \mathrm{Mn}$ - é um alomorfe para $b l$-, quando este é seguido diretamente por uma vogal nasal.
} 
Tratam-se de verbos intransitivos simples que, embora tenham apenas um argumento, recebem morfemas pessoais em dois ou mais lugares diferentes.

Este fenômeno é raro na língua lakota e ocorre apenas nos dois casos descritos acima. As línguas do grupo dhegiha ${ }^{17}$, também pertencentes à família siouan, apresentam marcação múltipla de uma mesma pessoa nos verbos de maneira muito semelhante ao caso apresentado em (5) e muito mais frequente ${ }^{18}$. Apresentamos abaixo apenas uma amostra a fim de comparação:

Ø-Ø-Gónya $\quad$ (3sgU)-(3sgA)-querer ele quer isso

Ø-shk-ón-hn-a $\quad$ (3sgU)-2sgA-STEM-2sgA-querer

você quer isso

$\varnothing$-shk-ón-hn-a-be $\quad$ (3sgU)-2sgA-STEM-2sgA-querer-PL

vocês querem isso

$\varnothing$-an-gónya $\quad$ (3sgU)-1dA-querer

Nós dois queremos dois

Ø-k-ón-bl-a $\quad$ (3sgU)-1sgA-STEM-1sgA-querer

eu quero isso

\footnotetext{
17 Incluem as variantes ponka, omaha, kanza, osage, quapaw. Embora sejam inteligíveis entre si e compartilhem a maior parte dos recursos, são consideradas línguas distintas pelos falantes, que pertencem a etnias diferentes.

${ }^{18}$ Um verbo composto como "correr para pegar algo" pode ter até 3 morfemas pessoais marcados. No exemplo abaixo, uma flexão pertence à raiz "pegar" e duas pertencem à raiz "correr":

$\varnothing$-Águ-tonyin (3sgU)-(3sgA)-pegar-correr $\quad$ Ele corre e pega (isso)

$\emptyset$-a-p-ú-a-tan-bl-in (3sgU)-STEM-1sgA-pegar-1sgA-STEM-1sgA-correr

eu corro e pego

$\emptyset$-a-shk-u-ya-ton-hni-n

(3sgU)-STEM-2sgA-pegar-2sgA-STEM-2sgA-correr

você pega e corre
} 


$\begin{array}{lll}\varnothing \text {-tón- } \varnothing \text {-yin } & (3 s g A)-S T E M-(3 s g A) \text {-correr } & \text { ele corre } \\ \text { ya-tón-hn-in } & \text { 2sgA-STEM-2sgA-correr } & \text { você corre } \\ \text { an-tónyin-be } & \text { 1dA-correr-PL } & \text { Nós corremos } \\ \text { a-tón-bl-in } & \text { 1sgA-STEM-1sgA-correr } & \text { eu corro }\end{array}$

$\begin{array}{lll}\varnothing \text { - } \text {-dónbe } & (3 s g \mathrm{U})-(3 \mathrm{sgA}) \text {-ver } & \text { ele vê isso } \\ \varnothing \text {-ya-sht-ónbe } & (3 s g \mathrm{U})-2 \mathrm{sgA} \text {-2sgA-ver } & \text { você vê } \\ \varnothing \text {-an-dónbe } & (3 s g \mathrm{U}) \text {-1dA-ver } & \text { Nós doisvemos } \\ \varnothing \text {-an-dónba-be } & (3 s g \mathrm{U})-1 \mathrm{dA} \text {-ver-PL } & \text { Nós vemos } \\ \varnothing \text {-a-t-ónbe } & (3 s g \mathrm{U})-1 \mathrm{sgA} \text {-1sgA-ver } & \text { eu vejo }\end{array}$

Nos exemplos acima, diversos alomorfes são usados simultaneamente para marcar a mesma pessoa. Eles podem ser prefixados e infixados (exemplos 7 e 8) ou duplamente prefixados (exemplo 9). Quando os morfemas são apenas prefixados, o mais próximo da raiz está sujeito às alterações fonológicas e irregularidades pertinentes ao contato direto com a raiz enquanto o outro, mais distante, é a forma utilizada nos verbos regulares.

É importante notar ainda, a semelhança entre as formas apresentadas em (5) e em (8), que correspondem parcialmente à ideia de "correr": ambas recebem os morfemas $b /$ - e 1 - como infixo, uma vez que a segunda parte da raiz começa $\mathrm{com} / \mathrm{y} /$, e os morfemas wa- (a- em kanza) e ya- no início da palavra. 


\section{Capítulo 3 Os pronomes independentes}

\subsection{Introdução}

Neste capítulo serão apresentadas as principais características dos pronomes independentes, bem como sua estrutura sintática. Para isso, serão introduzidas em 3.1 as ferramentas necessárias para a análise segundo a Gramática de papel e referência. Em seguida, investigaremos os pronomes em dois grandes grupos: iyé e ínš. Para uma melhor apreensão da morfologia e dos usos, serão apresentados também verbos, interrogativos e substantivos que compartilham características semelhantes. O objetivo deste capítulo é demonstrar que os termos que tem sido classificados como "pronomes" apresentam mais traços verbais que nominais.

\subsection{A estrutura da sentença segundo a Gramática de Papel e Referência}

A Gramática de Papel e Referência (VAN VALIN, 1997) busca desenvolver um modelo de análise para a teoria da Gramática Universal, respeitando o princípio da adequação tipológica. Este modelo compreende como estruturas universais da língua os seguintes contrastes:

1. O contraste entre elementos predicativos e não predicativos, ou seja, o núcleo da sentença e seus argumentos.

2. O contraste entre argumentos de um núcleo e demais adjuntos, como advérbios de tempo ou locativos.

A junção de um núcleo (NUC) com seus argumentos (ARG) formam uma unidade chamada CORE e a junção desta com os adjuntos (PERIPHERY), por sua vez, formam uma unidade chamada CLAUSE. Esta unidade pode 
corresponder à sentença inteira ou pode ser parte de uma outra sentença, criando uma oração subordinada, por exemplo. As duas distinções acima formam assim o que a teoria chama de Layered Structure of the Clause.

Em uma língua do tipo dependent-marking, como o português, em que os argumentos do verbo são sintagmas individuais, a representação sintática de uma oração como "Joesley entregou a gravação" seria a seguinte:

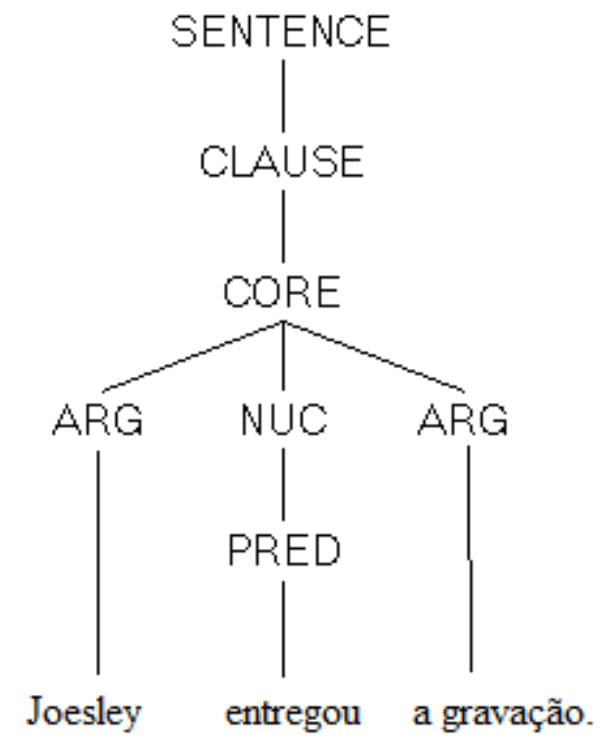

No caso das línguas do tipo head-marking, o modelo interpreta os morfemas pessoais afixados ao verbos como seus argumentos propriamente ditos. Uma vez que a terceira pessoa do singular e do plural inanimado não possui um morfema individual específico, é a ausência de marcas que permite sua interpretação correta ${ }^{19}$. Assim, os verbos wičháwakte "eu os matei" e wakté "eu o matei" e kté "ele o matou" são classificados da seguinte maneira:

\footnotetext{
${ }^{19}$ A Gramática de Papel e Referência não reconhece morfemas nulos nem estruturas subjacentes, apenas os morfemas que estão expressos oralmente na oração. A interpretação fica, então, dependente de outros fatores, como o contexto.
} 
(3.1) wičhá-wa-kté

ARG-ARG-NUC

3plAnimU-1sgA-matar

(3.2) Ø-wa-kté

ARG-ARG-NUC

(3sgU)-1sgA-matar

(3.3) Ø-Ø-kté

ARG-ARG-NUC
(3sgU)-(3sgA)-matar

Os verbos acima constituem por si só exemplos de orações completas. A raiz verbal kté, verbo transitivo, junta-se aos prefixos wa (1sgA) e wičha (3plAnimU) em 3.1 e 3.2 e a ausência de morfemas, indicada pelo sinal $\varnothing$, nos faz interpretar ator da ação ou o paciente como terceira do singular. ${ }^{20}$ Uma característica importante da terceira pessoa na língua lakota é que, caso não haja especificação, o argumento será sempre interpretado como sendo definido. Assim, não é possível interpretar a sentença 3.3 como "ele matou um" ou "uma pessoa o matou".

A representação sintática de uma oração como (3.1) é exemplificada abaixo. Observe que, com exceção da ordem em que os argumentos e o núcleo aparecem, não há diferença na representação entre a sentença do português e a do lakota. Isso é possível, pois o que está sendo marcado em ambas são as estruturas universais, ou seja, o contraste entre o núcleo (NUC) e seus argumentos (ARG). O que diferencia ambas as sentenças é a maneira como estes elementos são produzidos.

\footnotetext{
${ }^{20} \mathrm{O}$ paciente nos exemplos 3.2 e 3.3 não pode ser interpretado como plural, já que matar se refere a seres animados e existe um morfema específico para a terceira pessoa do plural animado (exemplo 3.1).
} 


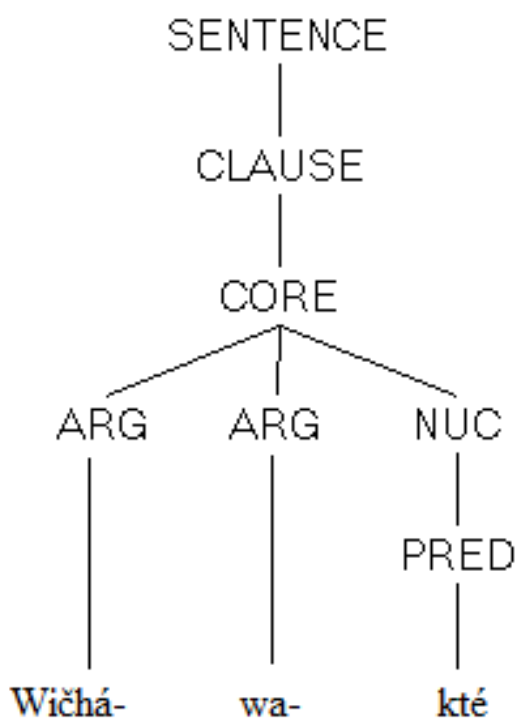

Apesar dos argumentos serem morfemas dentro do núcleo verbal, eles podem ser expandidos e especificados através de sintagmas relacionados ao verbos. Este sintagma não é considerado um argumento propriamente dito, mas uma referência a esse argumento e é sempre interpretado dentro do complexo verbal por um dos sinais (marcados ou não) descritos anteriormente. O termo que designa essa construção é Reference Phrase $(R P)$ ou sintagma de referência. As sentenças abaixo especificam o conteúdo dos argumentos através de seus RP:

(3.4) igmú kin hená

wičhá-wa-kte.

$\mathrm{RP}$ ARG-ARG-NUC

Gato DEF esses 3plAnimU-1sgA-matar

Eu matei esses gatos.

(3.5) igmú kin

$\varnothing$ Ø-wa-kté

RP

ARG-ARG-NUC

Gato DEF

(3sgU)-1sgA-matar

Eu matei o gato. 
(3.6) hokšíla kin igmú kin $\quad$-Ø-kté.

$\begin{array}{ll}\text { RP } & \text { ARG-ARG-NUC } \\ \text { Menino DEF gato DEF } & \text { (3sgU)-(3sgA)-matar } \\ \text { O menino matou o gato. }\end{array}$

Os RPs nos exemplos 3.4 e 3.5 só podem ser interpretados como pacientes do verbo matar pelo fato de haver a marca de primeira pessoa wa afixadas ao verbo. Em 3.6 o agente e o paciente são definidos pela ordem dos $R P$ : a ordem sintática mais comum entre os $R P$ é Agente $(A)$, Paciente $(U)$ e Núcleo Verbal (NUC). Assim, no exemplo dado, não há possibilidade de interpretar que foi o gato que matou o menino.

Segundo Van Valin (2010b), as principais características do RP são:

1. O RP não é associado a nenhuma função pragmática específica. Pode desempenhar tanto a função de tópico quando de foco em uma oração.

2. Pode ocorrer mais de uma vez por sentença, diferente de outros sintagmas como o Precore Slot ${ }^{21}$ (PrCS) e o Left Detached Position ${ }^{22}$ (LDP).

\footnotetext{
${ }^{21}$ PreCore Slot é o nome dado ao sintagma que antecede o CORE, ou seja, o núcleo e seus argumentos. É considerado uma das estruturas não universais, mas está presente em línguas como o alemão quando um interrogativo inicia uma oração. Geralmente não possui pausa ou quebra na entonação. Ex:

$\begin{array}{llll}\text { Was } & \text { ha-st } & \text { du } & \text { ge-mach-t? } \\ \text { o que } & \text { aux } & \text { tu } & \text { PERF-fazer-PERF } \\ \text { PrCS } & & \text { ARG } & \text { NUC }\end{array}$

"O que você fez?"

${ }^{22}$ Left Detached Position (LDP) é o nome dado ao sintagma que pode ser introduzido antes do CLAUSE, geralmente por uma pausa. O exemplo abaixo (Van Valin, 1998) mostra a ocorrência deste sintagma e do PrCS:

$\begin{array}{lllllll}\text { Yesterday, } & \text { what } & \text { did } & \text { Robin } & \text { show } & \text { to Pat } & \text { in the library? } \\ \text { Ontem } & \text { o que } & \text { aux } & \text { Robin } & \text { mostrar } & \text { para Pat } & \text { LOC-ART-biblioteca } \\ \text { LDP } & \text { PrCS } & & \text { ARG } & \text { NUC } & \text { ARG } & \text { PERIPHERY }\end{array}$

"Ontem, o que Robin mostrou para Pat na biblioteca?"
} 
3. Diferente de sintagmas como o LDP, o $R P$ não possui uma posição específica, ocorrendo em várias posições dependendo da língua.

4. Por não possuir uma função pragmática-discursiva específica, pode ocorrer também em orações subordinadas e relativas.

5. Contém em si apenas argumentos do núcleo, sendo sempre referenciados por algum morfema (ou ausência dele) afixado ao núcleo.

6. Aparece apenas em línguas do tipo head-marking.

Em relação à sua posição dentro da sentença, o $R P$ está localizado fora do CORE, uma vez que ele não é o argumento verdadeiro do núcleo, mas dentro do CLAUSE. A representação sintática da oração (3.6) é:

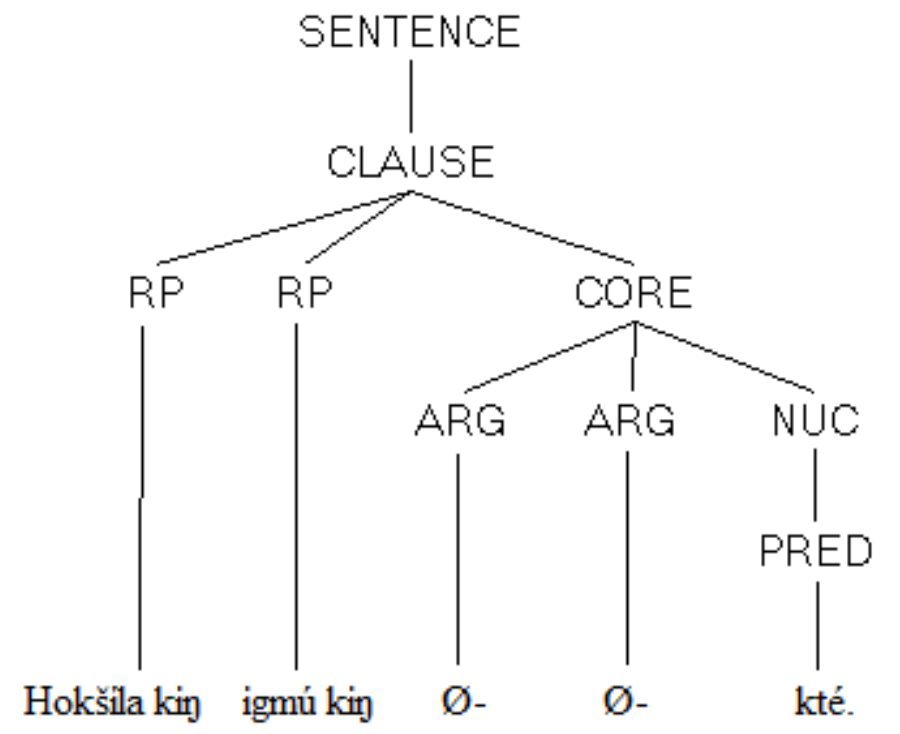

Outros tipos de constituintes como locativos, advérbios de tempo e de modo, apesar de encontrarem-se dentro da oração, não são considerados argumentos do núcleo verbal e encontram-se na posição chamada Periphery (PER). A sentença abaixo apresenta todos os constituintes introduzidos até o momento: 
(3.7)

$\begin{array}{llll}\text { Hínhanna } & \text { eyápaha kin } & \text { oyáte kin } & \text { wičhá- } \varnothing \text {-yaȟičhe } \\ \text { PER } & \text { RP } & \text { RP } & \text { ARG-ARG-NUC } \\ \text { Manhã } & \text { mensageiro DEF } & \text { povo DEF } & \text { 3plAnimU-(3sgA)-acordar }\end{array}$

"De manhã, o mensageiro acordou as pessoas."

A representação sintática de 3.7 é a seguinte:

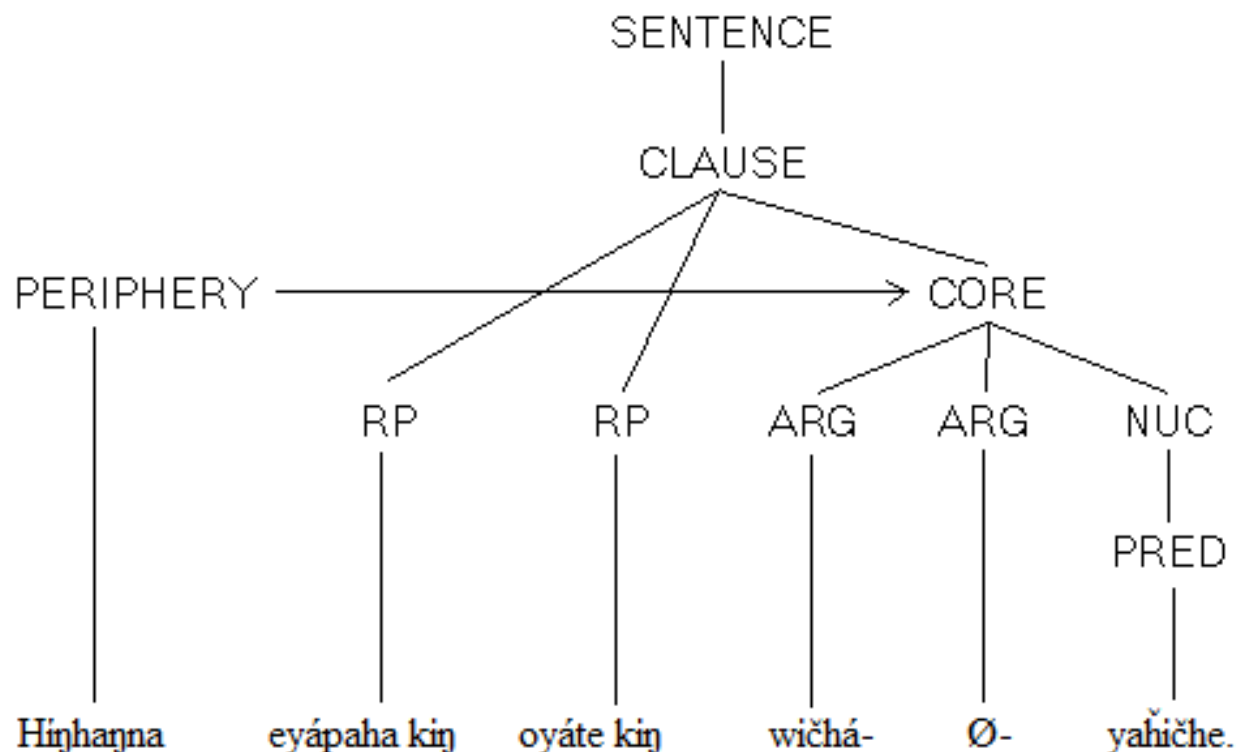

Observe que o sintagma intitulado PERIPHERY, assim como o RP, se encontra dentro do CLAUSE, mas está relacionado com o CORE. Esta representação indica o contraste entre os argumentos do verbo que compõe 0 CORE e os adjuntos.

Van Valin (2010b) questiona a inclusão dos morfemas pessoais afixados ao verbo no grupo dos pronomes pessoais. Um dos principais argumentos apresentados é o fato de a terceira pessoa poder se referir também a um $R P$ indefinido, como mostra o exemplo abaixo: 
(3.8)

igmú eyá wičhá-wa-kte-pi.

Gato IND 3plAnimU-1sgA-matar-PL

Eu matei alguns gatos.

Em X, igmú eyá é o RP marcado no verbo pelo morfema wičha. A contradição na classificação de wičha como um pronome pessoal reside no fato deste possuir sempre um sentido definido da mesma forma que o pronome "elas" do português não poderia substituir "algumas meninas" na sentença " $E u$ vi algumas meninas" sem alterar o significado geral da oração.

Além dos morfemas pessoais afixados ao verbo, a língua lakota possui outras formas de marcar pessoa dentro de uma oração: são os chamados "pronomes independentes" e "pronomes interrogativos". Estes podem aparecer tanto no $R P$, sozinhos ou com outros morfemas, como no núcleo verbal. Uma vez que jamais são usados no lugar de um argumento verbal propriamente dito, diferentemente das línguas do tipo dependent-marking, é necessário investigar seu comportamento morfossintático com mais atenção. Como será visto ao longo do capítulo, estes grupos "pronominais" e até mesmo alguns substantivos apresentam características de verbos e, por esta razão, optamos por omitir das representações sintáticas a indicação da classe gramatical. Esperamos que, com isso, o leitor procure observar seu comportamento sem classificá-lo previamente.

Um outro recurso que aparecerá por vezes nas árvores é conhecido como operator (operador). Trata-se de elementos importantes na construção da sentença, mas que não são predicados ou argumentos e modificam a sentença inteira ou parte delas. Estas partes serão indicadas sempre abaixo da sentença e variam de acordo com a natureza do morfema modificador. Por exemplo, enquanto as marcas de aspecto (ASP) modificarão o core, operadores de tempo (TNS) e evidencialidade (EVID) modificarão sempre o clause. 
Em lakota, esses elementos podem aparecer na forma de sufixos ou partículas independentes. Apresento abaixo uma lista de alguns dos operadores recorrentes nas narrativas e nos exemplos utilizados nesta dissertação. Indicarei para cada item um dos usos e, entre parênteses, a notação equivalente nas representações sintáticas enquanto operator.

$\begin{array}{lll}\text { Kin } & \text { artigo definido } & \text { (DEF) } \\ \text { K'un } & \text { artigo definido com referência ao passado } & \text { (DEF) } \\ \text { Čha } & \text { artigo definido, foco } & \text { (DEF) } \\ \text { Wan } & \text { artigo indefinido } & \text { (DEF) } \\ \text { Hé } & \text { demonstrativo singular } & \text { (DEIC) } \\ \text { Hená } & \text { demonstrativo plural } & \text { (DEIC) } \\ \text { Han/hin } & \text { sufixo que indica ação contínua } & \text { (ASP) } \\ \text { Kte } & \text { futuro } & \text { (TNS) } \\ \text { K'un } & \text { passado } & \text { (TNS) } \\ \text { Šni } & \text { negação } & \text { (NEG) } \\ \text { Škhé, kéye } & \text { fonte da informação } & \text { (EVID) } \\ \text { Ye/yo } & \text { imperativo } & \text { (IF) } \\ \text { Yeló, weló, ló } & \text { asserção, usado por homens } & \text { (IF) } \\ \text { He, hwó } & \text { interrogação } & \text { (IF) }\end{array}$

Entende-se por IF (illocutionary force) uma partícula ou forma expressa na língua que tem como função indicar se a sentença é uma asserção, uma pergunta, uma ordem etc. 


\subsection{Os pronomes independentes}

Embora não haja nenhum estudo exclusivo sobre os pronomes independentes até o presente momento, suas formas são citadas em outras pesquisas como Van Valin (1977) e Cumberland (2005), geralmente baseadas na interpretação dada por Boas \& Deloria (1941).

Na obra Dakota Grammar (B\&D, 1941) apresenta-se três paradigmas de pronomes independentes: iyé, iyéš e ínš. A estrutura morfológica dessas palavras é dada e a raiz e ou i é classificada como "demonstrativo indefinido". Quando núcleo verbal, mantém-se a classificação e nenhuma das formas é vista enquanto verbo.

Em uma curta introdução ao assunto, Van Valin (1977) apresenta os mesmos paradigmas, mas aponta a possibilidade do termo "demonstrativo indefinido" não ser o mais apropriado para descrever a raiz e. Cita ainda o uso do paradigma iyé como núcleo da oração sem classificá-lo como verbo propriamente dito.

Cumberland (2005), em seu estudo sobre a língua assiniboine, lista apenas dois paradigmas: ínš e iyé, assim como a ocorrência destes e dos pronomes interrogativos no núcleo verbal, classificando-os neste caso como verbo estativo. No entanto, não explora as possibilidades de morfemas que podem ser aplicados à raiz dos pronomes pessoais e interrogativos.

Outro trabalho que tem sido amplamente usado como obra de referência é o New Lakota Dictionary (2011). Embora seu objetivo não seja especificamente a discussão teórica, é a referência mais completa já produzida até o momento no que diz respeito à variedade no uso dos pronomes. A entrada dos termos em questão reconhece o uso pronominal (como $R P$ ) e o uso verbal (geralmente verbo estativo), assim como sua estrutura morfológica e seus paradigmas de flexão. O termo pronome não é questionado nem nos morfemas ligados ao verbo, estudados no capítulo anterior, nem em seu uso independente.

Para testar a validade e as limitações de sua classificação bem como possíveis alternativas de interpretação, buscamos descrever o uso dos 
pronomes no máximo de estruturas possíveis, seja no núcleo verbal ou no $R P$, além de sua interação com outros morfemas, geralmente sufixados. Buscou-se principalmente levantar as evidencias que permitem interpretar esses pronomes como formas verbais, tendo em mente o critério da adequação tipológica, para não atribuir aos morfemas estudados classificações que não encontrem correspondências em sua morfologia. Assim, a variação em pessoas verbais, formas negativas e estruturas subordinadas será exaustivamente apontada. A interpretação dos exemplos de acordo com a narrativa de que foi tirado também será também descrita sempre que necessário a fim de explicitar seu uso em contextos reais.

Os pronomes serão divididos e apresentados em três grupos: (1) iyé e seus derivados, incluindo iyéš, que é apresentado por Boas como um conjunto de pronomes à parte; (2) ínš e seus derivados e (3) míš miyé, que é uma junção dos itens (1) e (2).

\section{3 lyé}

A raiz iyé é usada para introduzir ou identificar entidades animadas ou não. Pode ser entendida como "ser algo especifico, definido" e nunca assume a função de incluir o termo a que se refere em determinada categoria de seres. Por exemplo, pode-se usar iyé para responder à pergunta “quem é ele?", que visa a identificação de uma pessoa, mas não é usada em contextos como "ele é um estudante/homem/inimigo?", pois neste caso o que se busca é classificar esta pessoa específica em um grupo maior, junto com outras em situação semelhante. Sua flexão segue o mesmo paradigma dos verbos estativos iniciados pela vogal /i/23:

\footnotetext{
${ }^{23} \mathrm{Na}$ terceira pessoa, quando precedida por um $R P$ de qualquer tipo, usa-se a forma é para o singular e épi para o plural.
} 


$\begin{array}{lll}\text { Ø-iyé/Ø-é } & (3 \mathrm{sgU}) \text {-ser } & \text { ele é } \\ \text { Ø-iyé-pi/Ø-é-pi } & (3 U) \text {-ser-PL } & \text { eles são } \\ \text { n-iyé } & 2 U \text {-ser } & \text { você é } \\ \text { n-iyé-pi } & 2 U \text {-ser-PL } & \text { vocês são } \\ \text { unk-iyé } & 1 \mathrm{dU} \text {-ser } & \text { nós dois somos } \\ \text { unk-iyé-pi } & 1 \mathrm{dU} \text {-ser-PL } & \text { nós somos } \\ \text { m-iyé } & 1 \mathrm{sgU} \text {-ser } & \text { eu sou }\end{array}$

As sentenças de 3.10 a 3.13 a seguir exemplificam o verbo iyé na posição de núcleo do predicado. Note que em todas elas o termo que está sendo identificado é marcado por um $R P$ definido, seja ele um nome próprio (3.10), um artigo definido (3.11 e 3.12) ou um demonstrativo (3.12). Além disso, ao tratar a raiz iyé como um verbo, subentende-se que um ou mais $R P$ correspondentes podem ser omitidos, caso não haja necessidade de explicitá-los (sentença 3.12).

\author{
Iktó he Ø-é yeló! (DT:44) \\ Iktó esse (3sgU)-(3sgU)-ser ENCL \\ "Esse é o lktómi!"
}




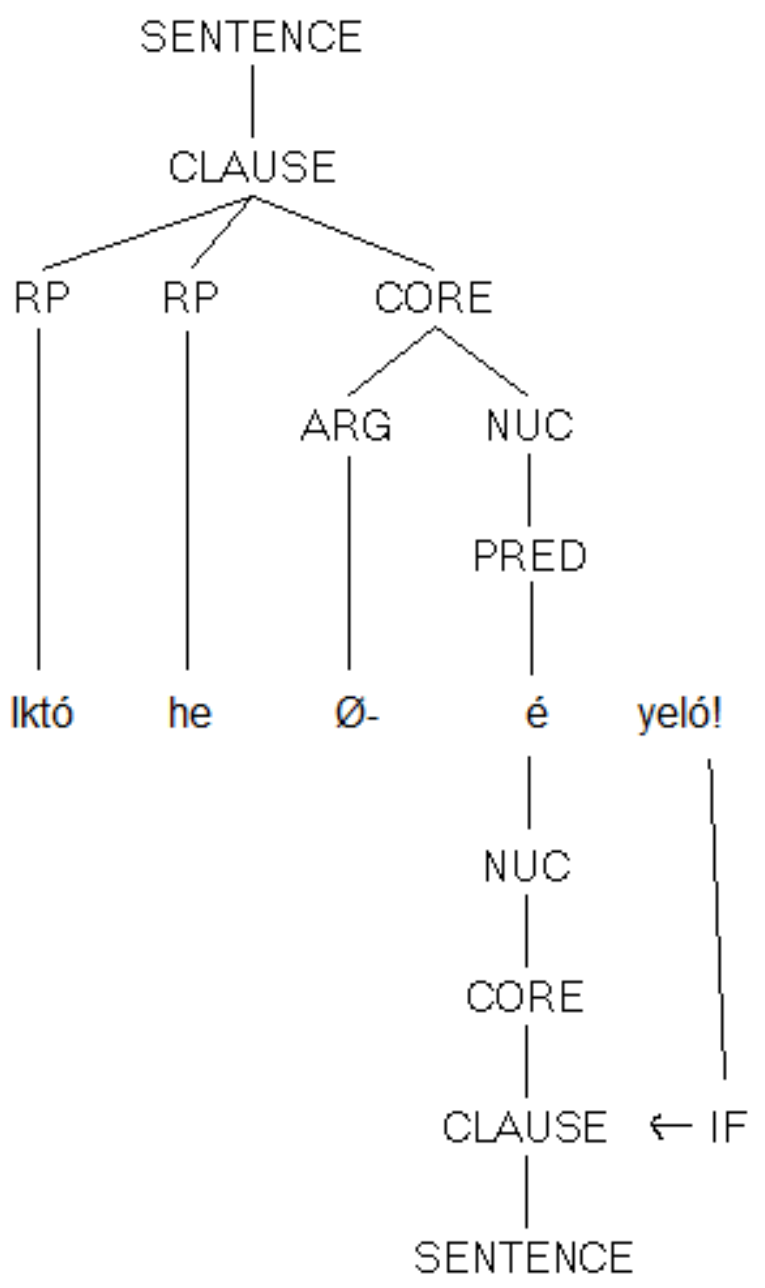

(3.11)

Hé Anúng Ité é- $\varnothing-\varnothing-y a-p i \quad$ kin $\varnothing$-é

Esse Dupla Face STEM-(3sgU)-(3sgA)chamar-PL DEF (3sgU)-ser ENCL "Este é aquele que chamam de Duas Faces." (DT:102) 


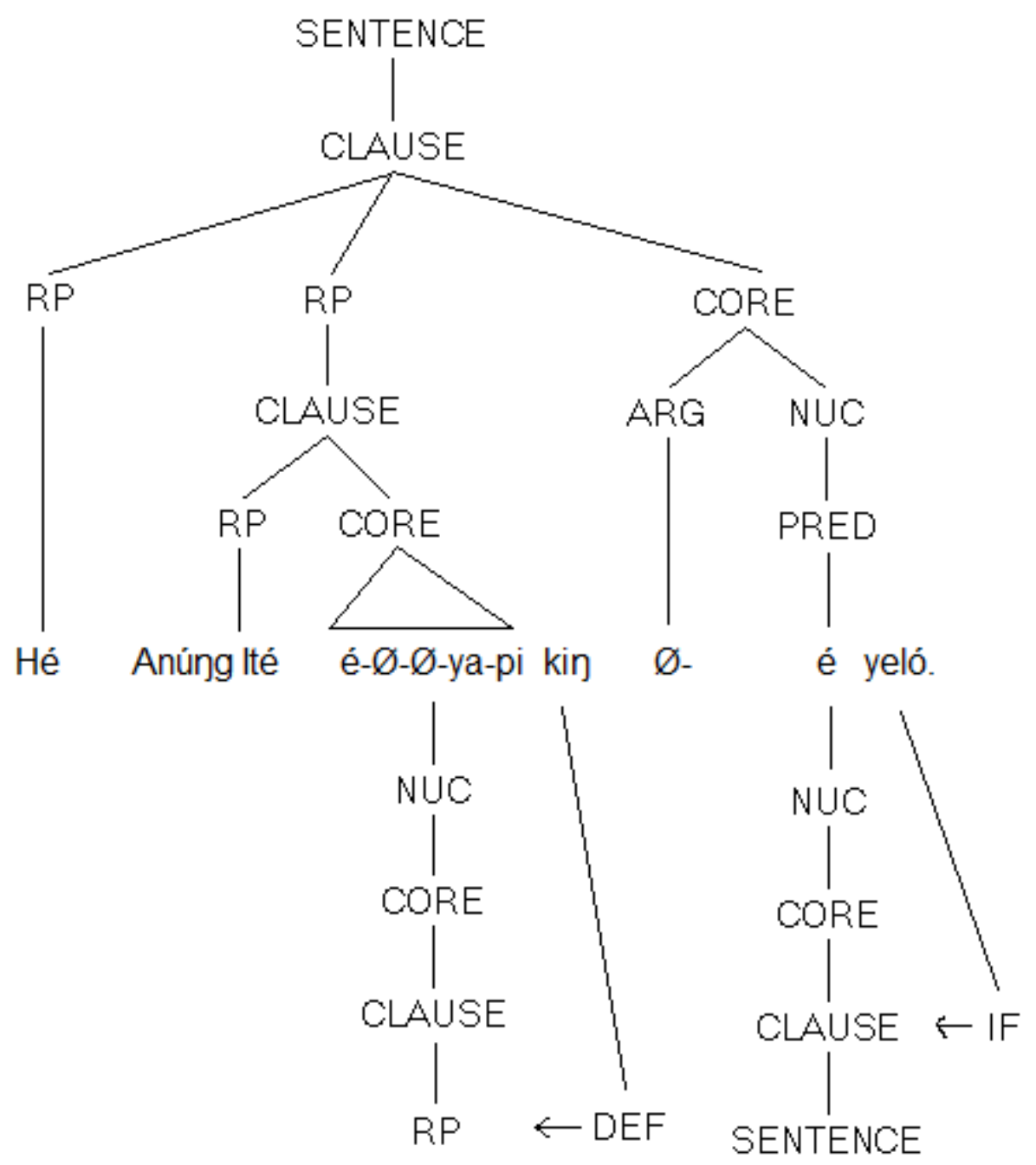

(3.12)

Táku wanžila kȟo-wá-kipȟe čin hé unčí tȟanázunspe k'un O que único STEM-1SG-medo DEF esse avó POS-machado DEF

Hé Ø-é yeló. (DT:103)

Esse (3sgU)-ser ENCL.

"A única coisa que temo é o machado de minha avó."

Ho, eyá tokhétuke éyaš, hé $\varnothing$-é yeló! INTERJ qualquer algo mas, esse (3sgU)-ser ENCL "Olhe, sem dúvida é ela!" (DT: 211) 
Assim como os demais verbos, iyé pode assumir forma negativa com o enclítico šni (Exemplo 3.14) e também se tornar complemento de verbos como slolyá "saber" (exemplo 3.15). Neste último caso, usa-se o artigo definido kin para marcar o sintagma.

$\begin{array}{llllll}\text { Čhanké } \varnothing \text {-yín } & \text { na } & \text { waná wičhóthi } & \text { wan él } & \varnothing \text {-ihúnni } \\ \text { Então (3sgA)-ir } & \text { e } & \text { agora acampamento } & \text { ART LOC (3sgA)- } \\ \text { chegar } & & & & \end{array}$

k'éyaš hé $\varnothing$-é šni čhanké héčhena $\varnothing$-yín na (...) mas este (3sgU)-ser NEG então assim (3sgA)-ir e "Por isso foi e então chegou a um acampamento, mas não era este (o certo) e continuou a seguir (...)" (DT: 139)

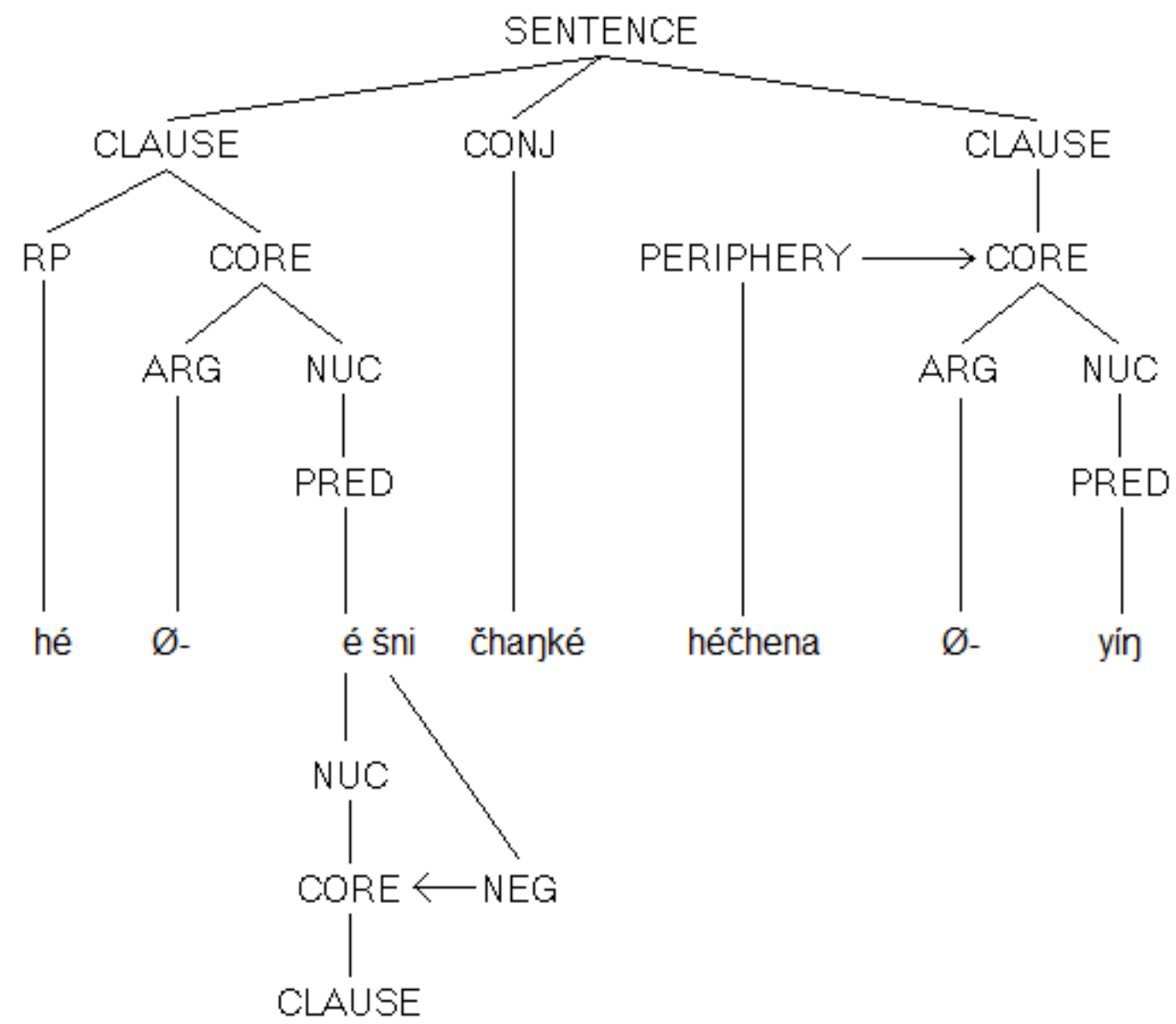


Kȟoškálaka wan wašté- $\varnothing-\varnothing$-lake č'un ehánk'un hé lé Homem jovem IND S-(3sgU)-(3sgA)-gostar DEF claramente esse este

Ø-é šni kin nakéš hehánl slol-Ø-Ø-yín (...) (3sgU)-ser NEG DEF finalmente depois STEM-(3sgU)-(3sgA)-saber "E então (ela) finalmente soube que este não era o homem que ela gostava." (DT: 47)

A língua lakota dispõe ainda de uma outra raiz verbal, que também pode ser parcialmente traduzida como o verbo ser do português. Sua flexão é regular e apresenta a seguinte forma:

$\begin{array}{lll}\text { Hé- } \varnothing \text {-čha } & \text { STEM-(3sgU)-ser } & \text { ele é } \\ \text { Hé- } \varnothing \text {-čha-pi } & \text { STEM(3U)-ser-PL } & \text { eles são } \\ \text { He-ní-čha } & \text { STEM-2U-ser } & \text { você é } \\ \text { He-ní-čha-pi } & \text { STEM-2U-ser-PL } & \text { Vocês são } \\ \text { He-ún-čha } & \text { STEM-1dU-ser } & \text { Nós dois somos } \\ \text { He-ún-čha-pi } & \text { STEM-1dU-ser-PL } & \text { Nós somos } \\ \text { He-má-čha } & \text { STEM-1sg-ser } & \text { eu sou }\end{array}$

Seu uso, no entanto, difere-se de iyé em um aspecto importante: é usado para incluir a entidade a qual se refere dentro de um grupo. Retomando $o$ exemplo dado no início deste tópico, pode responder à pergunta "ele é um estudante/ homem/ inimigo?". A ausência de RP na sentença também é possível e ocorre quando já se sabe qual grupo pode ser usado na classificação. 
(3.17)

Lé šungmánitu Ø-héčha.

Isto coiote (3sg)-ser

"Isto é um coiote."

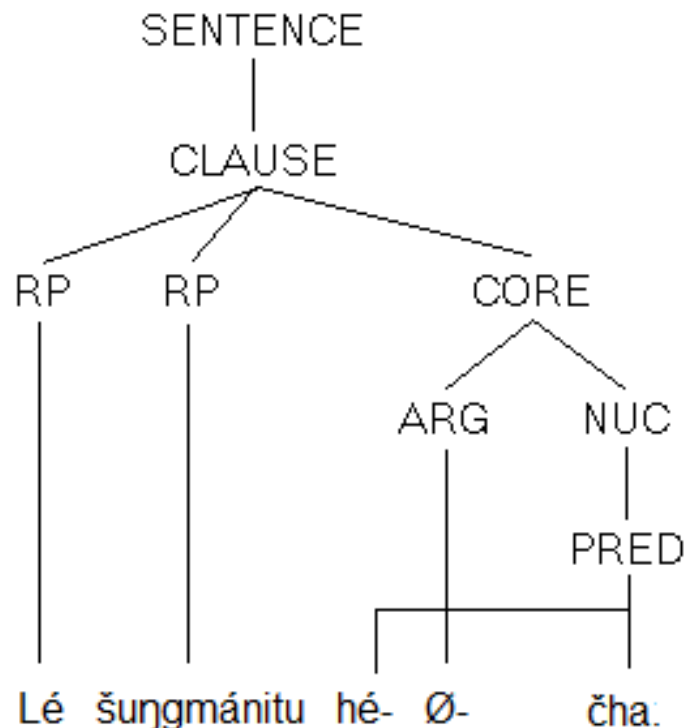

(3.18)

Ø-héčha.

(3sg)-ser

“É um deles." (É um representante de determinado grupo)

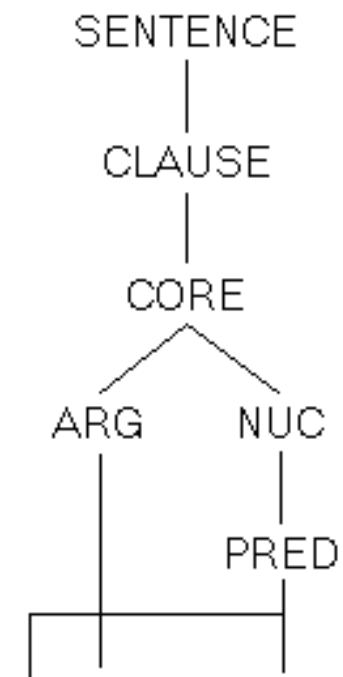

hé- $\varnothing$ - čha 
A sentença 3.17 seria uma possível resposta para a pergunta Hé táku hwo? "o que é isso?". Ao respondermos assim, estamos dizendo que o objeto de interesse pertence ao grupo dos coiotes, classificando-o, mas não o identificamos como uma entidade única no mundo. Supondo que este coiote em particular seja conhecido pelo nome Iktómi, a resposta apropriada seria a sentença 3.10 .

\subsection{1 lyé como argumento de um verbo (uso pronominal)}

O que tratamos aqui por ora de uso pronominal de iyé é sua ocorrência não enquanto núcleo do predicado, exemplificado no tópico anterior, mas dentro de um RP. Estas são as ocorrências que justificam a classificação de pronome, daí a nomenclatura. Quando se encontra nessa posição, é sempre referenciada no complexo verbal, seja com um morfema pessoal ou com a ausência de um, no caso da terceira pessoa do singular ou do plural inanimado.

$\begin{array}{llllll}\text { Wan, } & \text { witkó, mah̆píya } & \text { na } & \text { makh̆á } & \text { kin hená lé } \\ \text { INTERJ } & \text { tolo céu } & \text { e } & \text { terra } & \text { DEF } & \text { esses este }\end{array}$

m-iyé Ø-wa-káğe ló.

1sgU-ser (3sgU)-1sgA-fazer ENCL

"Olhe, tolo, Eu que fiz o céu e estas terras." (DT: 2) 


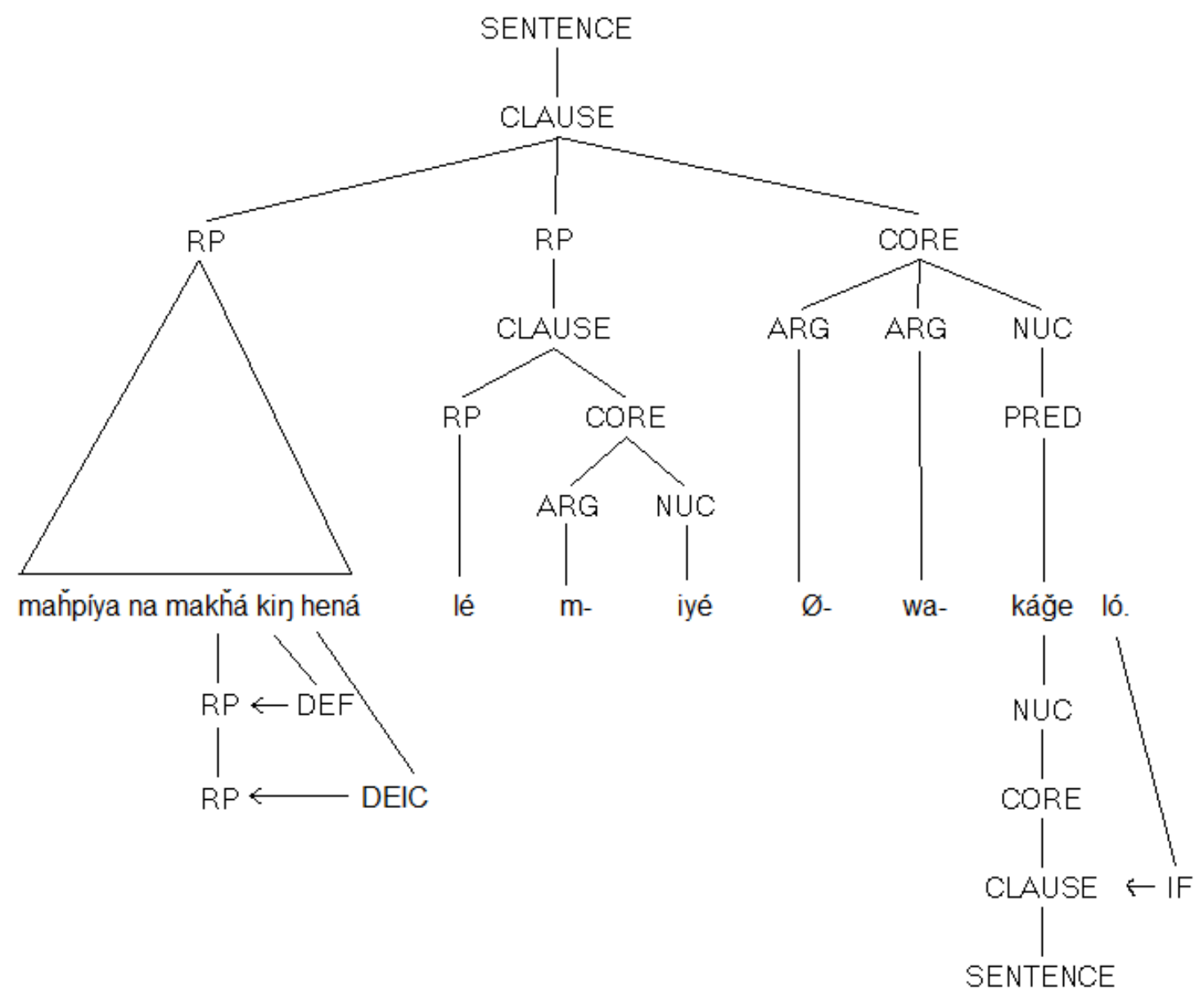

(3.20)

K'éyaš n-iyé e-Ø-h-é čin un bl-ušlókin

Mas 2sgU-ser STEM-(3sgU)-2sgA-dizer DEF POSP1sgA-tirar (sapatos)

kte ló.

FUT ENCL

"Mas já que você diz, vou tirá-los (os sapatos)" (DT: 101)

Em 3.19 e 3.20 , temos exemplos de iyé flexionado na primeira e na segunda pessoa respectivamente, funcionando como $R P$ do núcleo verbal.

As duas sentenças abaixo apresentam iyé em seu uso pronominal junto ao artigo čha, frequentemente usado para trazer o foco para o sintagma em questão ou para criar orações relativas. Seu uso, no entanto, parece ser optativo 
para iyé e as sentenças 3.19 e 3.20 podem ser interpretadas como sendo a mesma estrutura, mas com o artigo omitido. ${ }^{24}$

N-iyé čha ni-čákižin kte.

2sgU-ser ART 2sgU-sofrer FUT

"É você que vai sofrer." (NLD: 397, niyé)

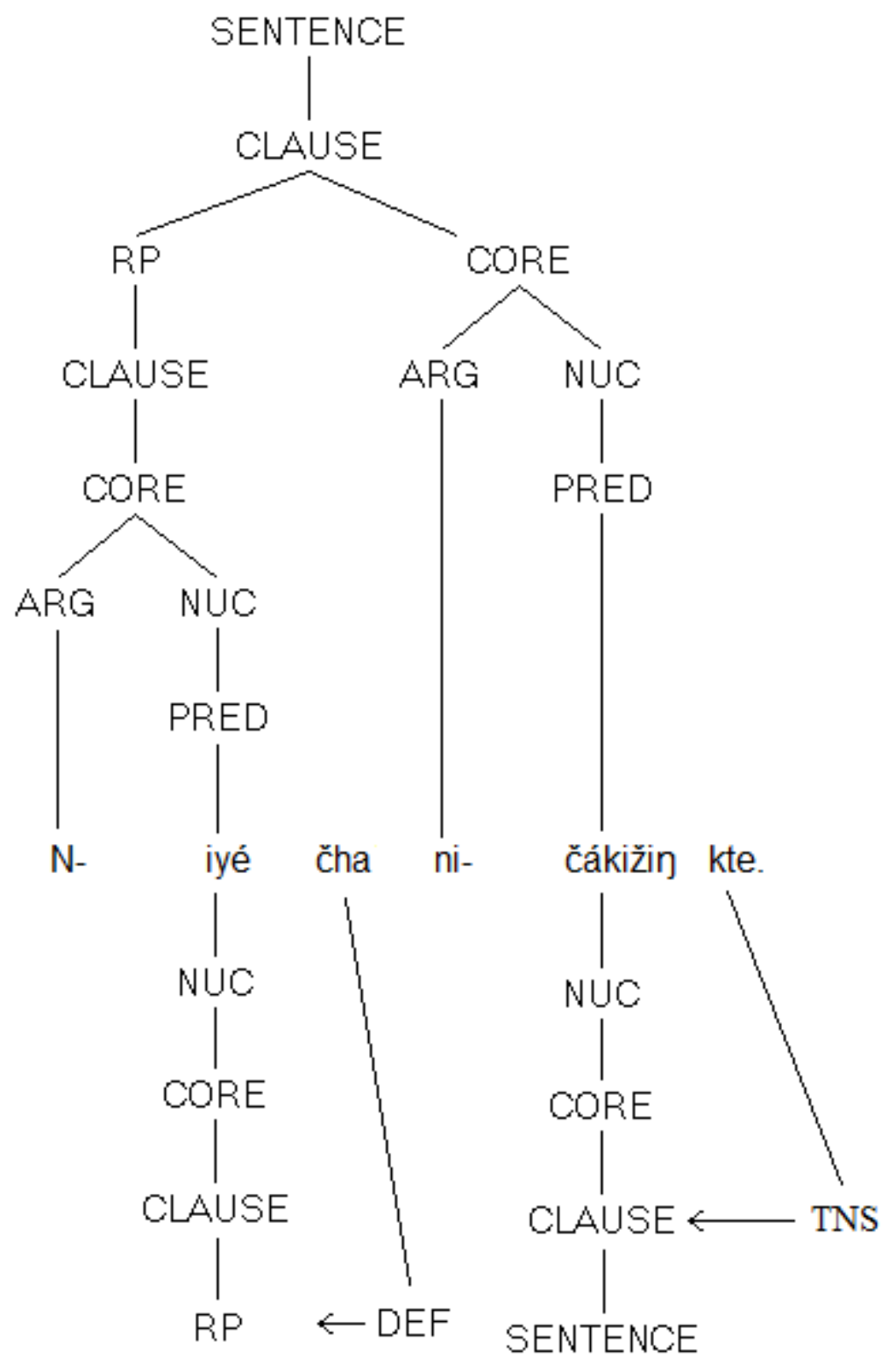

${ }^{24}$ Da mesma forma, as sentenças 3.19 e 3.20 poderiam conter o morfema čha sem alteração do significado. 
N-iyé-pi čha wówaš'ake kin yuhá n-anká-pi.

2sgU-ser-PL ART poder DEF ter 2sgU-sentar-PL

"São vocês que tem o poder." (NLD: 397, niyé)

Ao interpretar iyé como verbo em 3.21 e 3.22, podemos analisar a estrutura do $R P$ como sendo uma forma de clivagem, semelhante a de línguas do tipo dependent-marking, como o português.

A raiz iyé flexionada na segunda pessoa do singular ou do plural também pode ser usada como $R P$ em sentenças com verbos no imperativo, mas, uma vez que o imperativo é formado pela raiz verbal seguido pelas partículas ye ou $y o^{25}$, não haverá um morfema pessoal dentro do complexo verbal à qual ela se refere.

Misún, n-iyé $\quad$-khúte yo!

Irmãozinho sU-ser (3sgU)-atirar IMPER

"Irmãozinho, você atira nele!" (DT: 104)

${ }^{25}$ Ye é usado por mulheres e yo, por homens. No plural, essas partículas fundem-se ao sufixo pi e tornam-se pe e $p o$, respectivamente. 


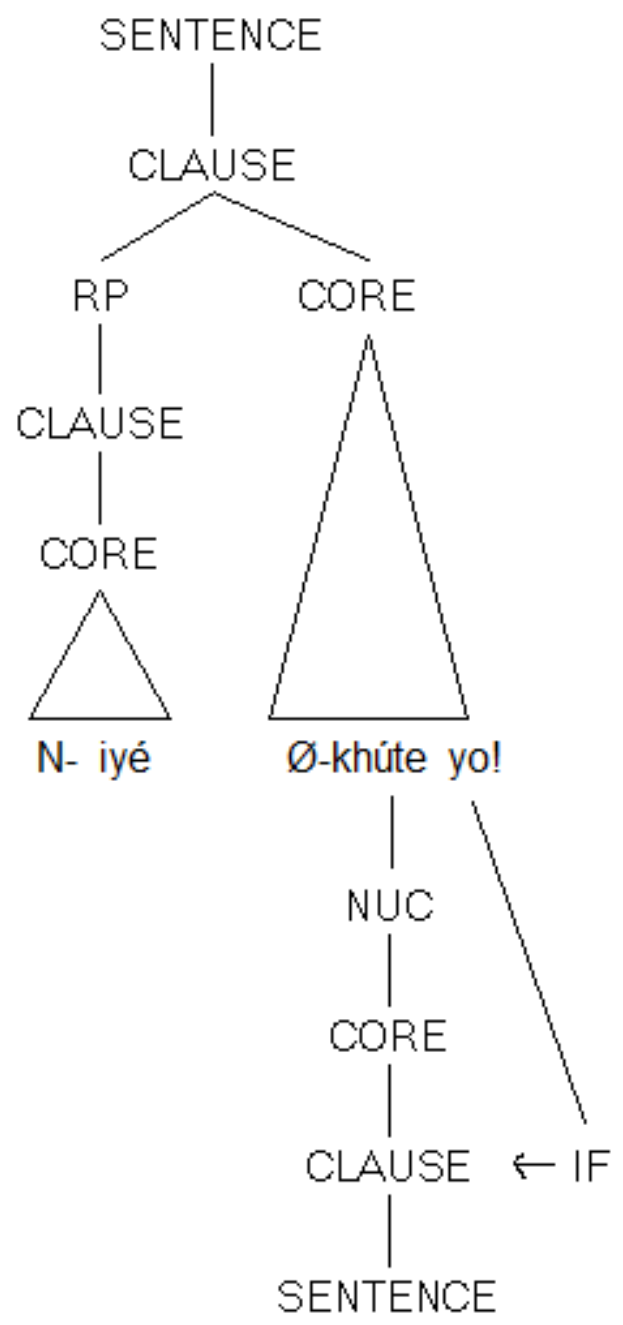

Curiosamente, o verbo héčha apresentado no tópico 3.2 também pode ocupar a posição de $R P$, mas, diferente de iyé, é tratado no New Lakota Dictionary apenas como verbo. Quando se encontra nesta posição, geralmente é traduzido como "um desse tipo", demonstrando uma relação com a função geral do verbo, que é classificar entidades.

Assim, o uso de héčha é complementar ao uso de iyé, tanto no núcleo da sentença quanto no RP. Enquanto o primeiro é usado para se referir a uma entidade de maneira genérica, classificatória, o segundo é usado para identificar entidades singulares. Caso iyé seja considerado um pronome, héčha deveria logicamente seguir a mesma lógica, uma vez que a estrutura sintática é a mesma. 


\subsection{Pronomes interrogativos, negativos e substantivos}

Além da iyé e héčha, existem outras raízes que compartilham situações semelhantes. Apresentaremos algumas delas aqui, embora nem todas sejam tratadas como pronome na literatura: os interrogativos tuwá "quem", táku "o que", o negativo tuwéni "ninguém" e alguns substantivos que designam pessoa, como hokšíla "menino" ou lakȟ́ta "lakota". Estas raízes podem ser usadas como RP, mas também aceitam morfemas pessoais, ou seja, podem ocupar a posição de núcleo verbal sem depender de nenhuma outra palavra. O paradigma de todas essas raízes é o mesmo dos verbos estativos.

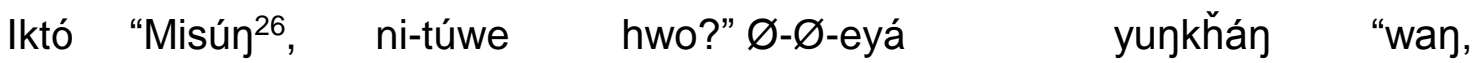
Iktó irmãozinho 2sgU-quem INT (3sgU)-(3sgA)-dizerentão INTERJ

lé Imáhe-Wičhóthi e-Ø-Ø-číya-pi kin hé Este Dentro-Eles-moram STEM-(3sgU)-(3sgA)-chamar-PLDEF esse

m-iyé yeló" $\varnothing$-Ø-eyá $\quad$ a-Ø-Ø-yúpta kéye. 1sgU-ser ENCL(3sgU)-(3sgA)-dizerSTEM-(3sgU)-(3sgA)-responder EVID "Iktó disse "Irmãozinho, quem é você?" e ele respondeu: "Eu sou o que chamam de Aquele-em-que-Eles-Moram-Dentro" (DT: 103)

\footnotetext{
${ }^{26}$ O vocativo misúy "irmãozinho" usado frequentemente pela personagem Iktómi, refere-se ao fato deste ser um dos seres mais antigos criados e, por isso, é considerado um irmão mais velho
} 
A representação sintática de 3.24 será dividida em duas partes, incluindo apenas o conteúdo da fala das personagens. Tratam-se de um questionamento sobre a identidade de uma delas e a resposta.

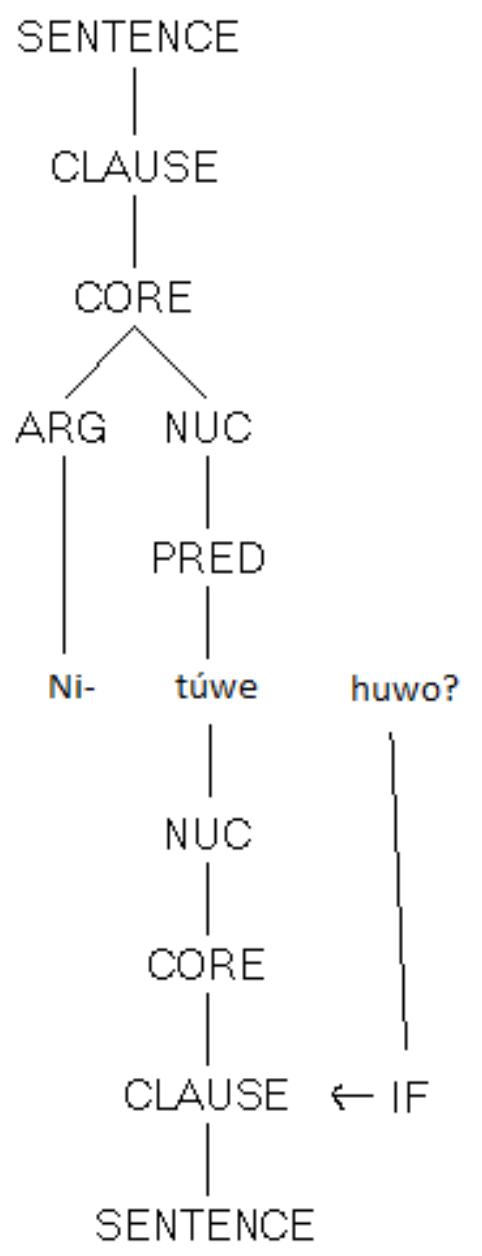

No exemplo acima, a raíz tuwé recebe o morfema pessoal de segunda pessoa ni, constituindo sozinha, o núcleo da oração. A resposta terá no lugar de tuwé, portanto, na posição de núcleo da sentença, a raiz iyé e não o nome da personagem: 


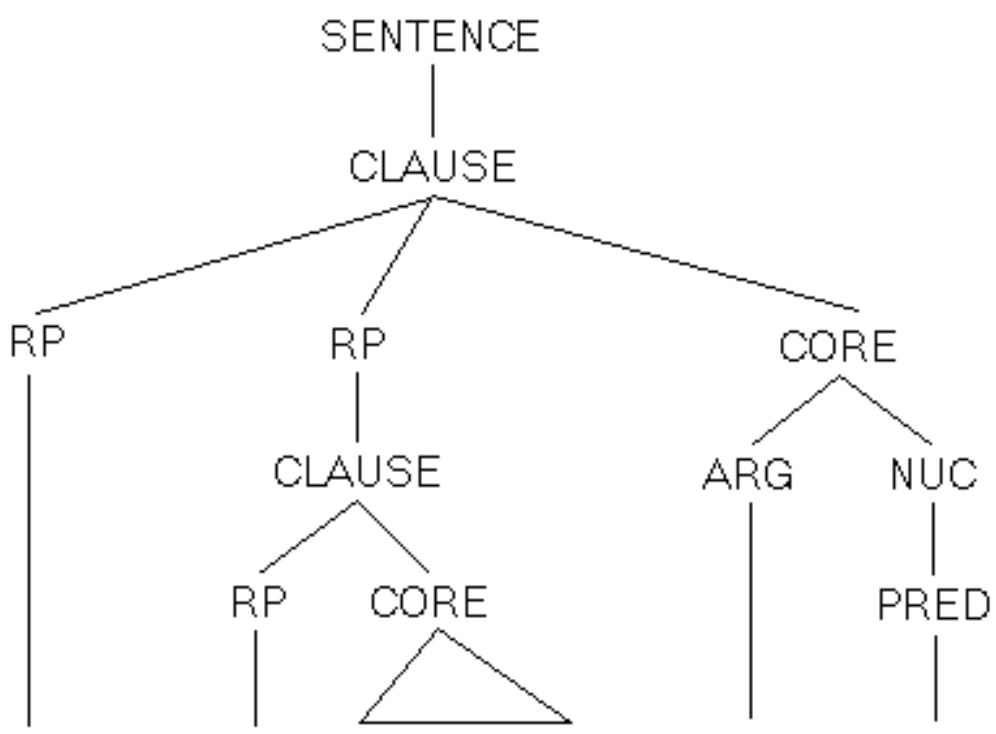

Lé Imáhe-Wičhóthi e-Ø-Ø-číya-pi kin m- me iyé yeló

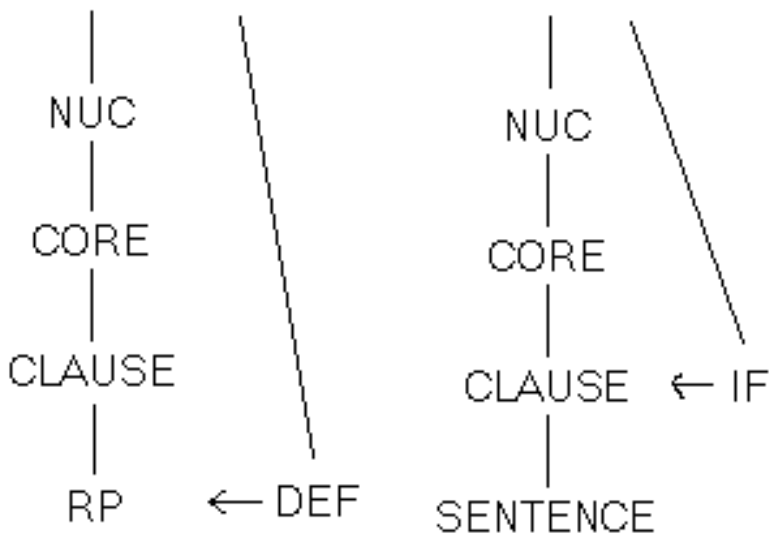

É importante notar ainda que há uma relação pragmática entre tuwé e iyé no trecho acima: são raízes usadas na identificação de pessoas. Da mesma forma, tuwé assume a função de $R P$, permitindo que se questione um dos argumentos do verbo (sentença 3.25). Pode também ser usado com o artigo čha (sentença 3.26), em construção análoga a das sentenças 3.20 e 3.21.27

\footnotetext{
${ }^{27}$ Note que na sentença 3.25 a raiz assume a forma tuwá. Este fenômeno ocorre com todos os verbos que fazem ablaut e a variedade de formas depende do morfema usado após a palavra.

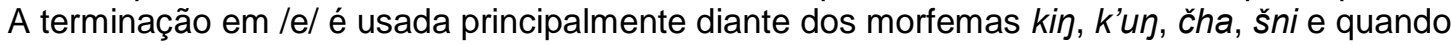
não é seguida por nenhuma outra palavra.
} 
(3.25)

Ø-Tuwá $\quad$-čhéya he?

(3sgU)-quem(3sgA)-chorar INT

"Quem está chorando?” (NLD: 565, tuwá)

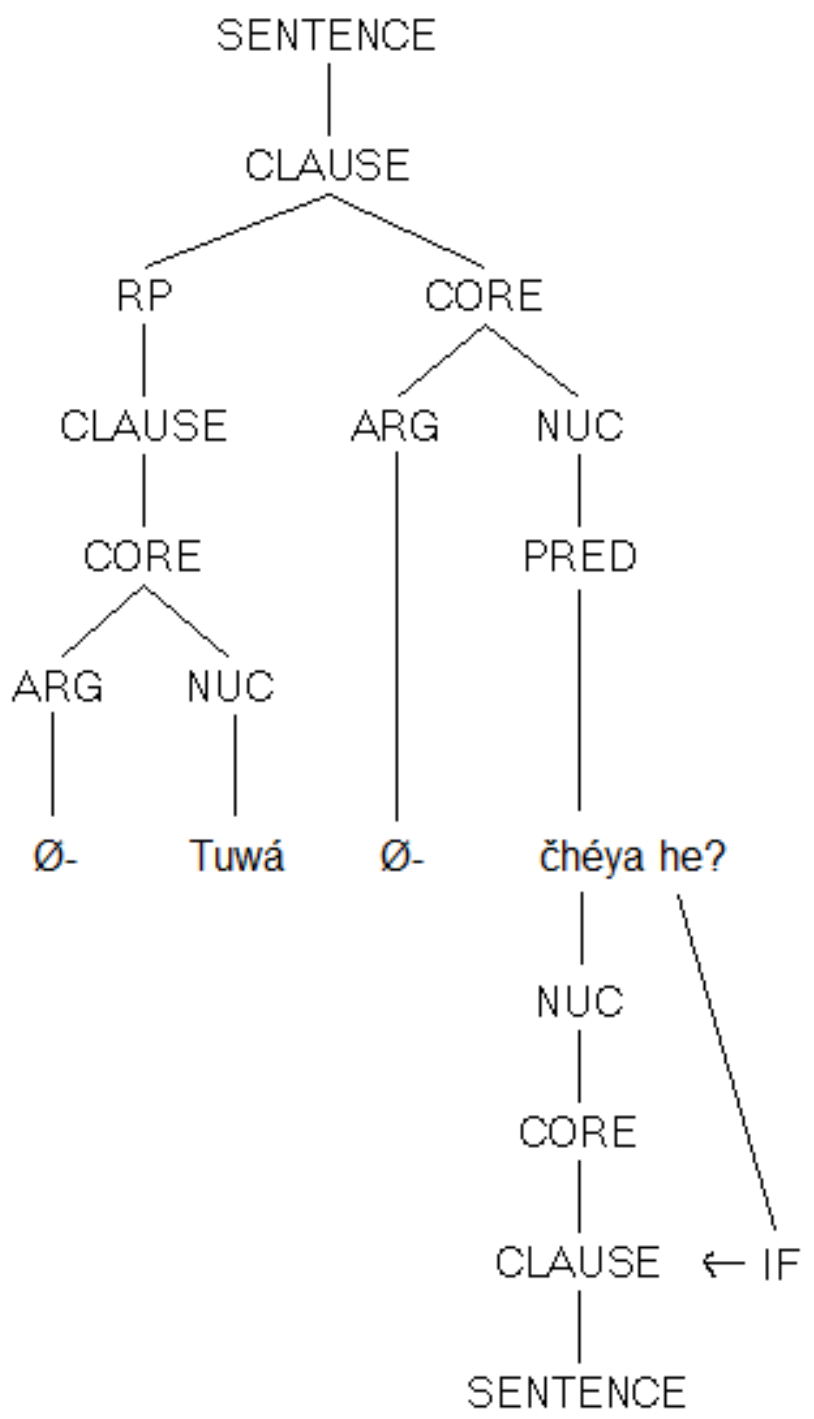

(3.26)

Hé $\varnothing$-tuwé čha léčhel o-má- $\varnothing$-ki-ȟ’an hwo?

Esse (3sgU)-quemART assim STEM-1sgU-(3sgA)-DAT-fazer INT "Quem foi que me fez isso?" (DT:121) 


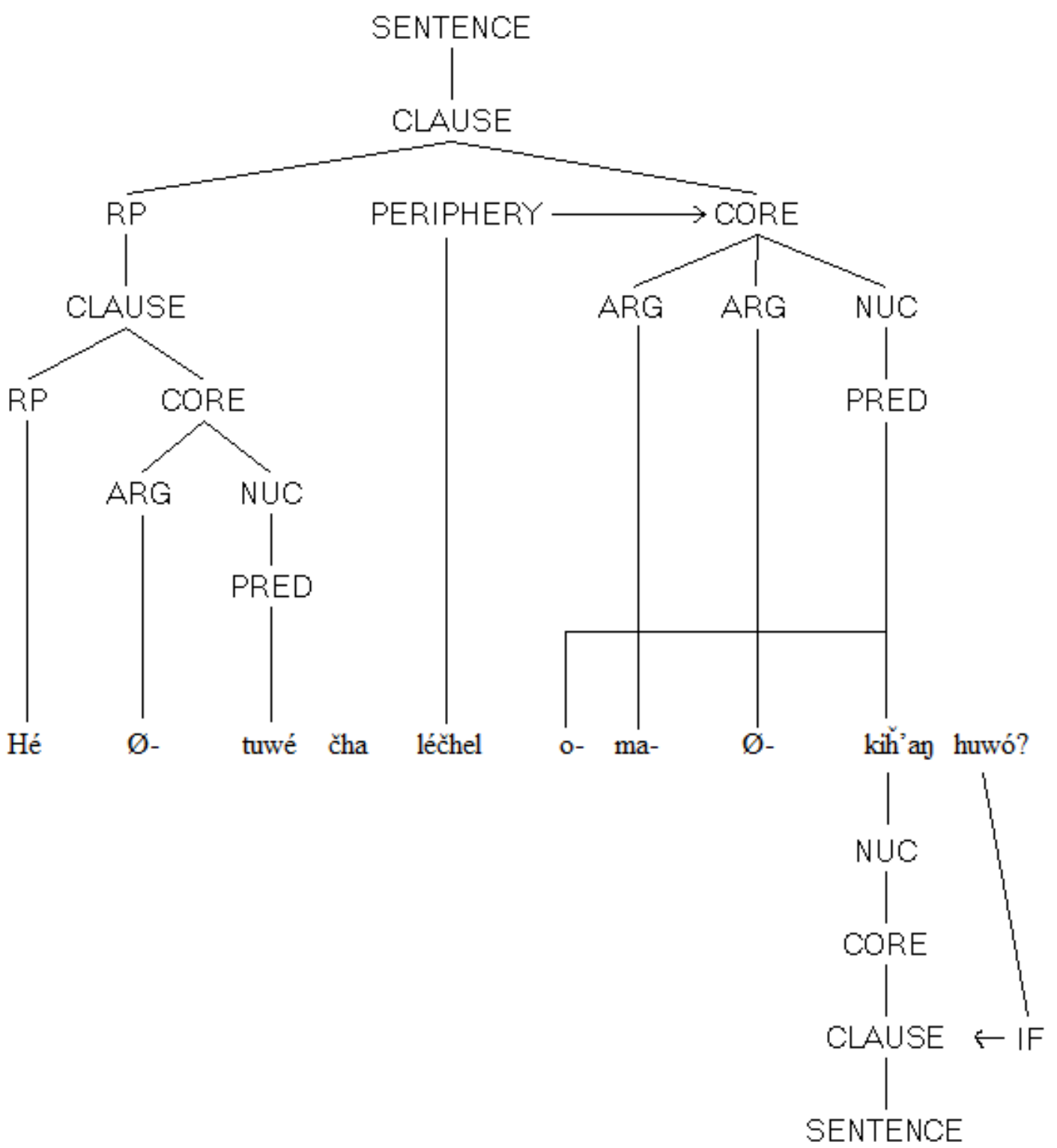

A sentença a seguir nos mostra mais uma evidência de que o uso pronominal de tuwé pode ser também interpretado como verbo:

Lé ni-túwe čha wa-ún-ši-ya-la héčihan

Este 2U-quem ART STEM-2U-ter.compaixão se 
[thiyópa kin] Ma-kí-yuğan yo.

[porta DEF] 1sgU-DAT-abrir IMPER

"Quem quer que seja você, tão gentil, abra (a porta) para mim." (DT: 89)

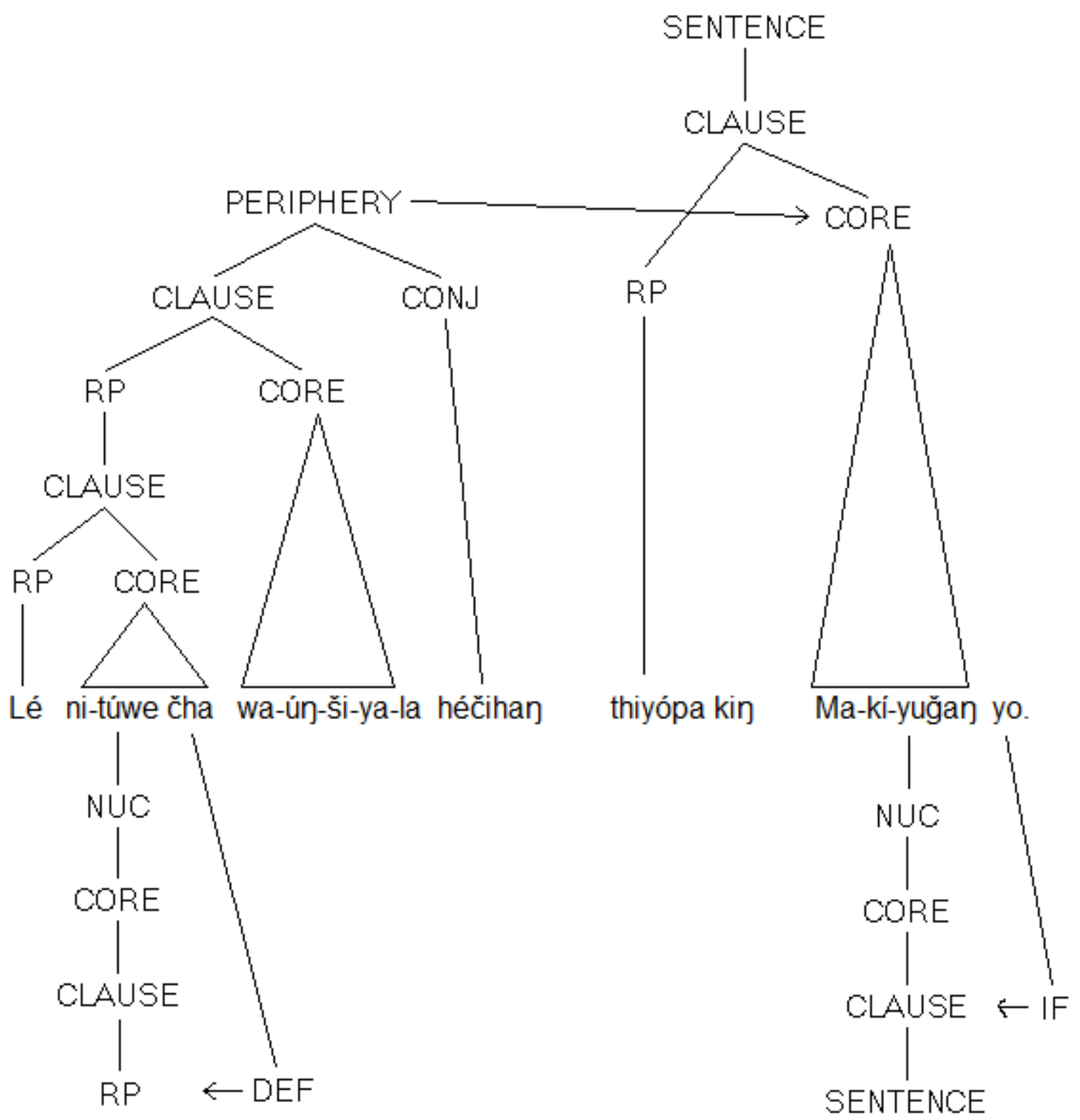

Ao mesmo tempo em que o sintagma lé nitúwe čha é $R P$ do verbo waúnšila, referenciado neste pelo morfema de segunda pessoa ya, recebe em si próprio uma marca pessoal, constituindo assim um núcleo de predicado dentro do próprio RP. Trata-se da mesma estrutura presente nas sentenças 3.21, 3.22 
e 3.26. A oração Lé nitúwe čha waúnšiyala, por sua vez, é subordinada ao verbo Makíyuğan yo através da conjunção héčihaク, usada introduzir uma oração interrogativa.

A forma negativa tuwéni "ninguém" também é usada no núcleo verbal e no $R P$. Por ter um sentido negativo, aparece junto com o enclítico šni quando é o núcleo da oração. As sentenças em 3.28 e 3.29 a mostram na posição de núcleo da oração e de $R P$. Não foi encontrado nenhuma ocorrência desta raiz com o morfema čha.

Ma-túweni šni.

1sgU-ninguém NEG

“Eu não sou ninguém.” (NLD: 566, tuwéni)

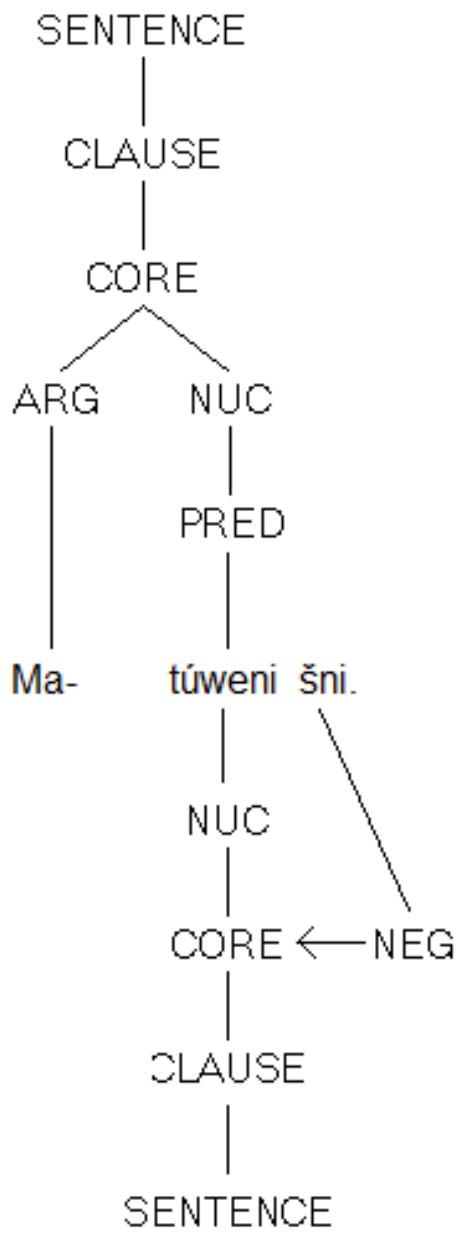


Ø-Tuwéni wan-má- $\varnothing$-yanke šni.

(3sgU)-ninguém STEM-1sgU-(3sgA)-ver NEG

"Ninguém me viu." (NLD: 566, tuwéni)

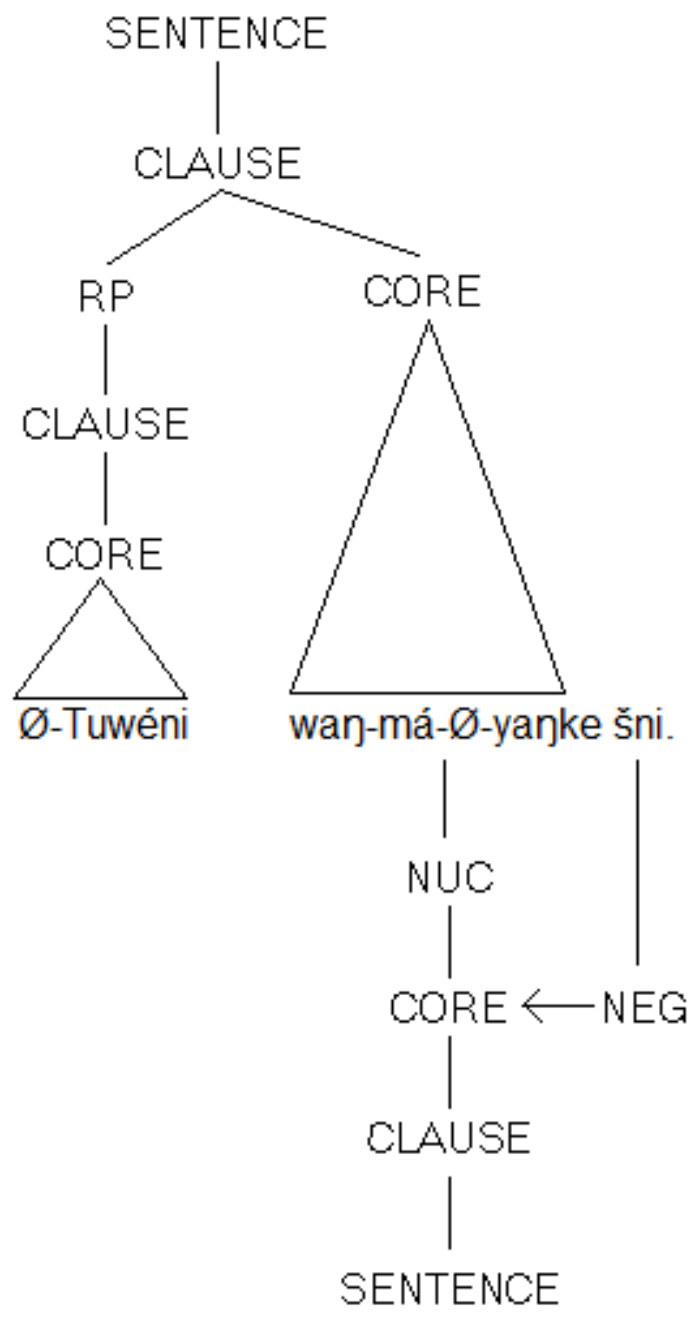

Em seguida, apresentamos a raiz táku "o que". Embora seja mais utilizada na terceira pessoa para se referir a seres não humanos e seres inanimados (compare a pergunta em 3.30 e a resposta em 3.31), pode receber também qualquer um dos morfemas pessoais. Quando se trata de seres humanos, questiona informações como grupo social de pertença, gênero ou fase da vida (sentenças 3.32 e 3.33). 
(3.30)

Lé Ø-táku he?

Isto (3sgU)-o que INT

"O que é isto?" (NLD: 519, táku)

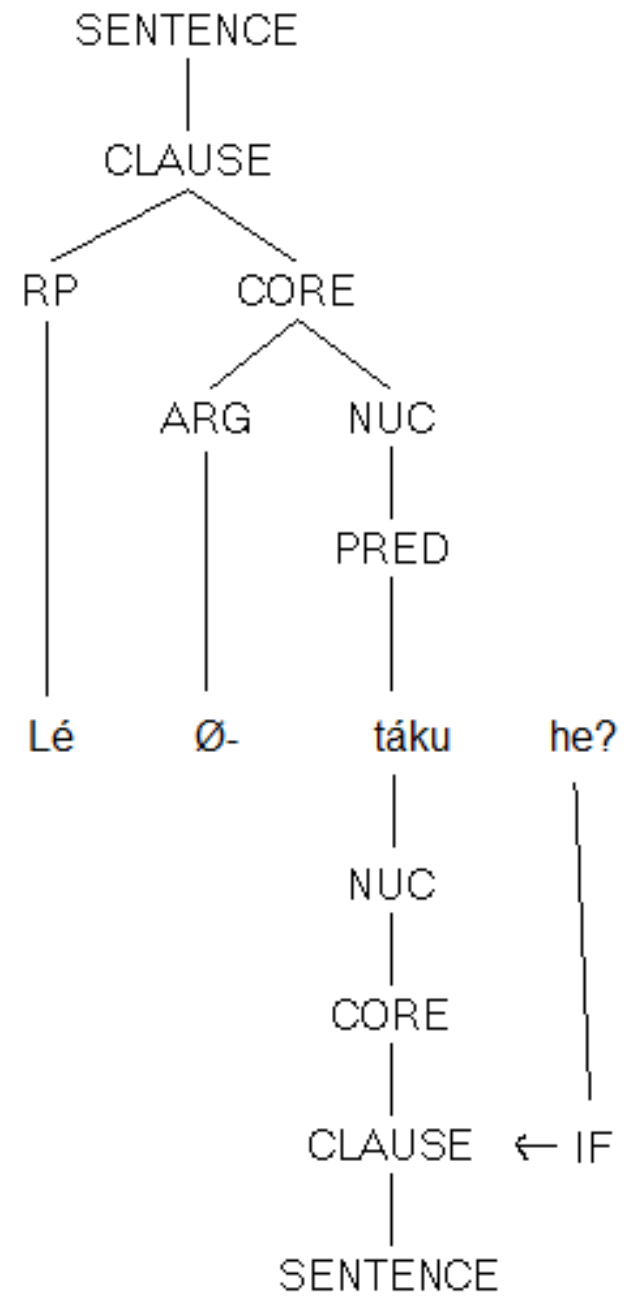

(3.31)

Lé wówapi Ø-héčha.

Isto livro (3sgU)-ser

"Isto é um livro." (NLD: 519, táku) 


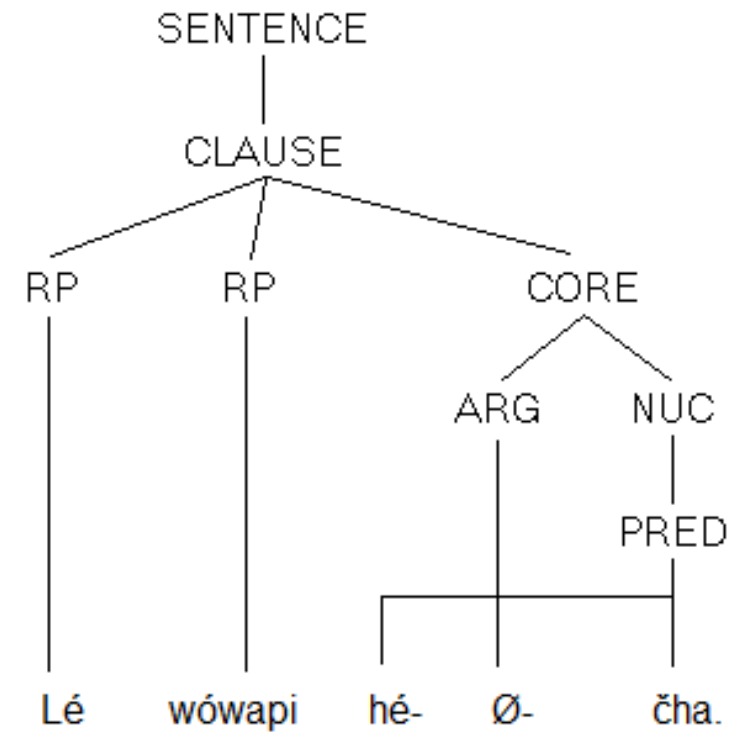

(3.32)

Ni-táku he?

2U-o que INT?

"O que você é?" (NLD: 519, táku)

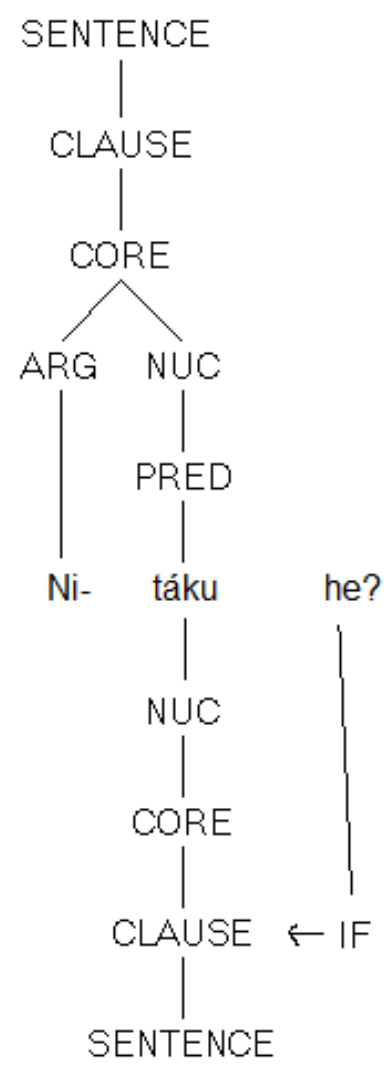


Lakȟóta he-má-čha.

Lakota STEM-1sgU-ser

“Eu sou lakota.” (NLD: 519, táku)

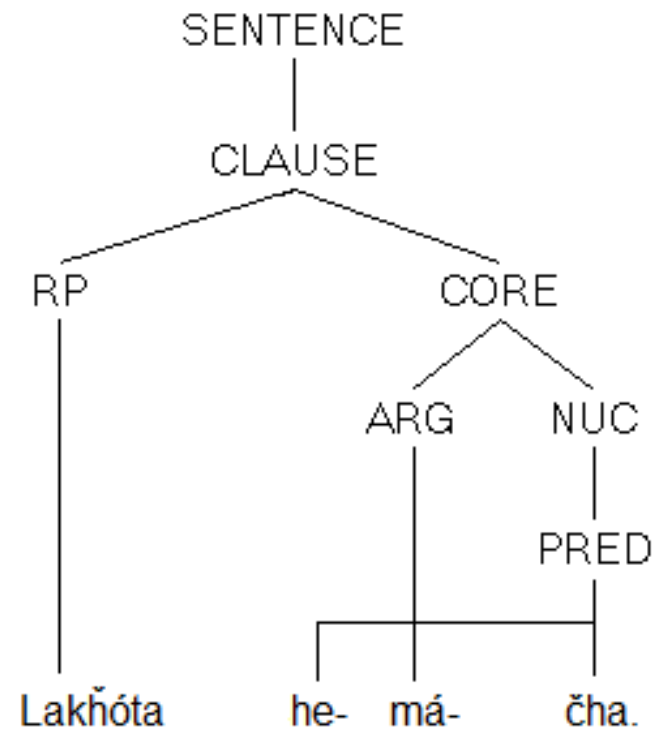

Como pode ser notado nos dois últimos exemplos, da mesma forma que tuwé e iyé nas orações em 3.24, há uma relação pragmática entre táku e héčha: se a informação que se busca é uma característica compartilhada por outros indivíduos (como o fato de pertencer ao povo lakota), é natural que a resposta venha acompanhada de héčha.

Apesar de não ser o foco principal deste trabalho, é importante abordar aqui um pouco sobre os substantivos que designam pessoa em lakota. Substantivos como hokšíla "menino", wičháša "homem" ou lakhóta "lakota" aceitam os morfemas pessoais da mesma maneira como os verbos estativos e outras palavras que temos visto até aqui. Observe abaixo o paradigma de hokšila: 


\begin{tabular}{|c|c|c|}
\hline Ho-Ø-kšíla & STEM-(3sgU)-menino & ele é um menino \\
\hline Ho-Ø-kšíla-pi & STEM(3U)-menino-PL & eles são meninos \\
\hline Ho-ní-kšila & STEM-2U-menino & você é um menino \\
\hline Ho-ní-kšila-pi & STEM-2U-menino-PL & Vocês são meninos \\
\hline Ho-ún-kšila & STEM-1dU-menino & Nós dois somos meninos \\
\hline Ho-ún-kšila-pi & STEM-1dU-menino-PL & Nós somos meninos \\
\hline Ho-má-kšila & STEM-1sg-menino & eu sou um menino \\
\hline
\end{tabular}

Uma característica interessante que difere o lakota de outras línguas em que o substantivo também recebe marcas pessoais é o fato de o morfema não indicar posse, mas sim se referir a alguma característica da entidade descrita. Seu uso é análogo ao do verbo héčha, sendo possível a troca entre as duas sentenças:

Ni-táku he?

2U-o que INT?

O que você é? (NLD: 519, táku) 


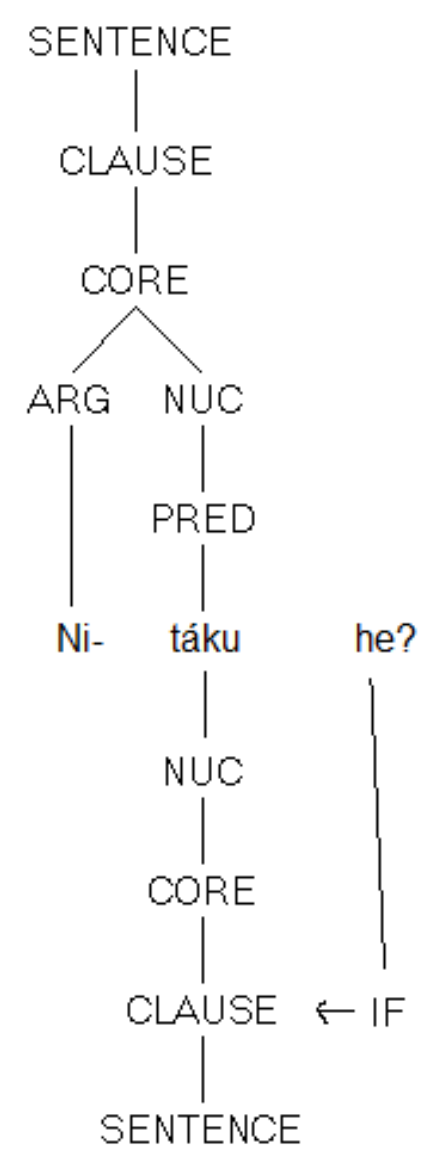

(3.36)

Hokšíla he-má-čha.

menino STEM-1sgU-ser

"Eu sou um menino."

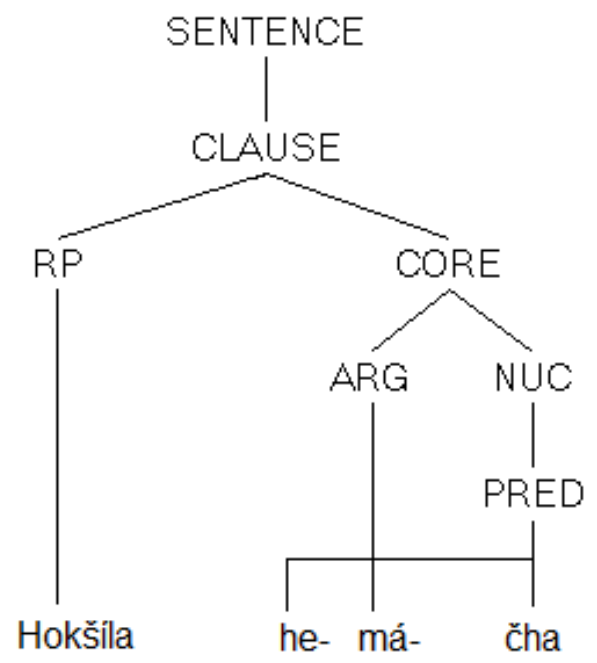


Ho-má-kšila.

STEM-1sgU-menino

"Eu sou um menino."

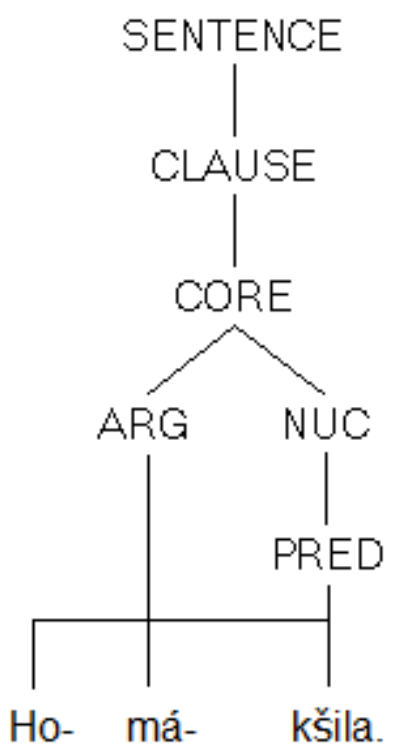

Como resposta para a pergunta em 3.35 , podem ser usadas tanto a sentença 3.36 como a sentença 3.37. A diferença entre uma e outra é apenas estrutural: enquanto em 3.36 o núcleo é o verbo héčha e o substantivo hokšila é o RP do seu argumento, em 3.37 o núcleo da oração é o próprio hokšíla, com os morfema pessoal devidamente posicionado. A representação sintática das duas respostas é dada abaixo:

Este uso de nomes como hokšila no núcleo de uma sentença é restrito à classificação de uma entidade e não pode ser usado no lugar de iyé. Outras palavras que se comportam de maneira semelhante são: wičhíčcala "menina", wínyan "mulher", wičháša "homem", kȟškálaka "rapaz" wikhóškalaka "moça", wičháhčala "velho", winúȟčala "velha", lakhóta "lakota". O termo maǧážu "chuva" pode ser usado tanto para indicar a chuva quanto para indicar a ação de chover, dependendo da posição em que se encontra dentro da oração: 
Maǧážu kin $\varnothing$-sní

Chuva DEF (3sgU)-gelado.

"A chuva é gelada."

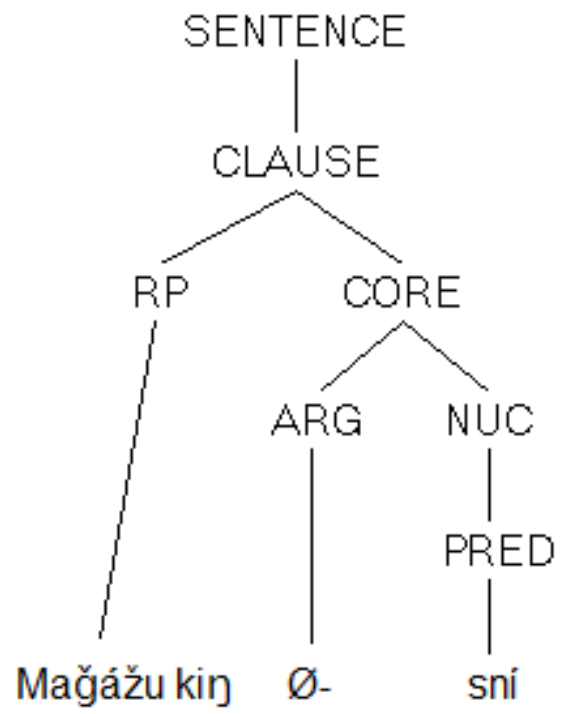

No exemplo acima, maǧážu ocura a posição de $R P$ em referência ao argumento da raiz sní "gelado". Na sentença abaixo, entretanto, ocupará a posição de núcleo do predicado:

Ø-Maǧážu kte šni.

(3sgU)-chuva FUT NEG

"Não vai chover." 

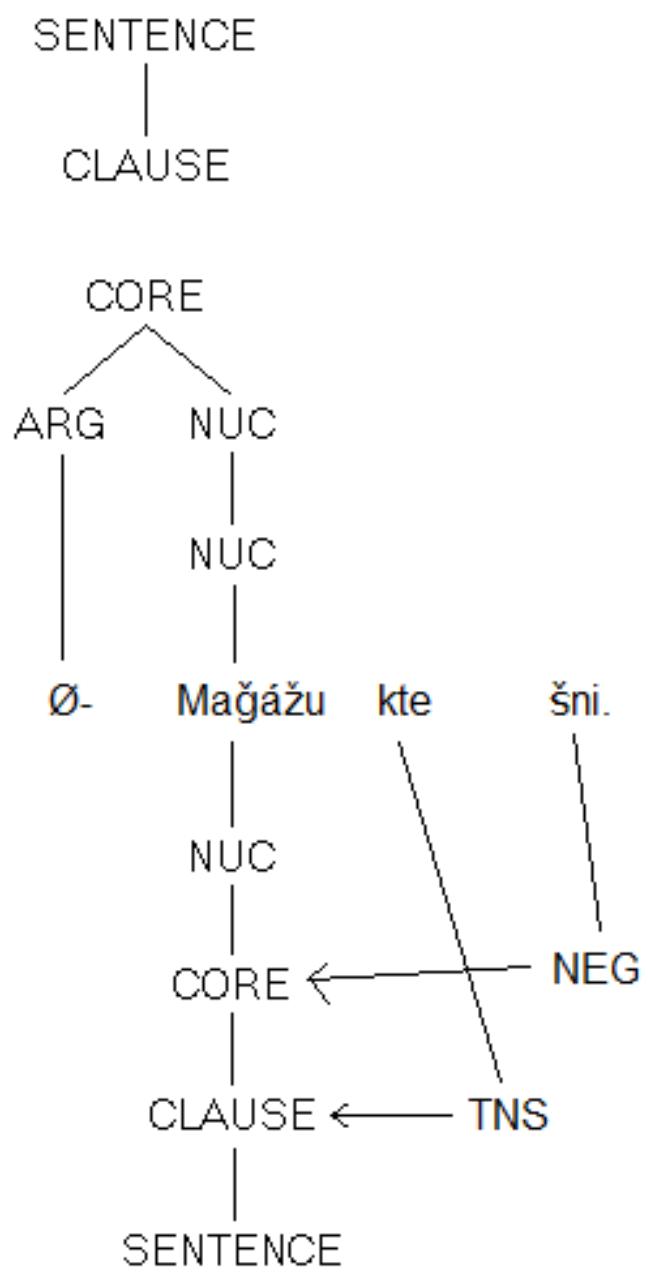

O que possibilita o termo maǧážu ser interpretado como verbo ou como substantivo é principalmente o fato de ser usado exclusivamente na terceira pessoa do singular e desta ser compreendida através da ausência de morfema pronunciado. Em 3.39 percebe-se ainda o uso do enclítico kte, usado com os verbos para indicar futuro.

Os substantivos em lakota podem ser classificados como verbos estativos se levarmos em consideração que a terceira pessoa é a própria raiz e que esta pode ocupar o núcleo de uma oração sem a necessidade de héčha. Uma característica desse tipo de construção é que ela terá sempre o sentido de classificação e não de identificação. 
Lé $\varnothing$-wówapi he?

Isto (3sgU)-livro INT

"Isto é um livro?"

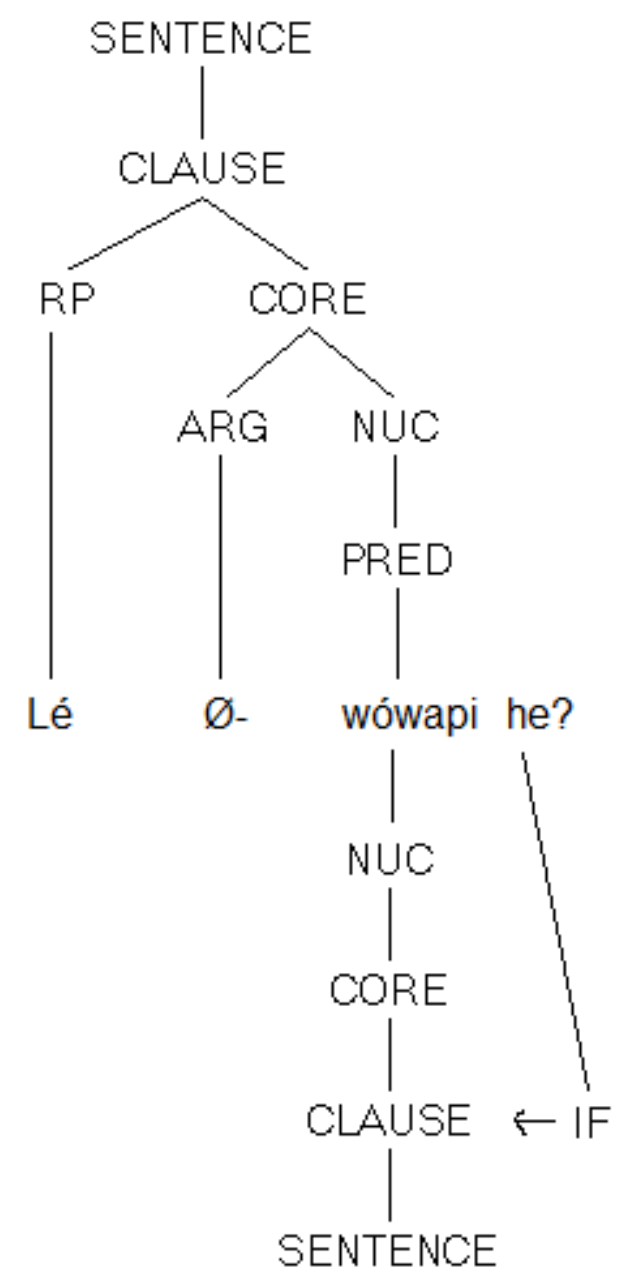

(3.41)

Lé $\quad$-wówapi šni

Isto (3sgU)-livro NEG

"Isto não é um livro." 


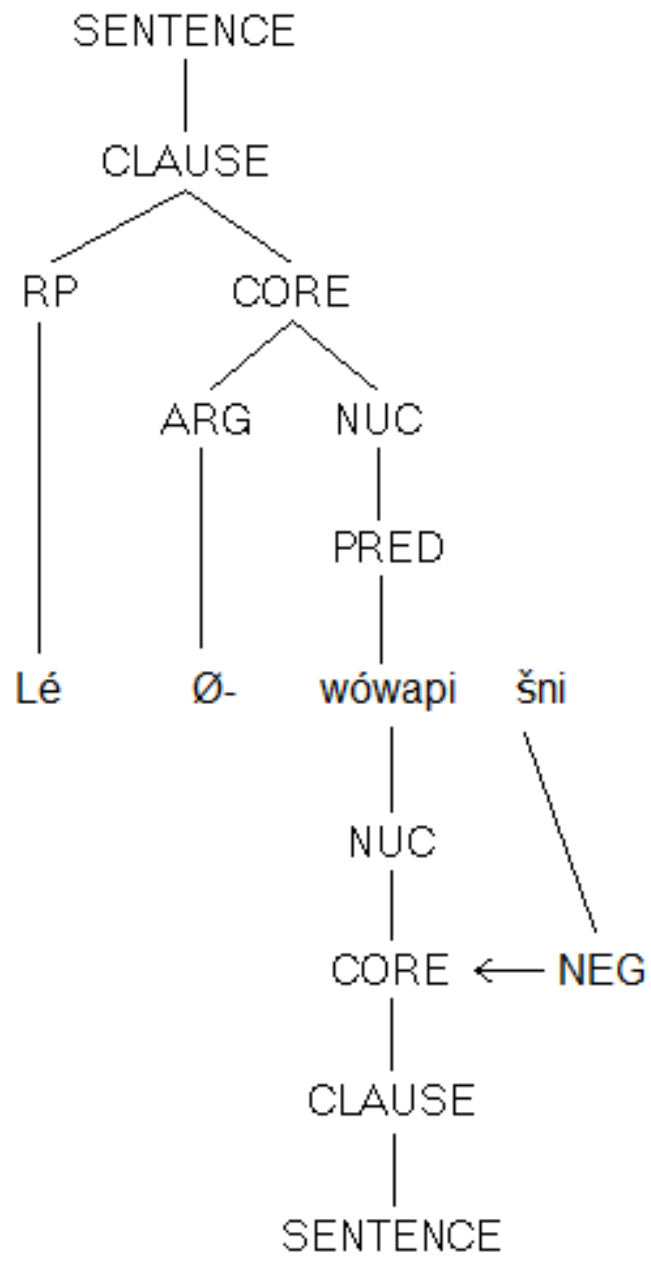

Em 3.40 e 3.41 o substantivo wówapi "livro" é usado como núcleo da oração. Em 3.40, questiona-se a classificação do objeto e em 3.41, nega-se usando o enclítico šni. Da mesma maneira como as sentenças contendo palavras que se referem a seres humanos, as duas sentenças poderiam ser reescritas usando o verbo classificatório héčha. Os dois casos acima mostram, portanto, que substantivos inanimados também são capazes de assumir posição de núcleo. Entretanto, da mesma como mağážu "chuva", seres inanimados dificilmente receberão morfemas pessoais, uma vez que costumam se referir à terceira pessoa e esta nunca é marcada. 


\section{5 lyé em conjunto com posposições}

O paradigma de iyé é também a forma que precede algumas posposições. Este tipo de sintagma costuma exercer função de periphery na sentença, ou seja, não se torna um argumento obrigatório do verbo principal.

$\begin{array}{lllllr}\text { Tuwá } & \text { táku } & \text { m-iyé } & \text { etánhan } & \text { napsíl } & \text { i-Ø-yáye } \\ \text { Alguém } & \text { o que } & 1 \text { sgU-ser } & \text { de } & \text { pulando } & \text { STEM-(3sgA)- } \\ \text { sair } & & & & & \end{array}$

čin hé $\varnothing$-Ø-ičú hántanhanš (...)

DEF este (3sgU)-(3sgA)-pegar se

"Se alguém tirar algo do que sair pulando de dentro de mim..." (DT: 105)

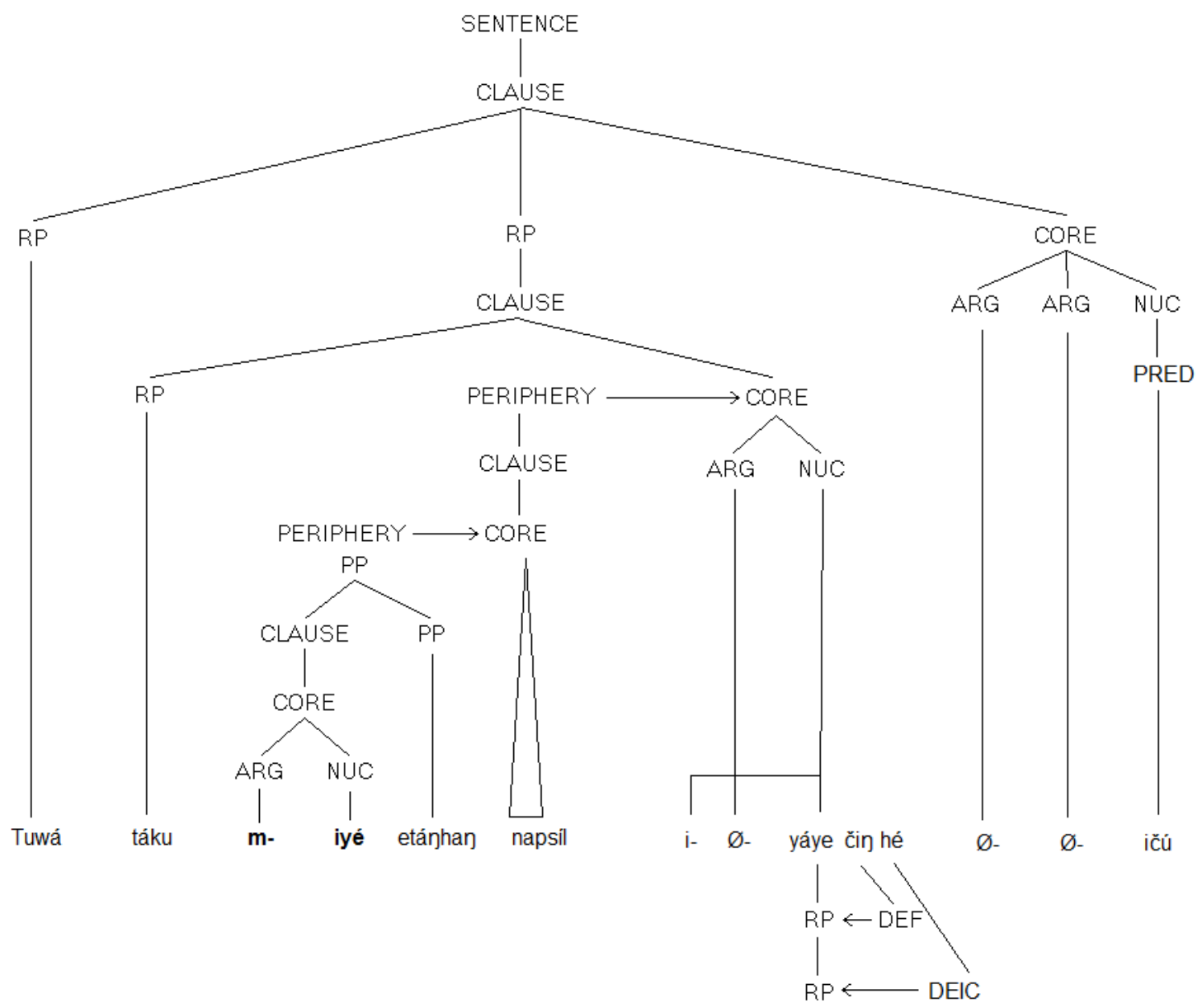


Em 3.24, o constituinte miyé etánhan não é um $R P$ do verbo, mas está localizado no periphery, mostrando que a raiz iyé também pode ocupar esta posição. Se interpretarmos etánhan como um verbo em posição de períphery, iyé poderia ser visto como um $R P$ deste e iyé etánhan seria considerado uma oração subordinada ao verbo napsíl. Apesar de frequentemente ser classificado como posposição, etánhan também pode assumir posição de núcleo da oração com morfemas pessoais:

A próxima construção a ser estudada é a junção do verbo iyé com a conjunção aditiva na. Esta pode ser diretamente posposta a um verbo ou a um substantivo (próprio ou não), mas jamais é usada depois de artigos de qualquer tipo ou depois demonstrativos. Para formar um sintagma válido, é necessário usar o verbo iyé entre o sintagma e a conjunção, criando-se assim uma oração aditiva.

$\begin{array}{clllll}\text { (...) wačhók'in } & \text { k'un hená } \varnothing \text {-é } & \text { na } & \text { nakún } & \text { špánšni } \\ \text { Tostado } & \text { DEF } & \text { esses }(3 s g U) \text {-ser } & \text { e } & \text { também } & \text { cru }\end{array}$

Ø-hiyéye č’un iyúhala

(3sgU)-espalhado DEF tudo

"Toda essas (carnes) tostadas e também as cruas espalhadas." (DT: 27)

$\begin{array}{llllll}\text { Wínyan } & \text { k'un } & \text { waná wičhóthi-ta } & \varnothing \text {-aglípi na čhínča } & \text { núnpa } \\ \text { Mulher } & \text { DEF } & \text { agora aldeia-LOC } & \text { (3sgA)-chegar e } & \text { criança } & \text { dois }\end{array}$
k'un hená $\varnothing$-é-pi
na hingnáku kin kȟó
DEF esses (3sgU)-ser-PL
e seu marido DEF também 
Wan-wíčha-glák-khiya-pi kheš átayaš él

STEM-3pIAnim-ver-CAUS-PL mas nada LOC

é-wičha- $\varnothing$-wačhin

šni.

STEM-3plAnim-(3sgA)-interessar-se NEG

"A mulher agora foi trazida para o acampamento e fizeram-na olhar para seu marido e seus dois filhos, mas ela não deu nenhuma atenção." (DT: 211)

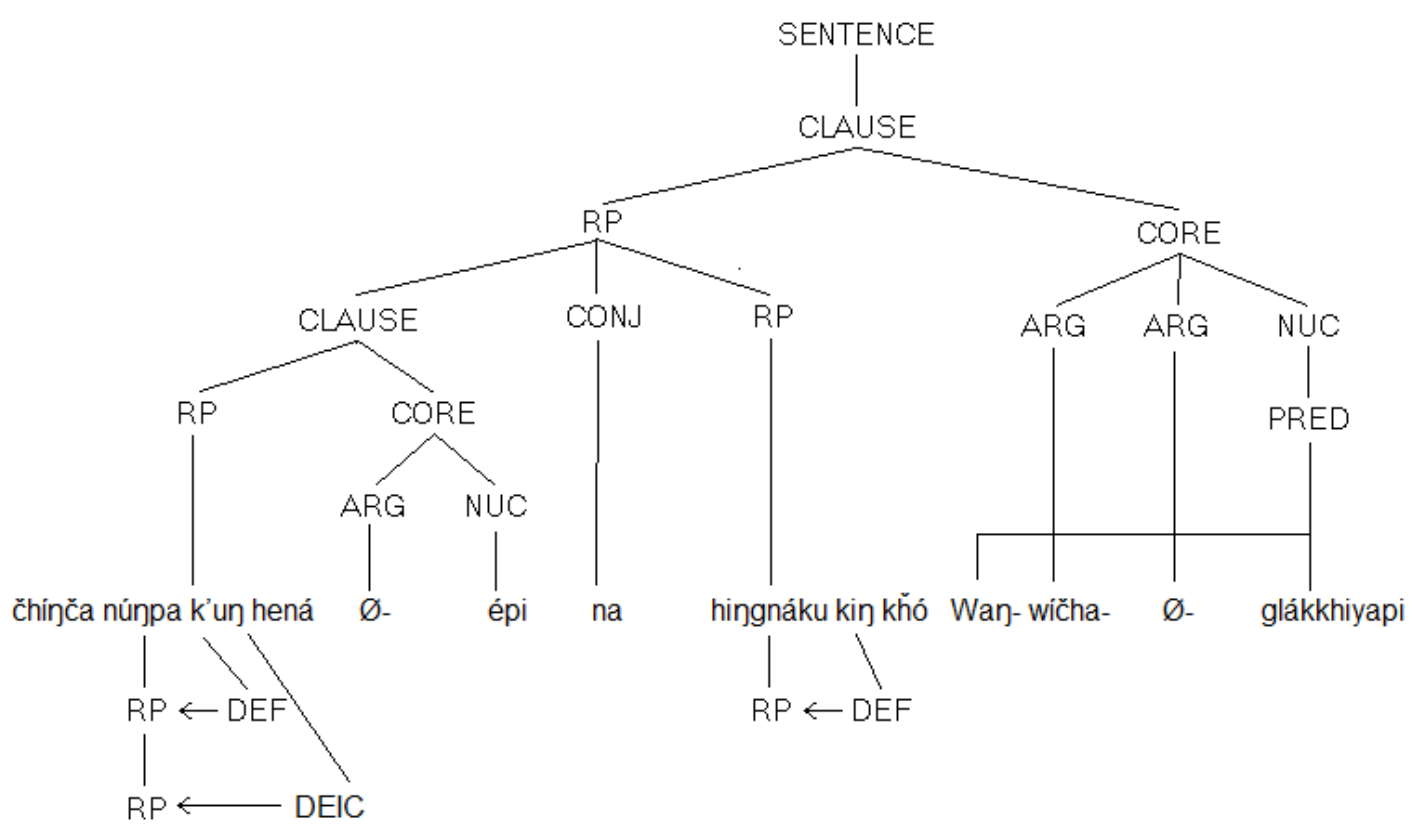

Os dois exemplos acima nos mostram $R P$ com a conjunção na em sua composição. De imediato pode se notar que o verbo iyé não é repetido em cada um dos itens somados, mas apenas naquele que carrega o artigo k'un e o demonstrativo hená. Outro detalhe é, apesar de nos dois casos a conjunção estar somando itens no plural, o verbo iyé recebe o sufixo pi apenas em 3.40.

A próxima estrutura é formada com a posposição káyeš "até mesmo" e, da mesma forma que a conjunção na, não pode ser precedida diretamente por artigos ou demonstrativos. Assim, insere-se o verbo iyé, criando uma oração dentro do $R P$. 
Hohú kin $\quad$-é káyeš i-Ø-Ø-čú-pi.

Osso DEF (3sgU)-ser até mesmo STEM-(3sgU)-(3sgA)-pegar-PL “Eles pegaram até mesmo os ossos." (NLD: 102, é káyeš)

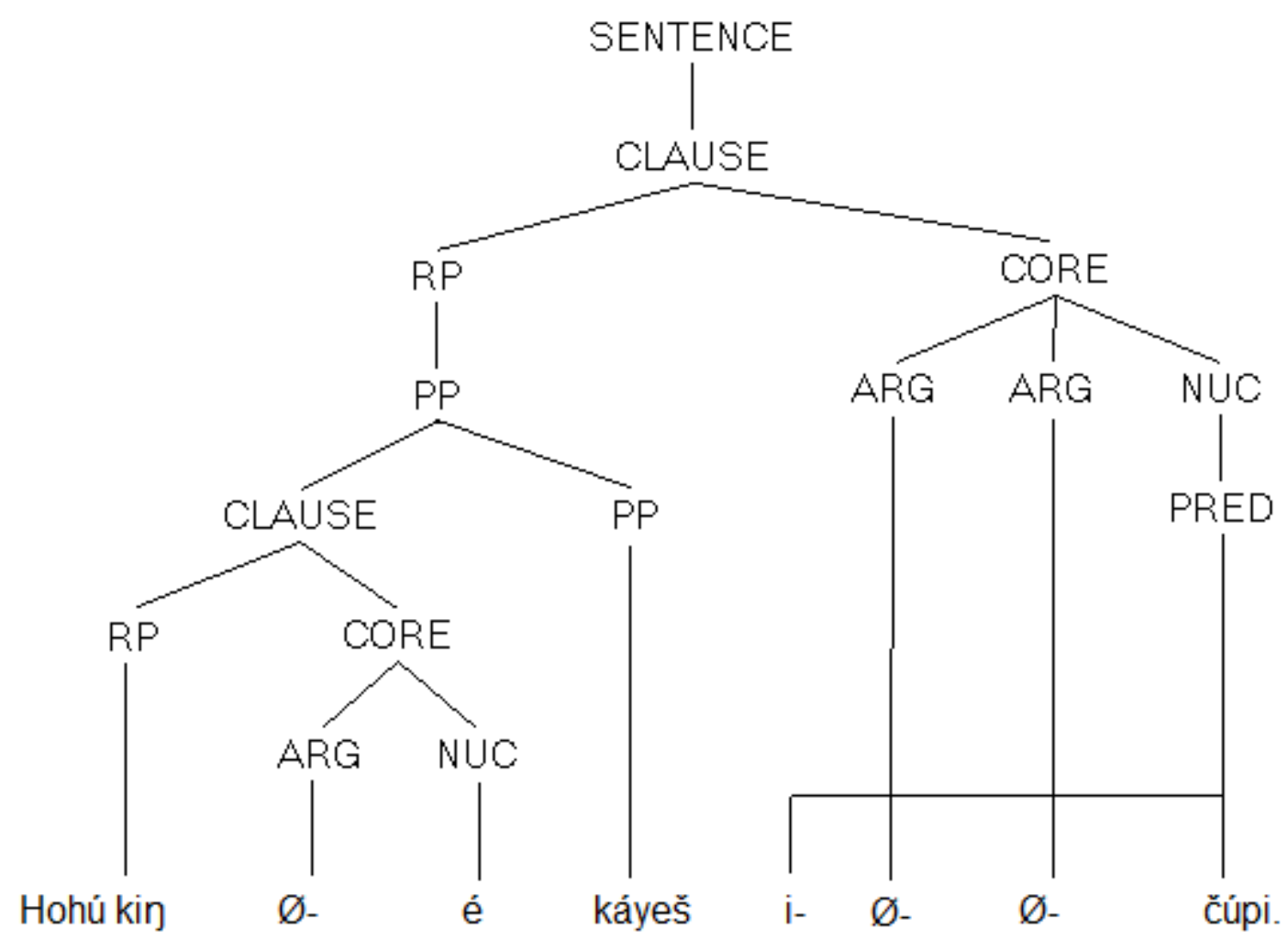

Neste primeiro exemplo, káyeš aparece com um substantivo no singular e o RP funciona como Undergoer do núcleo verbal ičú. Uma vez que o substantivo é marcado com um artigo definido, inclui-se o verbo iyé na terceira pessoa do singular. Nas orações 3.46 e 3.47, apresentadas abaixo, percebe-se a variação de pessoa no núcleo verbal do RP: em 3.46, iyé encontra-se no plural por referir-se a uma entidade naturalmente pluralizada. Em 3.47, usa-se a primeira pessoa exatamente nas mesmas condições dos exemplos anteriores.
Thítakuye $\varnothing$-é-pi
káyeš
ó-Ø-Ø-kiya-pi
Parentes
(3sgU)-ser-PL
até mesmo
STEM-(3sgU)-(3sgA)-ajudar-PL 
šni.

NEG

"Nem mesmo os parentes o ajudaram." (NLD: 103, é káyeš)

M-iyé káyeš théhanyan čha o-wá-kihi šni.

1sgU-ser até mesmo longe ART STEM-1sgU-poder NEG

"Nem mesmo eu posso continuar (ir tão longe)." (NLD: 103, é káyeš)

Por último, apresentamos a interação entre iyé e a posposição s'e, usada para fazer comparações. Esta conjunção, assim como na, pode incluir ou não o verbo iyé, mas há uma alteração no significado e no uso. Observe os exemplos:

John $\varnothing$-é s'e líla $\varnothing$-witkó-tkoke.

John (3sgU)-ser como muito (3sgU)-louco-REDUP

"Ele é tão louquinho quanto John." (NLD: 103, é s'e)

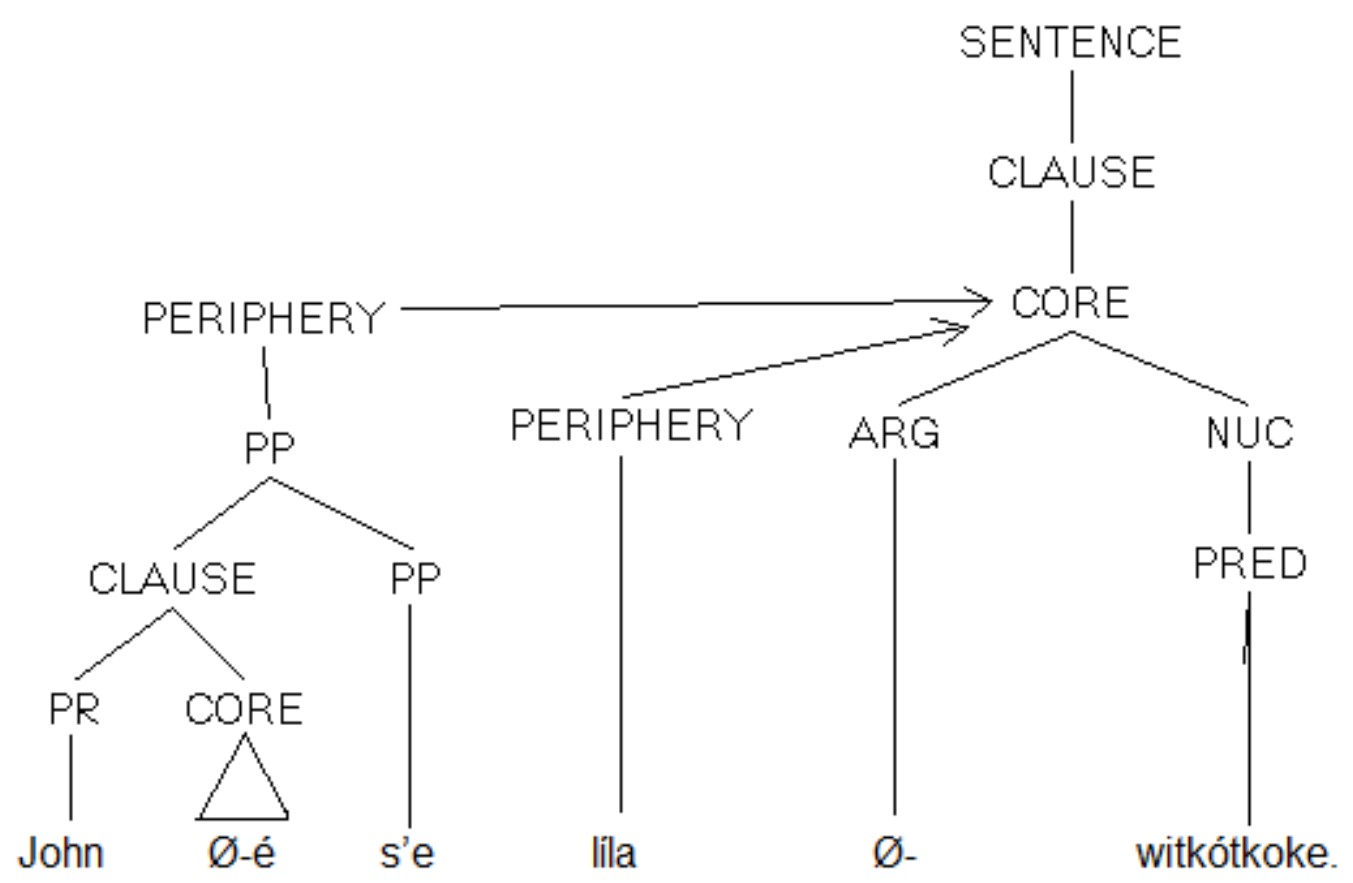




Wakhánheža s'e wa- $\quad$-náh̆'un
Criança como ABS-(3sgA)-ouvir NEG
"Ele é desobediente como uma criança." (NLD: 503, s'e)

Em 3.48 e 3.49, os elementos de comparação são, respectivamente, John e Wakhánheža "criança". A diferença entre eles reside no fato de que John é uma entidade específica, ao contrário de Wakh̆ánheža, que designa a criança em geral. Assim, a presença de iyé se torna lógica, já que é o verbo usado na identificação. Outra característica de iyé nesta construção é a possibilidade de receber os morfemas das demais pessoas, formando miyé s'e, niyé s'e etc.

3.50 apresenta a conjunção s'e precedida por outro verbo, a fim de comparação. Nota-se que o núcleo verbal wanyánke ocupa exatamente a mesma posição que iyé nos dois exemplos anteriores.

Wan- $\varnothing$ - $\varnothing$-yánke šni s'e $\varnothing$-yanká-he.

STEM-(3sgU)-(3sgA)-ver NEG como (3sgA)-sentar-DUR

"Ele estava sentado como se não tivesse notado isso." (NLD: 503, s'e)

\section{6 lyeš}

A raiz iyé pode juntar-se ao sufixo š para criar um sentido adversativo, contrastando a pessoa em questão com outras já citadas no texto. Este sufixo é usado para marcar contraste em algumas conjunções e advérbios.

M-iyé-š lé tȟokáheya wa-hí k'un.

Eu-advers este primeiro 1sgA-vir PAS

"Fui eu que cheguei primeiro (e não os outros)." (NLD: 256, iyéš) 


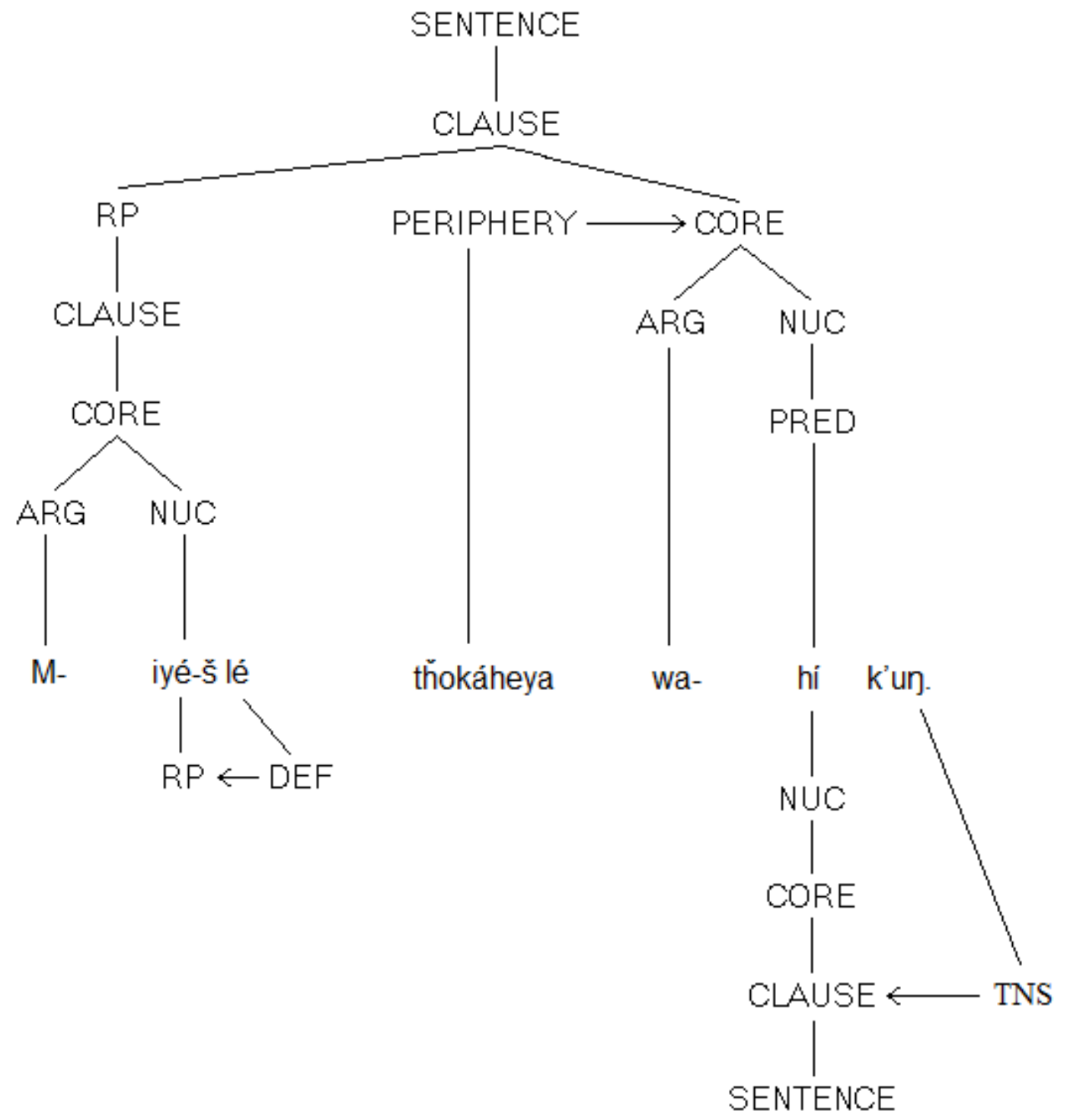

Embora na gramática de Boas iyéš seja apresentado como um conjunto à parte de pronomes, este pode ser agrupado dentro de iyé. Uma prova disso é que a ideia de contraste que o sufixo š adiciona pode ser usada em outras posições, como pode ser verificada no exemplo abaixo:

Thibló

wičá-Ø-la

šni tkȟáš

miyé

Irmão mais velho

STEM-3sgA-concordar

NEG mas

eu 
lyówin-wa-ye.

STEM-1sgA-aceitar

“Meu irmão não concorda com aquilo, mas eu aceitei." (NLD: 256, iyéš)

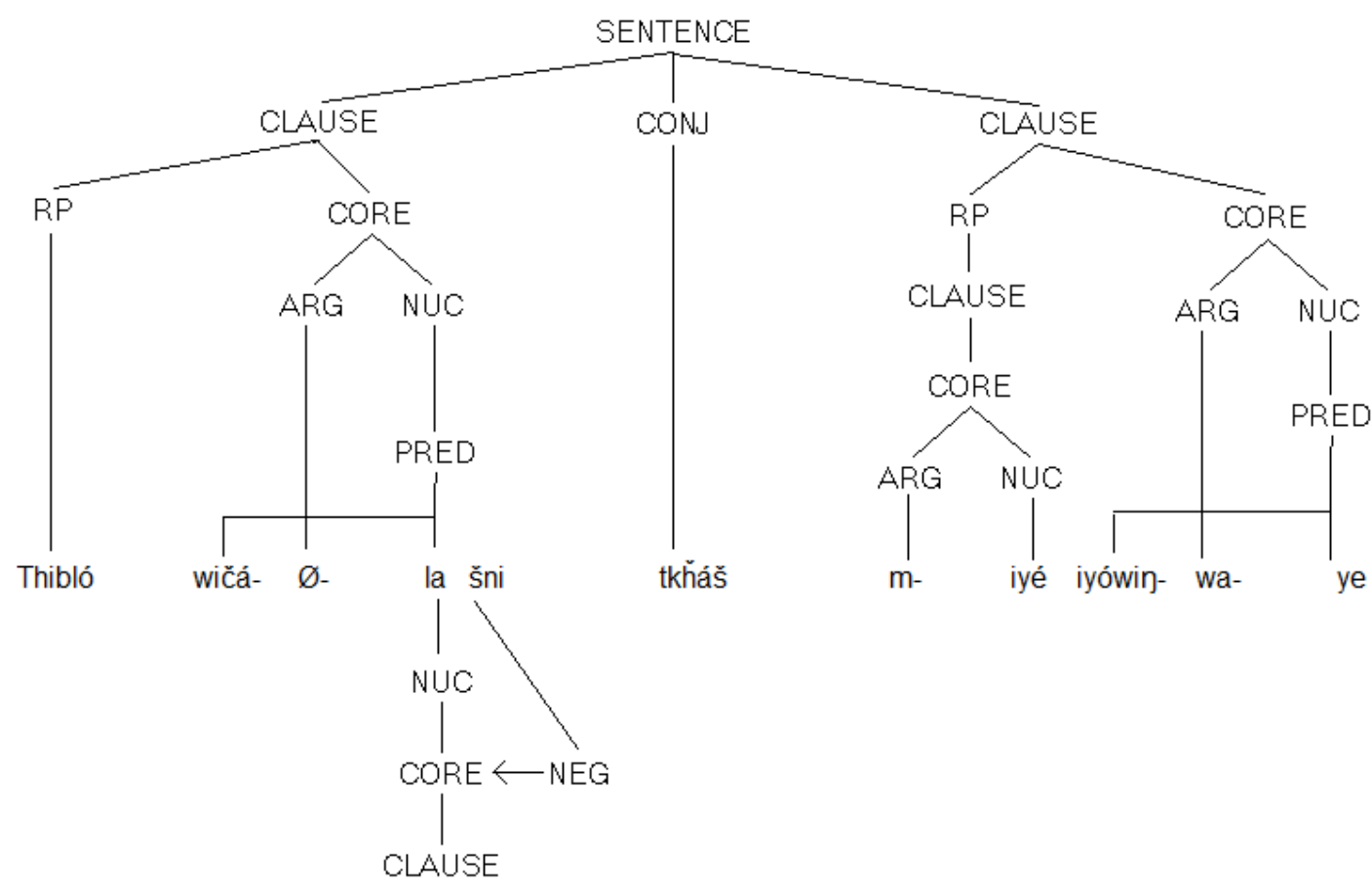

Na sentença acima, o sufixo adversativo não se encontra na pessoa que forma o segundo contraste (miyé), mas na conjunção que a antecede. A forma (...) tkh̆á miyéš (...) também é aceita.

\section{7 ínš}

O terceiro grupo de "pronomes" a ser estudado neste trabalho apresenta algumas das características já levantadas nos dois grupos anteriores, mas possui também problemas particulares tanto na forma quanto no uso. A intenção da análise aqui apresentada não é chegar a uma conclusão definitiva sobre a melhor forma de classificá-los sintaticamente, mas identificar possibilidades de interpretação. 


\subsubsection{Estrutura morfológica}

O terceiro paradigma apresenta algumas inconsistências em relação a sua estrutura morfológica. Diferente de iyé, a terceira pessoa não diferencia singular de plural para substantivos animados. Além disso, nenhuma das formas no plural acompanham o sufixo pi, possivelmente pela presença do sufixo š.

$\begin{array}{lll}\text { Ø-Ín-š/í-š/é-š } & (3 s g U)-S T E M-C O N & \text { ele/eles } \\ \text { N-í-š } & \text { 2sgU-STEM-CON } & \text { você/vocês } \\ \text { Unk-í-š } & 1 \text { dUU-STEM-CON } & \text { nós dois/nós } \\ \text { M-í-š } & 1 \text { sgU-STEM-CON } & \text { eu }\end{array}$

Estes termos são formados pela junção três morfemas ${ }^{28}$ : a raiz $\mathrm{i} / \mathrm{e}^{29}$, um dos morfemas pessoais prefixado (ou a ausência dele no caso da terceira pessoa), e o sufixo š, usado após conjunções e advérbios para indicar a ideia de contraste.

\subsubsection{Ocorrências e usos}

Devido a presença do sufixo š, todas as suas ocorrências indicam alguma forma de contraste entre dois termos citados ou um subentendido. Os exemplos abaixo mostram seu uso com um nome próprio, um substantivo com artigo definido, com um demonstrativo e sem nenhuma outra palavra no mesmo sintagma:

\footnotetext{
${ }^{28}$ Esses termos serão identificados com a sigla CON (contraste) na glossa, levando em consideração seu uso.

${ }^{29} \mathrm{~A}$ terceira pessoa apresenta os alomorfes $i$ e $e$ na raiz, possivelmente variações da raiz iyé e seu alomorfe é. A nasalização nas duas primeiras pessoas ocorrem devido à presença de consoantes nasais.
} 
$\begin{array}{lllll}\text { Hehányan } & \text { waná tȟatȟánka } & \text { k'un } & \text { íwaȟte- } \varnothing \text {-lašni } & \text { kéye. } \\ \text { Até } & \text { agora búfalo } & \text { DEF } & \text { STEM-(3sgU)-irritado } & \text { EVID }\end{array}$

“Cȟáš čhín tókhel Ø-ȟ’anphíča he?" Ø-Ø-eyá

INTERJ claro como (3sgA)-poder.agir INT (3sgU)-(3sgA)-dizer

yunkȟán Iktó iš hehánl léčhel Ø-Ø-eyá kéye: (...)

então Iktó CON depoisassim (3sgU)-(3sgA)-dizerEVID

Chegando nesse ponto, agora o búfalo estava irritado. "Afinal, como podemos fazer?" disse e então lktó disse assim: (...) (DT: 33)

Em 3.54, temos íš modificando o nome próprio Iktó. Este $R P$ se refere ao papel semântico actor referenciado no verbo. O contraste, no entanto, é feito em relação à outra personagem da narrativa, thatȟánka "o búfalo", presente na oração anterior. Assim, o contraste é estabelecido entre duas orações. Outra característica importante que deve ser notada é o fato de íš estar sendo usado não para substituir um substantivo, mas como modificador de um, uma vez que o sufixo š não se liga diretamente a substantivos.

Hokšila kin ínš "Ho, ečha unčí, itázipa na Menino DEF CON INTERJ Neste caso avó arco e

wanhínkpe kȟó m-ičáğa yo" $\varnothing$-Ø-eyá (...)

flecha também 1sgU-produzir IMP (3sgU)-(3sgA)-dizer

E o menino disse: "então, vó, faça para mim um arco e flechas também." (DT: 99)

Em 3.55, ís aparece junto ao sintagma definido hokšila kin e estabelece o contraste com a personagem unči "avó", já conhecida na narrativa. O sintagma Hokšila kin ínš, por sua vez, é RP do núcleo verbal eyá "dizer". 
Yunkȟán hé iš o-Ø-yúspa-pi yunkȟán leyá Então esse CON LOC-(3sgU)-(3sgA)-capturar-PL então ao contrário

tohánhanyan ská k'un hehánhanyan hohú kin Ø-šéča škhé. De longe branco DEF somente osso DEF (3sgU)-seco EVID "Então ao pegarem este (cavalo) as partes que de longe eram brancas eram na verdade osso seco." (DT: 212)

Em 3.56, temos ís modificando o demonstrativo hé. Este exemplo nos mostra ainda que o RP formado por ínš pode desempenhar também o papel semântico de undergoer e não só de actor. No contexto dessa narrativa, o contraste é estabelecido entre o cavalo que é capturado (o termo cavalo não aparece na oração) e os outros cavalos citados.

Ektáni wa-ún yunkȟán ínš $\varnothing$-gličú.

Lá 1sgA-estar então CON (3sgA)-voltar

"Eu fiquei lá e ele voltou para a casa." (NLD: 225, íň)

A oração em 3.57 apresenta ínš formando sozinho o $R P$ do verbo gličú. O contraste é estabelecido entre a terceira pessoa do singular e a primeira, marcada no verbo da oração anterior. Como podemos notar nos exemplos dados, o contraste não é marcado em todos os elementos que estão sendo comparados, mas apenas no segundo.

As sentenças a seguir nos apontam algumas peculiaridades deste grupo:

Ho, Iktó, niš Ø-hehántu weló!

INTERJ Iktó CON (3sg)-é.hora ENCL

"Oh, Iktó, é sua vez!" (DT: 34) 
Em 3.58, temos a forma da segunda pessoa níš como $R P$ em um verbo geralmente impessoal. O sufixo de contraste se refere a lktómi e ao falante.

A oração 3.59 abaixo mostra outra característica peculiar de ínš: a possibilidade de usá-lo com sintagmas interrogativos e indefinidos.

$\begin{array}{lllll}\text { héčhetu-Ø-la-pi } & \text { na } & \text { waná unmá } & \text { Ø-gnín } & \text { na } \\ \text { STEM-(3sgA)-decidir-PL } & \text { e } & \text { agora um.deles } & \text { (3sgA)-ir.pra.casa e } \\ \text { pȟéta a-Ø-ú } & \text { na } & \text { unmá } & \text { íš éna awányang } \\ \text { Fogo STEM-(3sgA)-trazer } & \text { e } & \text { um.deles } & \text { CON lá observando }\end{array}$

Ø-nážin kta Ø-kéya-pi kéye.

(1sgA) FUT (3sgA)-dizer.isso-PL EVID

"Elas decidiram e disseram que uma iria (para casa) pegar o fogo e outra ficaria lá observando." (DT: 39)

A sentença em 3.59 nos mostra duas personagens, não especificadas, que discutem e tomam uma decisão. A partícula ís é usada para contrastar a ação que cada uma deve cumprir, mas não se sabe qual das duas realizará qual ação, pois os dois $R P$ de actor são marcados pelo termo indefinido unmá "um deles". Íš, portanto, pode acompanhar tanto sintagmas definidos (3.57 a 3.57) quanto sintagmas indefinidos (3.59 e 3.60 abaixo).

O exemplo a seguir apresenta mais um caso interessante. O narrador, após contar dois desfechos diferentes para uma mesma narrativa, apresenta uma terceira variante iniciando da seguinte maneira:

Etán ínš Ø-héya-pi.

IND CON (3sgA)-dizer-PL 
Alguns dizem isso. (DT: 44)

Em 3.60 temos ínš modificando o artigo indefinido etán "alguns". O constituinte formado funciona como agente do verbo héyapi "dizem". O contraste está estabelecido entre os narradores dos dois primeiros desfechos e os narradores de um terceiro, que não serão especificados.

\subsubsection{Análise sintática}

A análise sintática do paradigma ínš apresenta desafios particulares. 0 objetivo desta dissertação não é chegar à conclusão de qual é a melhor forma de classificá-lo sintaticamente, e sim prover duas formas distintas de interpretálo, cada uma com suas próprias consequências. De qualquer forma, como se verá adiante, a maneira como o sintagma é interpretado sintaticamente não irá alterar a estrutura de informação da sentença, permitindo assim o estudo da estrutura enquanto uso pragmático.

A maneira tradicional de interpretar o paradigma ínš é enquanto pronome pessoal e consequentemente a análise sintática tenderá a aproximá-lo da classe dos nomes. $O$ exemplo abaixo ilustra a associação feita entre um nome e o paradigma aqui estudado:

\begin{tabular}{|c|c|c|c|}
\hline Ma-wá-ni & yunkȟán & igmúth̆anka & wan \\
\hline STEM-1sgA-andar & e então & leão da montanha & INDEF \\
\hline wan-Ø-bl-ake & k'éyaš & wan-r & -yanke \\
\hline STEM-(3sgU)-1sgA-ver & mas & CON STEN & U-(3sgA)-ver \\
\hline
\end{tabular}

šni.

NEG

"Caminhava e então vi um leão da montanha, mas ele não me viu." 
Na sentença acima, o termo igmútȟanka introduzido na primeira oração é retomado na segunda contextualmente. Ínš é usado para contrastar os dois atores apresentados, a pessoa que viu o animal e o animal que não viu a pessoa. Interpretando ínš como um pronome, a representação sintática da sentença acima seria:

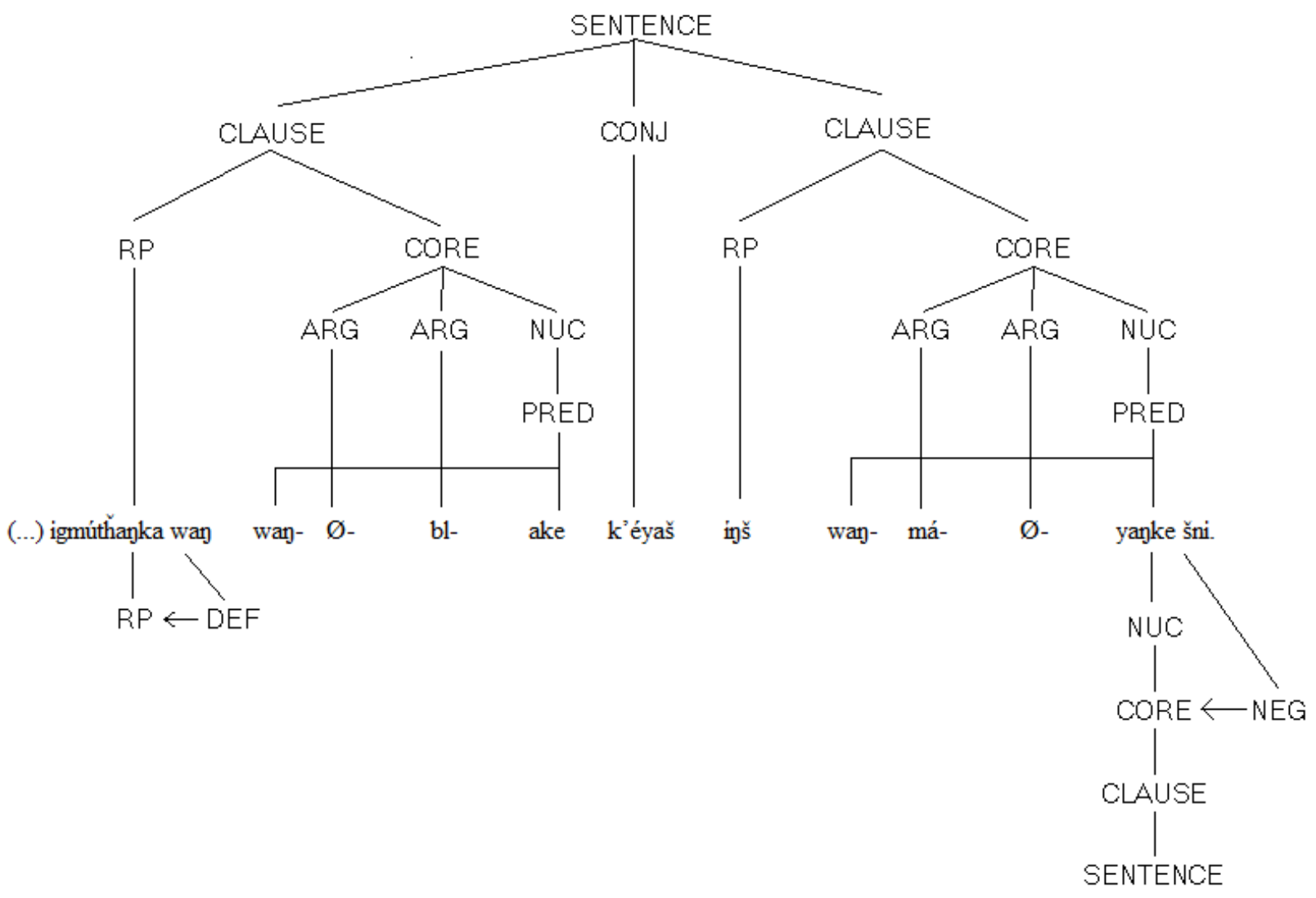

Uma vez que a primeira e segunda pessoas não podem ser substituídas por substantivos, a análise é feita por analogia com a terceira pessoa e a classificação não é alterada:

Thibló wičá-Ø-la šni tkȟá míš iyówin-wa-ye Irmão STEM-(3sgA)-concordar NEG mas CON STEM-1sgA-aceitar. "Meu irmão não concordou, mas eu aceitei." (NLD: 368, mí̌) 


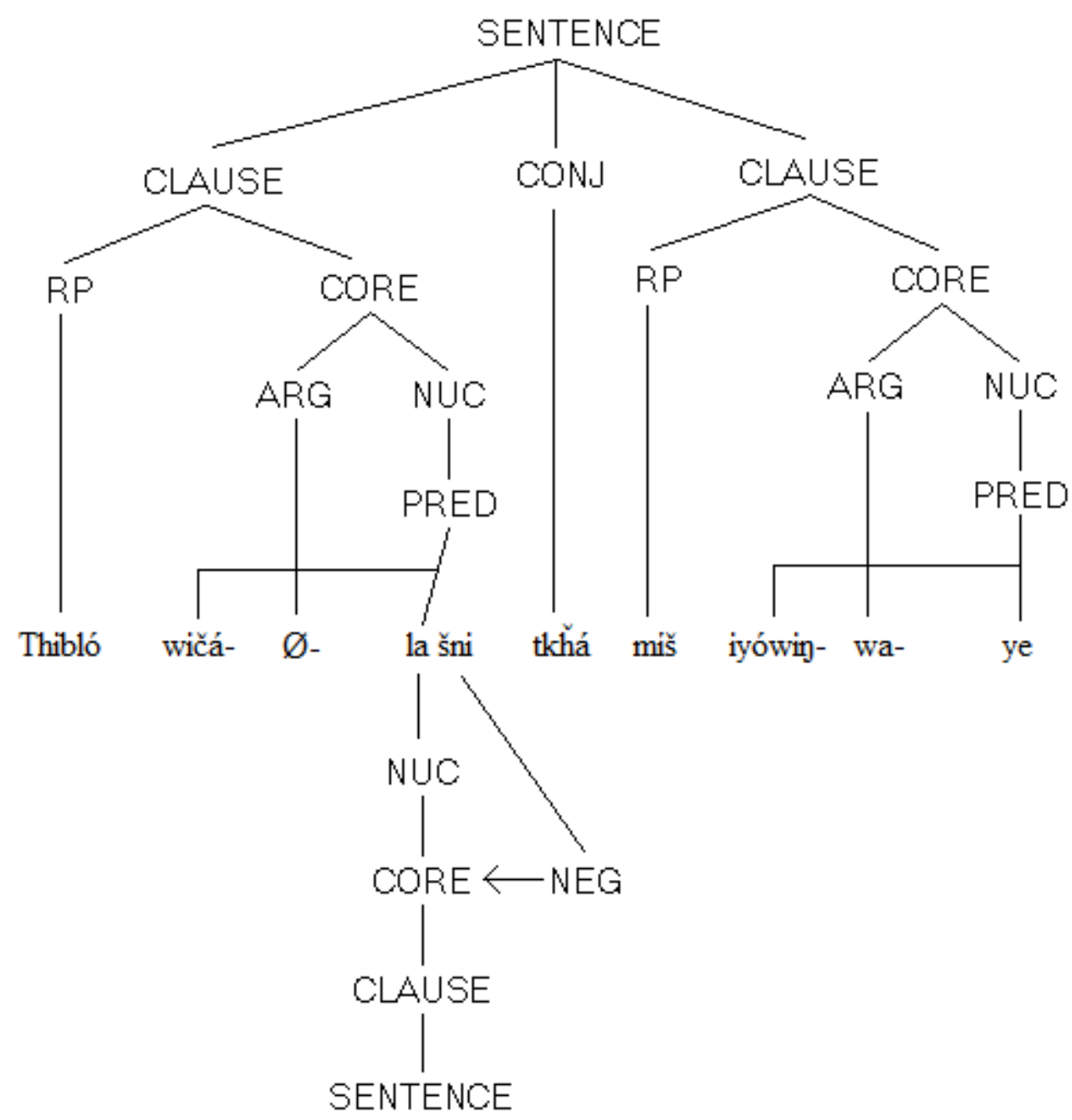

A análise acima apresenta alguns problemas interessantes. O primeiro já foi discutido nos paradigmas anteriores: se o paradigma for interpretado não como um pronomes e sim como um verbo, como será feita a análise sintática? Poderá ela interpretar a variedade de manifestações do paradigma igualmente bem ou melhor? O segundo problema, que é específico deste conjunto, é a coocorrência com outros substantivos. Reescrevo abaixo o exemplo (3.55) apresentado anteriormente: 


$\begin{array}{llllll}\text { Hokšíla } & \text { kin } & \text { ínš “Ho, } & \text { ečha } & \text { unčí, itázipa na } \\ \text { Menino } & \text { DEF } & \text { CON INTERJ } & \text { Neste caso avó arco e }\end{array}$

wanhínkpe kȟó m-ičáğa yo" $\varnothing$-Ø-eyá (...)

flecha também 1sgU-produzir IMP (3sgU)-(3sgA)-dizer

E o menino disse: "então, vó, faça para mim um arco e flechas também." (DT: 99)

Na sentença acima, há a necessidade de interpretar hokšila kin ínš como um único sintagma, pois não há como o sujeito de uma oração aparecer em dois sintagmas diferentes. No entanto, de que forma pode um pronome pessoal coexistir com o nome que ele deveria substituir?

Uma possibilidade é considerar este uso do paradigma como algum outro tipo de marcador. Assim, as duas ocorrências apresentadas em 3.62 e 3.63 passam a possuir uma relação dissociada, ainda que o uso de ambas seja 0 mesmo. De qualquer forma, cria-se um novo problema: como classificar este marcador? Seria uma partícula ou um pronome pessoal adjetivo, uma vez que no segundo caso ocorra normalmente depois de um substantivo?

Outro problema, também presente nos outros paradigmas estudados, é como classificá-lo como pronome pessoal se ínš é capaz de se referir a termos indefinidos e como representá-lo sintaticamente.

No presente estudo, apresentarei duas maneiras distintas de analisar a estrutura sintática do RP: (1) classificando ínš como um operador, ou seja, transferindo o reconhecimento do núcleo do RP para o substantivo; (2) aproximando ínš da estrutura de um verbo e, embora com algumas ressalvas, reconhecendo neste o núcleo do RP. Em ambos os casos, tentarei demonstrar inconsistências.

A primeira possibilidade de análise a ser discutida é a do reconhecimento do substantivo enquanto núcleo do RP. Neste caso, ínš aparece sempre 
orbitando o núcleo e o sintagma não possui argumentos internos. As representações sintáticas de 3.55 e 3.60 abaixo ilustram o modelo:
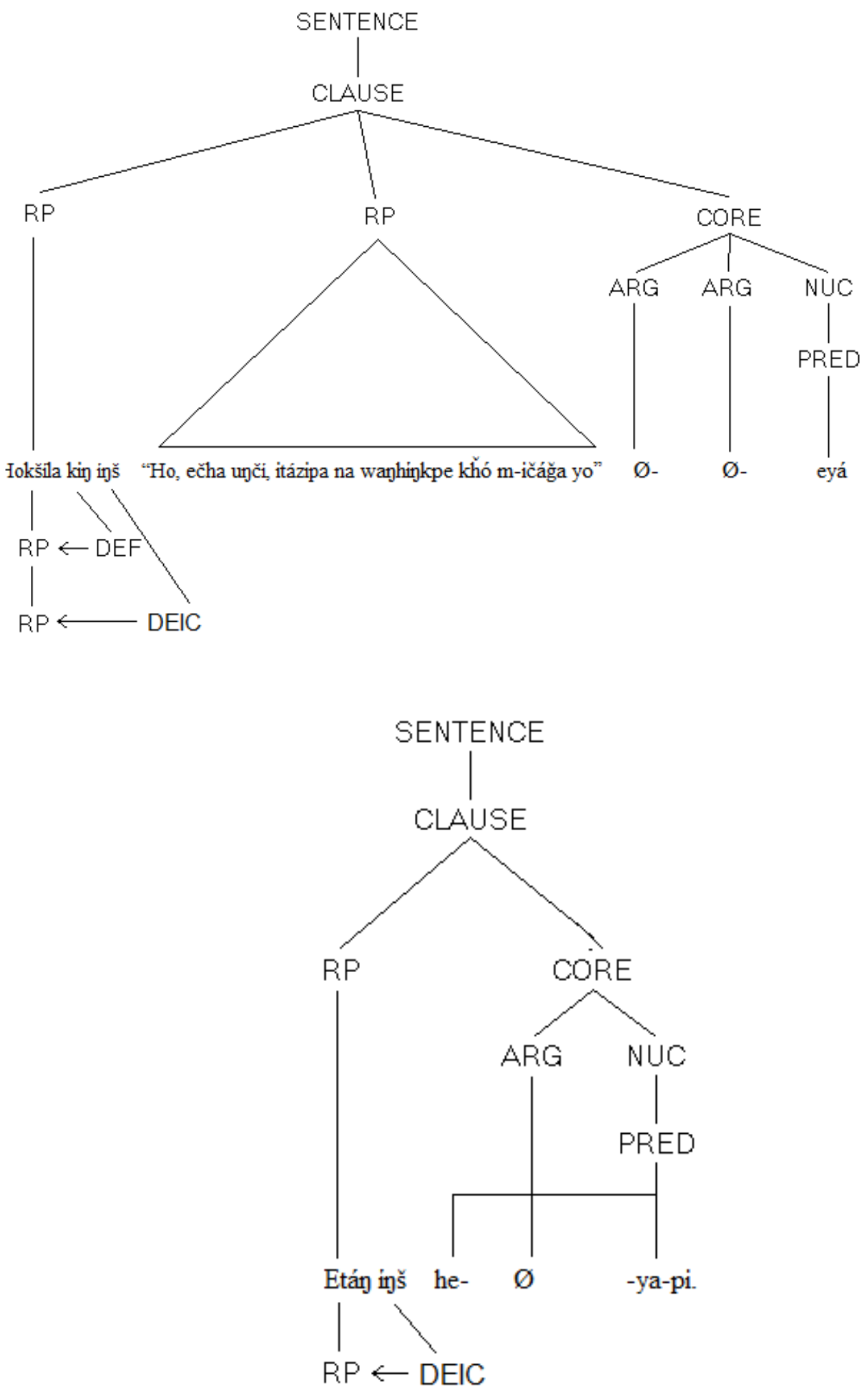
Nos exemplos acima, ínš não desempenha nenhuma função sintática específica, é apenas uma partícula associada a um sintagma e sua ocorrência se baseia na intenção de topicalizar o substantivo hokšíla da sentença (3.55) e do indefinido etán da sentença (3.60).

Caso seja optado por utilizar este modelo, é necessário que ínš seja ainda interpretado como operator, possivelmente como DEF ou DEIC.

Dois problemas surgem a partir deste modelo. O primeiro diz respeito à generalização: caso ínš seja classificado como operator, ele não pode ocupar o núcleo de um sintagma e a sentença (3.61) apresentada anteriormente precisará ter uma outra representação, ainda que o uso de ínš nos dois casos seja o mesmo. Desta forma, na tentativa de identificá-lo como pronome, há uma cisão na classificação de ínš: o pronome pessoal, que pode de fato substituir um nome, e o operator, que aparece sempre acompanhado do nome. O segundo problema é o fato do modelo ignorar a estrutura interna da palavra, apresentada em 3.53, mesmo que tal estrutura seja razoavelmente clara. Para este modelo, a associação de ínš a um termo indefinido talvez possa ser ignorada, já que neste caso ínš estará sempre na posição de operator e poderá ser argumentado que, não sendo um pronome propriamente dito, a terceira pessoa do paradigma poderá desempenhar um uso puramente pragmático.

A segunda possibilidade de análise segue a lógica que tem sido trabalhada nesta dissertação. Dada as semelhanças morfológicas com os paradigmas iyé e iyéšs, apresentadas anteriormente, como a atribuição de morfemas pessoais (argumentos), é possível interpretar ínš não como uma partícula, mas como o núcleo do sintagma, de maneira muito semelhante aos exemplos dados até o momento. As sentenças 3.55 e 3.60 seriam representadas da seguinte maneira: 

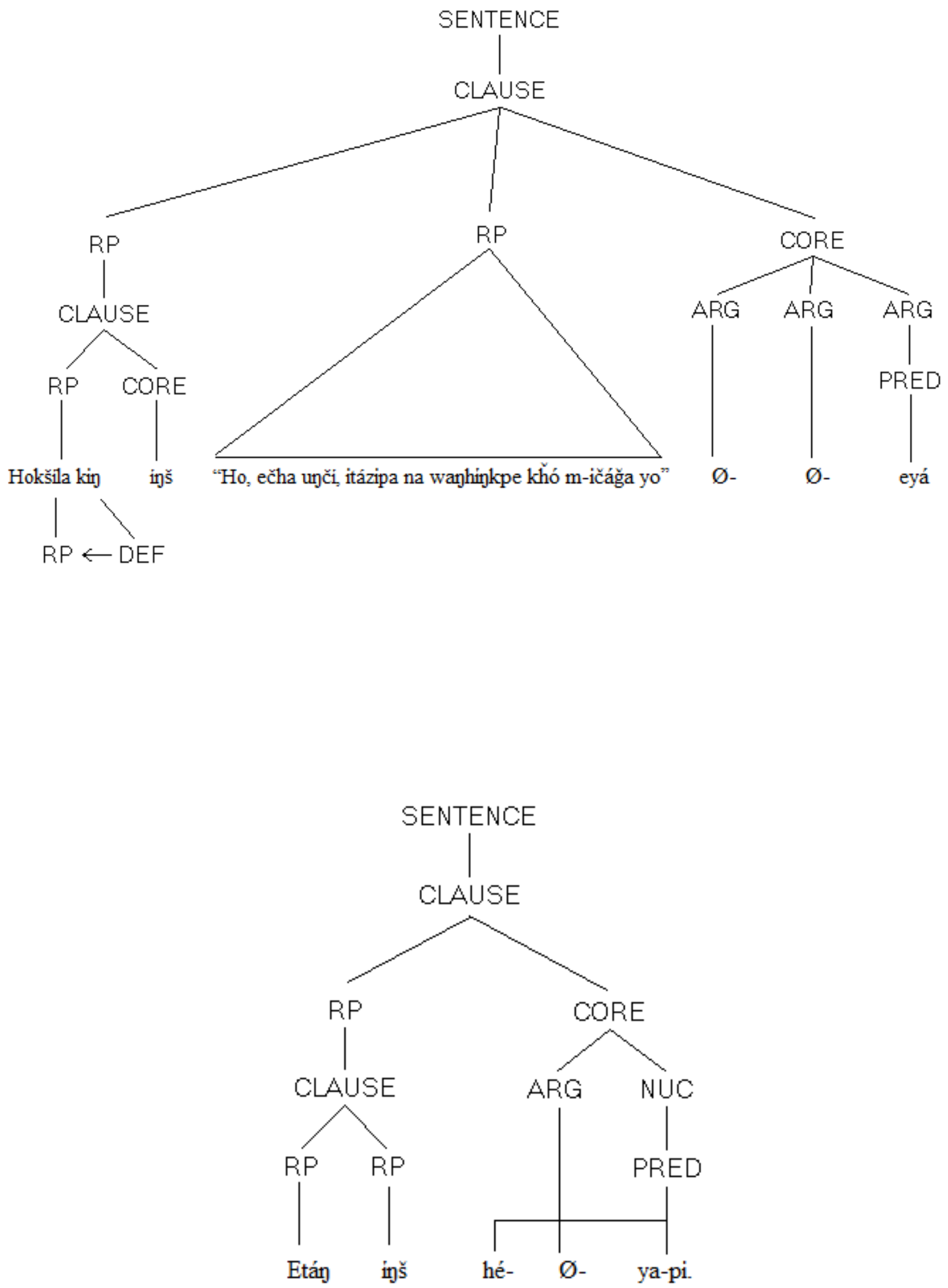
Segundo esta interpretação, em 3.55, o núcleo do sintagma não é mais o substantivo, mas ínš e o substantivo hokšila passa a ser interpretado como argumento referenciado no núcleo. Trata-se então da mesma estrutura sintática empregada pelos outros paradigmas aqui descritos e, assim sendo, carrega a mesma relação com seus argumentos. Isto pode explicar o uso de um termo indefinido com ínš em 3.60, uma vez que o morfema (ou ausência dele) no verbo pode se referir tanto a termos definidos como a termos indefinidos.

A sentença 3.62 ilustra a ocorrência de ínš no $R P$ sem um substantivo que o acompanhe:

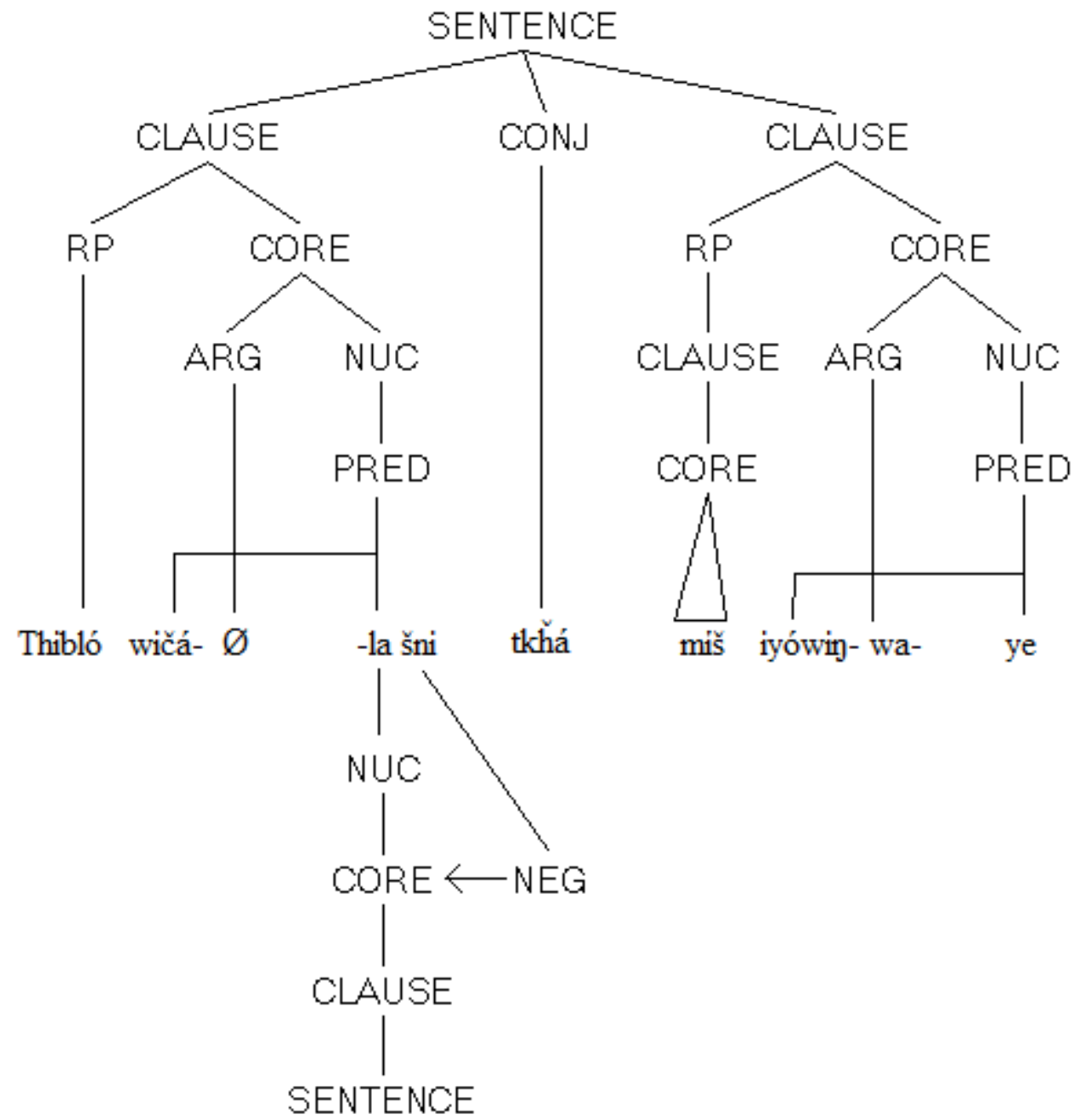

Ao analisar ínš como núcleo do sintagma capaz de possuir argumentos e, portanto, seus próprios RPs, não há nenhum problema em assumir que tais argumentos não sejam descritos quando forem subentendidos pelo contexto, da mesma forma como qualquer outro núcleo verbal desta língua, ou seja, não há 
necessidade de distinguir a estrutura sintática de ínš quando o substantivo não for pronunciado.

Uma particularidade de ínš que é dividida com iyéš é o fato destes dois paradigmas não poderem ser núcleo de uma oração principal. O motivo é justificado pelo próprio uso: a junção de uma marca pessoal com o sufixo š é usada para topicalizar determinado RP. Assim, não faz sentido que ínš ou iyéš desempenhe o núcleo de uma oração da mesma forma que iyé ou tuwé poderiam.

\subsection{4 Ínš-eyá}

Outro uso comum de ínš é com a partícula eyá. Neste caso, cria-se o sentido de "também" e varia de acordo com a pessoa. Usado em outros contextos, eyá não possui este significado ${ }^{30}$, então deve ser interpretado sempre em conjunto com ínš. O paradigma para todas as pessoas é:

$\begin{array}{lll}\text { Ø-Ín-š-eyá } & \text { (3sgU)-STEM-CON-também } & \text { ele/eles também } \\ \text { N-í-š-eyá } & \text { 2sgU-STEM-CON-também } & \text { você/vocês também } \\ \text { Unk-í-š-eyá } & \text { 1dU-STEM-CON-também } & \text { nós dois/nós também } \\ \text { M-í-š-eyá } & \text { 1sgU-STEM-CON-também } & \text { eu também }\end{array}$

Da mesma forma como nos casos apresentados no tópico anterior, pode ser usado em $R P$ junto com outro substantivo ou com um demonstrativo.

\footnotetext{
${ }^{30}$ Apesar disso, optei por traduzi-lo como "também" na glossa. Esta tradução deve ser usada apenas no contexto acima descrito.
} 
(Iktó) pahá wan kákhel Ø-Ø-yá-hin kta hánl ĺya inš-eyá (Iktó) colina IND lá (3sgU)-(3sgA)-ir-DUR FUT CONJ Íya CON-também

unmá ečhíyatanhan Ø-hiyáya (...)

outro vir de (procedência) (3sgA)-passar

"Quando (Iktó) caminhava lá por uma colina, lya também passava vindo de uma outra direção". (DT: 1)

Míš-eyá wa-wáčhi kte.

1sgCON-também 1sgA-dançar FUT

Eu também vou dançar. (DT: 43)

Em 3.65, ínš-eyá refere-se a ĺya, formando juntos o $R P$ do núcleo verbal hiyáyá "passar". Em 3.66, constitui sozinho o RP do verbo wačhí "dançar". Como pode-se notar na representação abaixo, ínš-eyá pode ser representado da mesma maneira que ínš: 


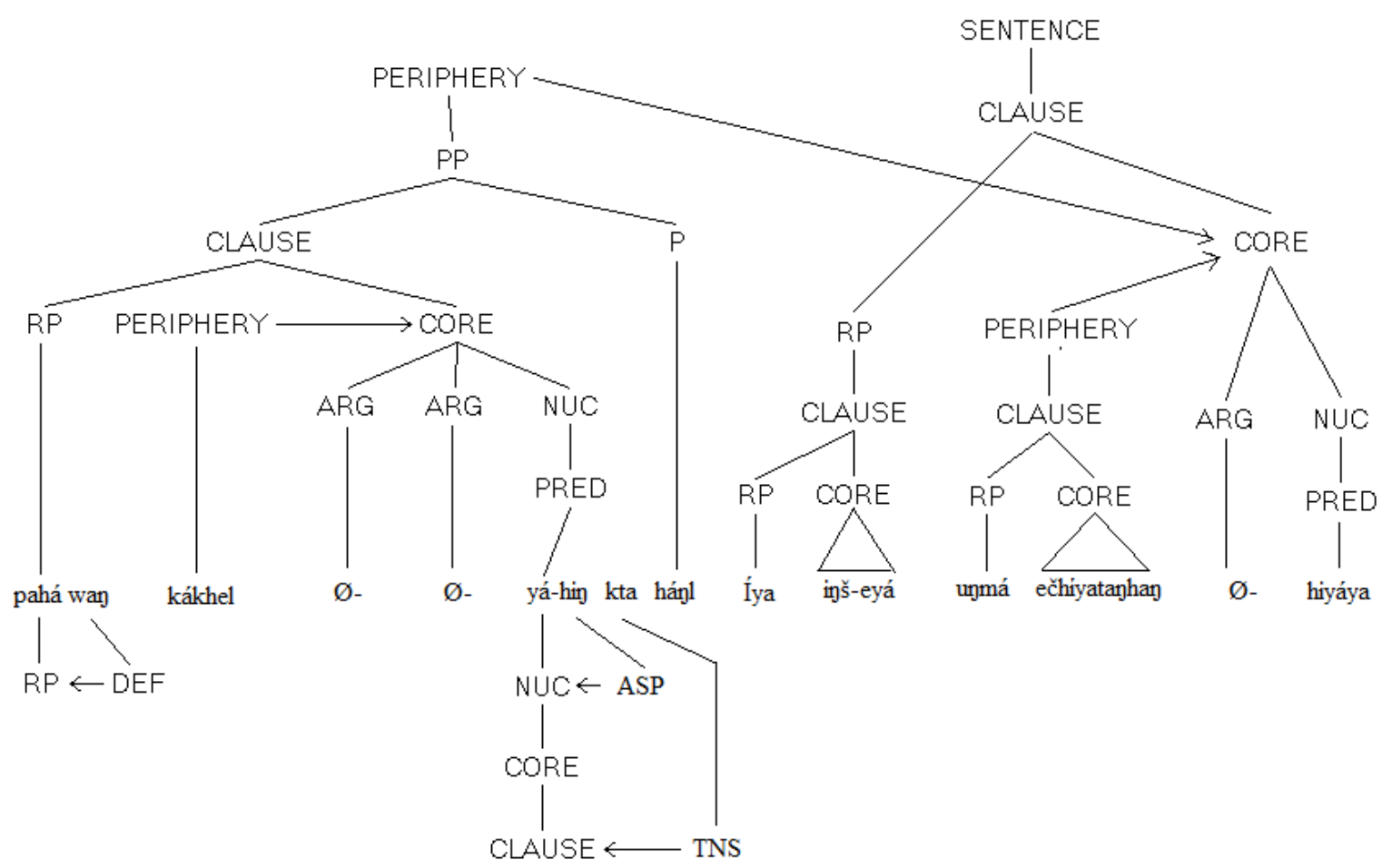

\section{8 Ínš iyé}

O terceiro e último grupo de marcadores de pessoa a ser trabalhado aqui é na verdade uma combinação dos dois primeiros. A junção de ínš com iyé, ambos devidamente flexionados, reforça inda mais o foco na entidade que realiza a ação, excluindo a possibilidade de outra pessoa participar do ato. Pode ser traduzido como "ele mesmo". O paradigma abaixo enumera as possibilidades de flexão:
$\varnothing$-ín-š Ø-iyé
(3sgU)-STEM-CON (3sgU)-ser
ele mesmo
n-í-š n-iyé
2sgU-STEM-CON 2sgU-ser
você mesmo
unk-í-š unk-íye
1dU-STEM-CON 1dU-ser
nós mesmos
m-í-š m-iyé
1sgU-STEM-CON 1sgU-ser
eu mesmo 
Uma vez que ínš não recebe o sufixo pi, o plural do paradigma acima pode ser compreendido através do plural no verbo principal. Observe abaixo um exemplo na primeira pessoa:

m-í-š m-iyé héčhelwówičala Ø-bl-uhá šni 1sgU-ser-CON 1sgU-ser assim fé 3sgU-1sgA-ter NEG

“Eu mesmo não tenho uma fé assim." (NLD: míš miyé, 369)

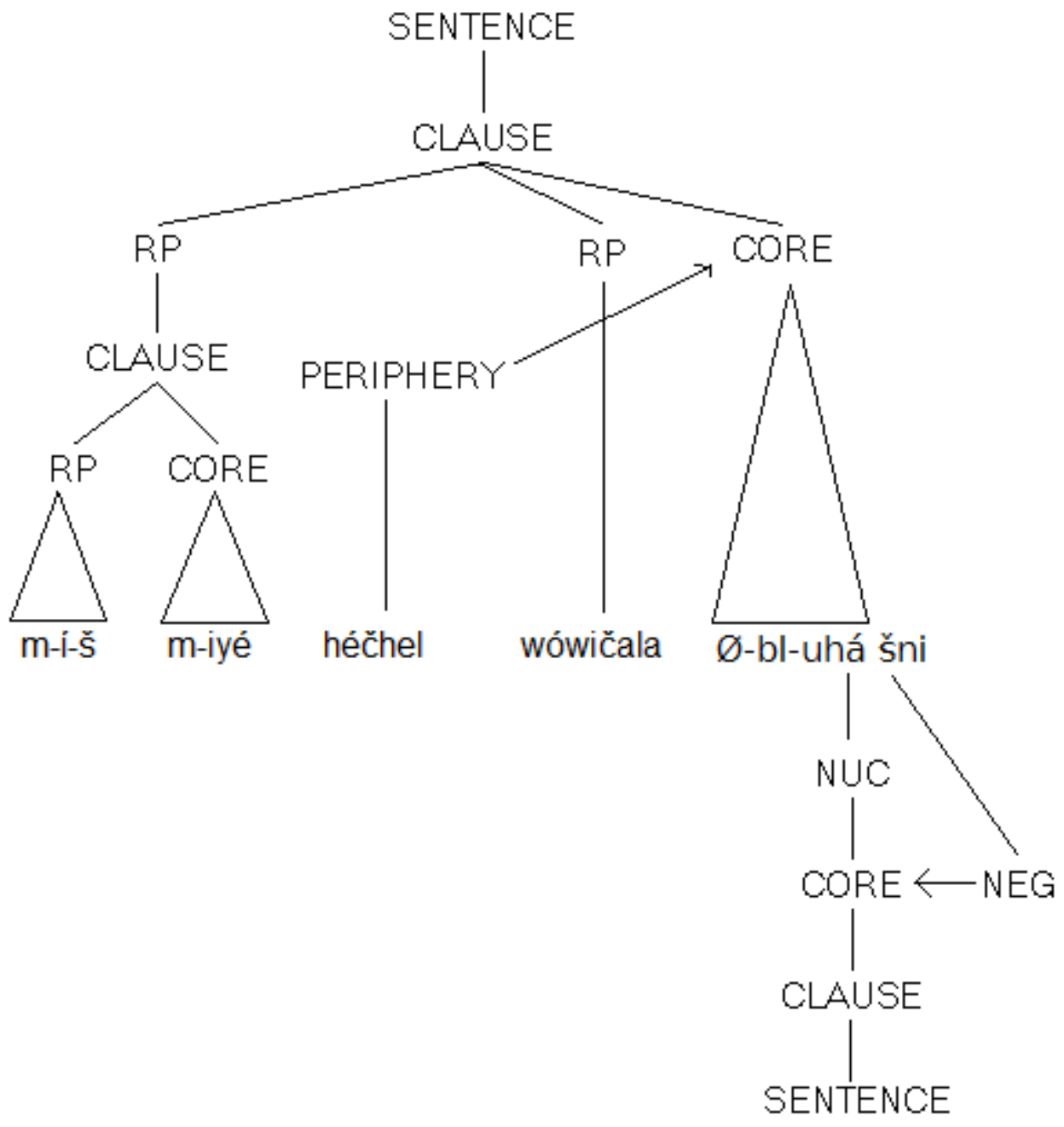

Em 3.68, míš miyé é o RP que corresponde ao agente no verbo yuhá. Dentro do $R P$, temos miyé como núcleo e míš como $R P$ deste núcleo. Quanto ao uso da estrutura, temos o foco da oração em inš iyé, criando um contraste 
com alguma entidade não citada diretamente na sentença e excluindo a primeira pessoa da proposição "ter determinada fé."

M-í-š m-iyé kin ma-khíli yeló.

1sgU-ser-CON 1sgU-ser DEF 1sgU-esperto ENCL

"Eu sim sou muito inteligente." (DT:40)

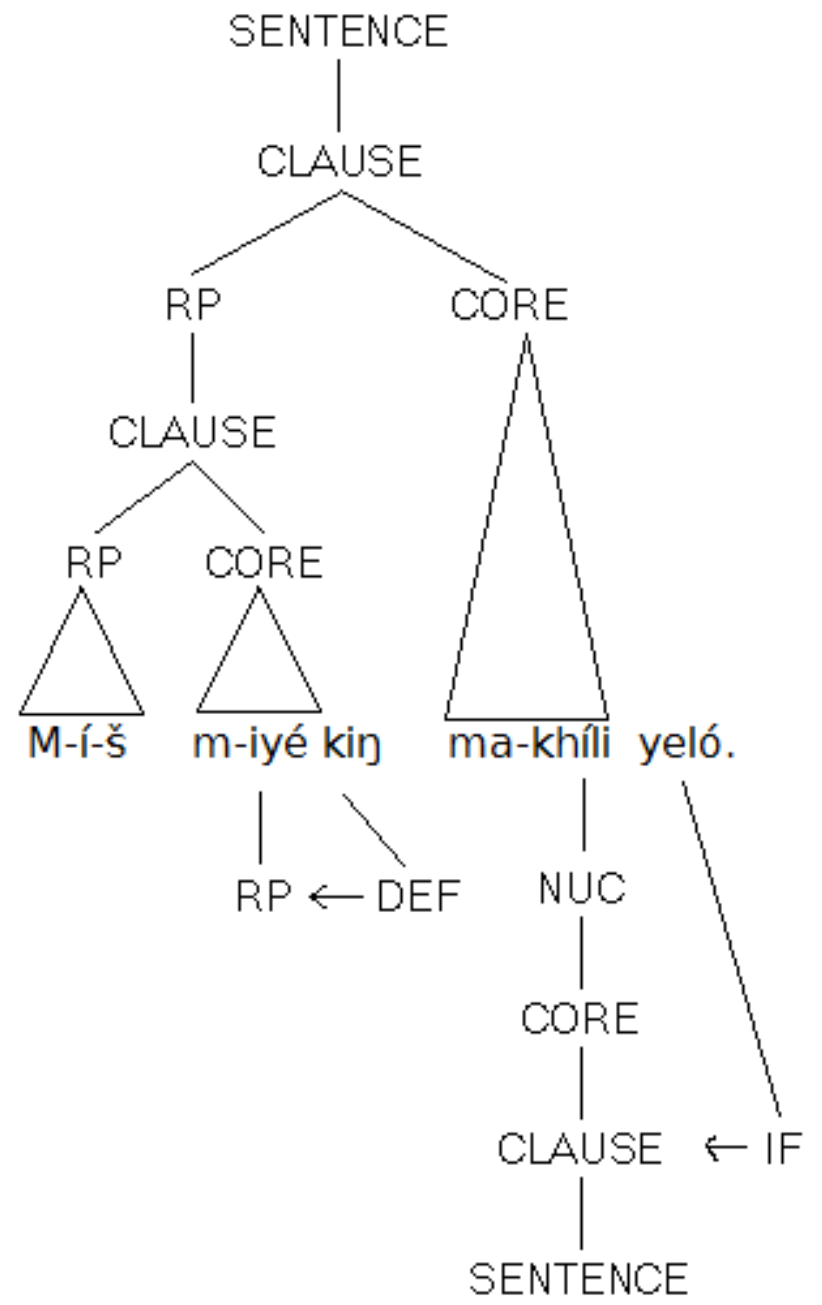

Há pouca alteração na sentença acima no que diz respeito à estrutura de ínš iyé. O que pode ser notado ainda é a possibilidade de utilizá-lo com o artigo definido kin, embora não seja necessário, e o uso de mís miyé com um verbo estativo. No contexto em que a sentença acima apareceu, a personagem iktómi 
vangloriava-se de sua própria esperteza perante a inocência de duas mulheres. Observe que a sentença precisa ser entendida como "eu mesmo sou assim", excluindo outras entidades da qualidade descrita. Não se deve confundir com o sentido "até mesmo eu sou assim", que em lakota seria miyé káyeš.

Para transmitir este uso através de um substantivo, não se usa ínš, mas iyé em conjunto com o termo iyúnkȟala (pessoalmente):

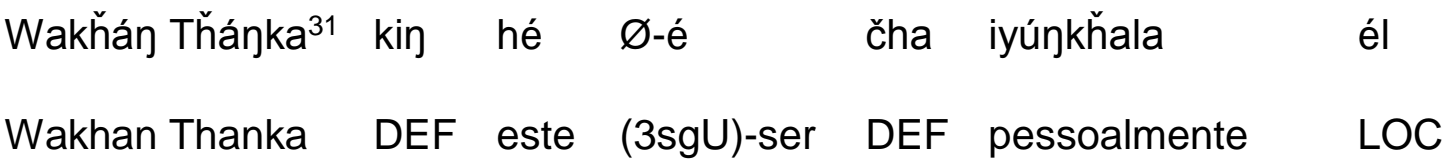

Ø-Ø-hí.

(3sgU)-(3sgA)-vir.

"Wakhan Thanka veio pessoalmente até ele." (DT:213)

\footnotetext{
${ }^{31}$ Literalmente "Grande Sagrado" ou "Grande Poder", constitui na religião o conceito que talvez mais se aproxime de um deus exclusivo. No entanto, de acordo com alguns mitos, não há possibilidade de quantificá-lo e nem mesmo as divindades mais poderosas possuem total compreensão de sua manifestação. Um de seus nomes religiosos é Tobtópa, que significa literalmente "quatro vezes quatro", demonstrando sua infinitude (quatro e seus múltiplos são números sagrados para a religião lakota).
} 


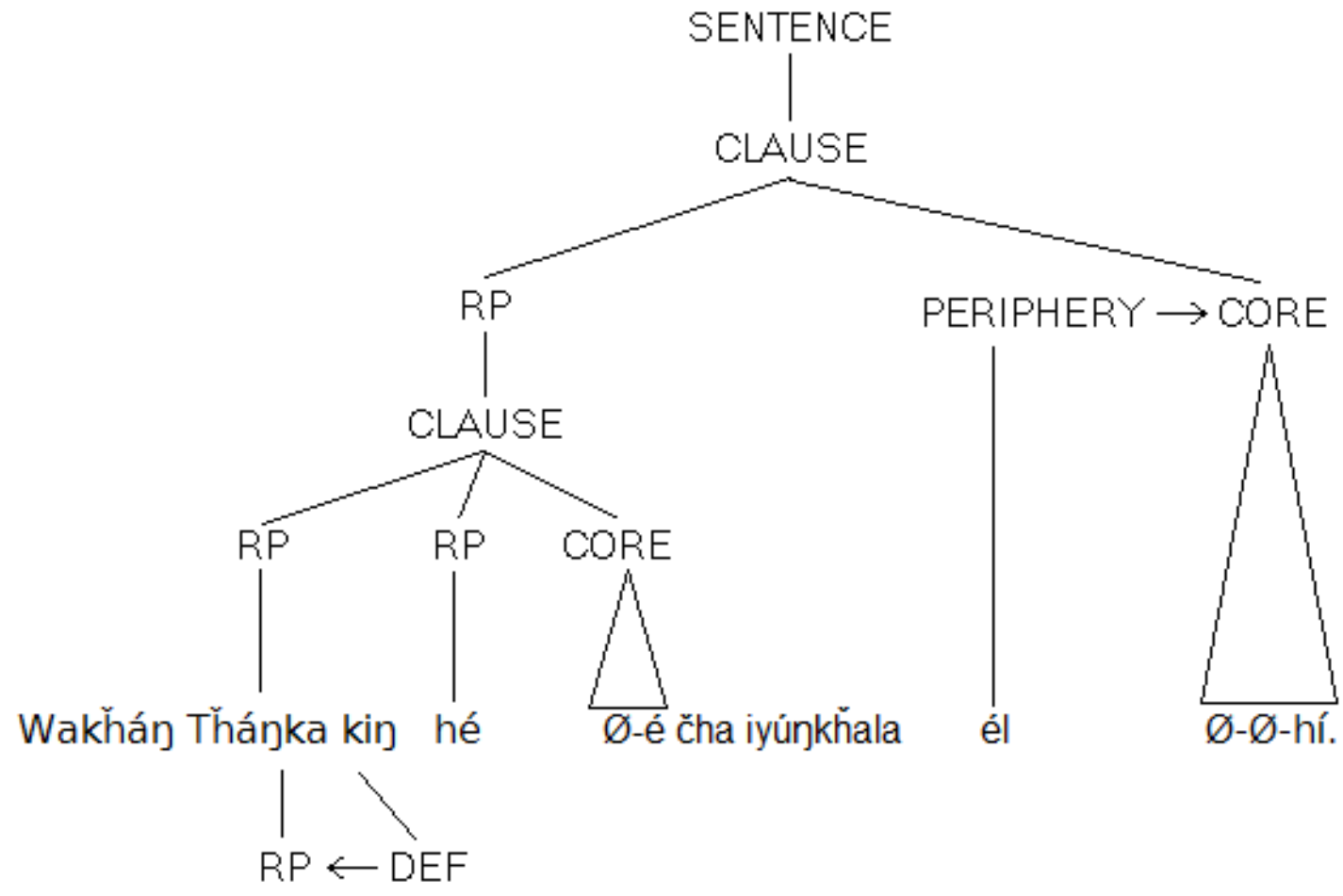

Como pode ser visto em 3.70, iyúnkȟala não desempenha uma função sintática específica, como um RP. Embora este termo conste no dicionário como advérbio, talvez não seja a forma mais adequada de classifica-lo, já que sempre segue um $R P$ definido e não parece se relacionar diretamente com o núcleo do predicado. Talvez iyúnkh̆ala seja melhor descrito como um operator.

lyúnkh̆ala pode ser usado ainda como alternativa para ínš iyé com ou sem a presença de um substantivo:

Wičháȟčala kin Ø-iyé iyúnkȟala $\quad$ Ø-hí.
Velho
DEF (3sgU)-ser pessoalmente
(3sgA)-vir

"O velho veio pessoalmente." (NLD: iyúnkȟala, 266) 


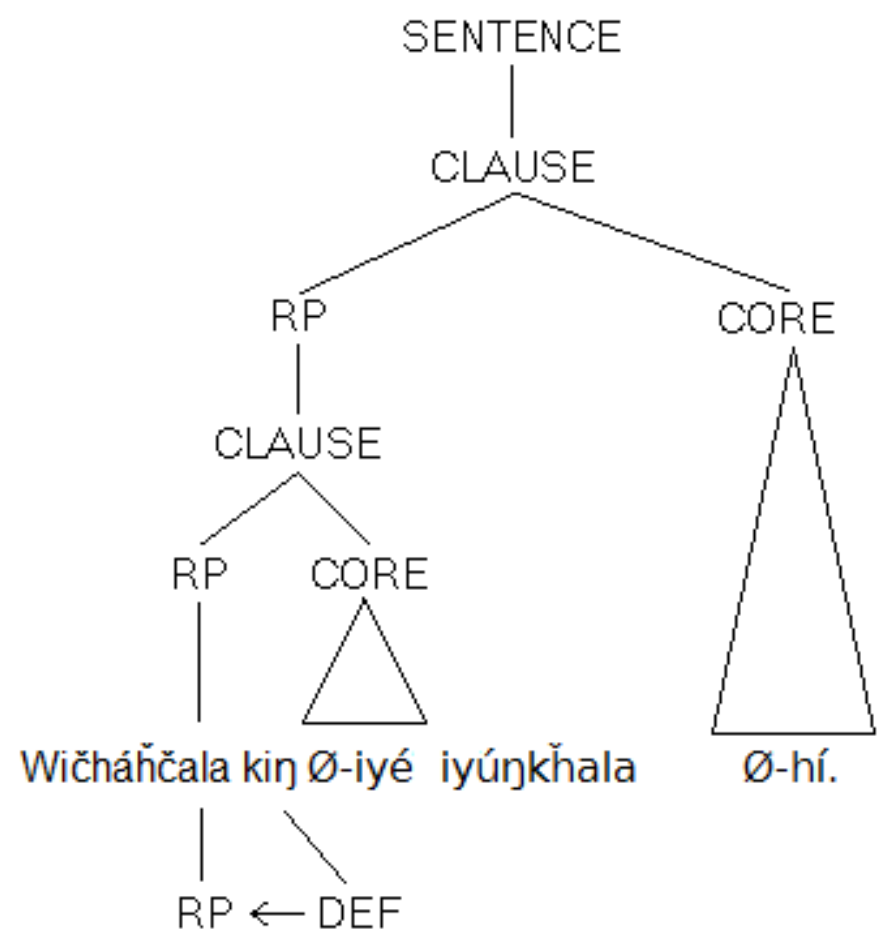

(3.72)

Ø-lyé iyúnkȟala ektá $\varnothing$-Ø-í

(3sgU)-ser pessoalmente LOC (3sgU)-(3sgA)-ir.

“Ela foi pessoalmente até ele." (NLD: iyúnkȟala, 266)

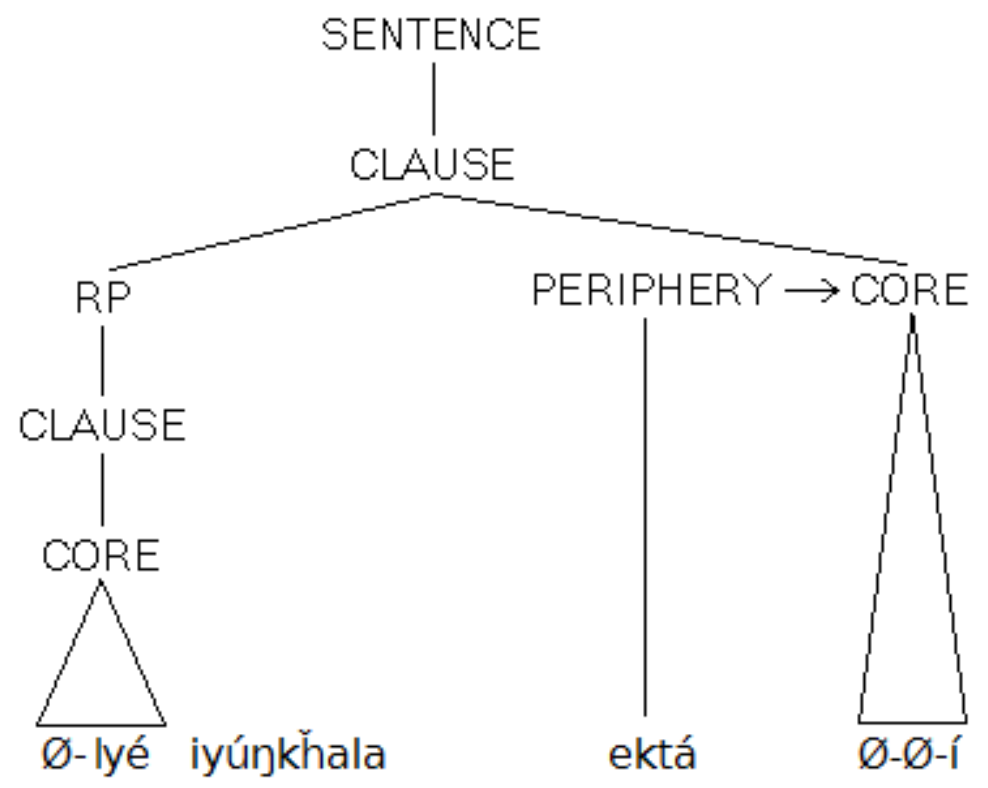


Enquanto em 3.71 nós temos um exemplo de iyé com uma estrutura muito mais simples que aquela apresentada em 3.70, na sentença 3.72 temos iyé iyúnkh̆ala sendo empregado da mesma maneira como ínš iyé. Note que em qualquer um dos casos, iyé não pode ser omitido. 


\section{Capítulo $4 \quad$ Pronomes independentes nas narrativas orais}

\subsection{Introdução}

No capítulo 3 foram apresentadas as diferentes formas do que a literatura vem chamando de "pronome independente." Procurou-se apontar características que os aproximassem da classe dos verbos através de sua estrutura interna e das ocorrências.

O objetivo deste capítulo é, a partir das estruturas de informação apresentadas pela RRG, investigar um outro aspecto dos dois paradigmas apresentados, iyé e ínš: seu uso enquanto estrutura de foco dentro das narrativas que serviram de base ao corpus. Esperamos assim descrever a relação pragmática entre a estrutura verbal, seus argumentos e os demais sintagmas de referência, levando em consideração a construção da oração dentro do texto.

\subsection{Estruturas de Foco}

A Gramática de Papel e Referência (VAN VALIN, 1997) possui sua própria representação da estrutura de foco dentro da sentença. Baseada em Lambrecht (1994), busca estabelecer uma relação entre a morfossintaxe e aspectos discursivo-pragmáticos. Três tipos de foco são considerados: (1) Predicate Focus, estrutura que apresenta a relação tópico-comentário; (2) Sentence Focus, que tem como foco a sentença inteira e (3) Narrow Focus, que direciona o foco para um constituinte específico. As sentenças a seguir exemplificam cada uma das possibilidades listadas. $O$ ângulo que pende para baixo das sentenças na representação sintáticas representa o Potential Focus Domain, isto é, o espaço na oração em que o foco poderia ocorrer. O triângulo interno representa o Actual Focus Domain, o foco que de fato se manifestou em determinada sentença. 
$(4.1)$

Hokšila kin hé Ø-táku tókh̆- $\varnothing$-un he?

Menino DEF esse (3sgU)-o queSTEM-(3sgA)-fazer INT

"O que esse menino fez?"

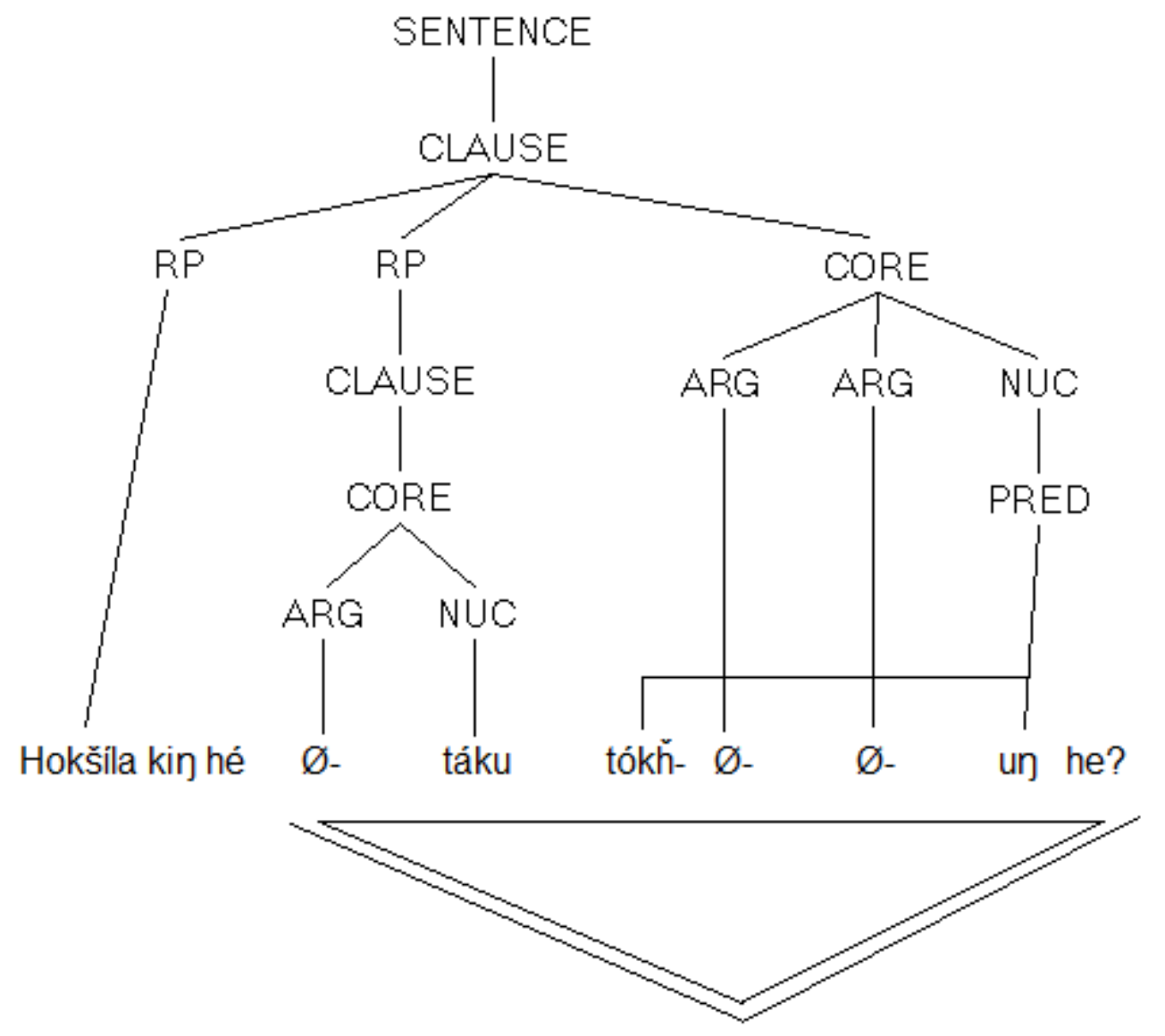

A sentença 4.1 apresenta a estrutura conhecida como Predicate Focus. Nela temos hokšila kin hé como tópico e o restante da oração como a informação

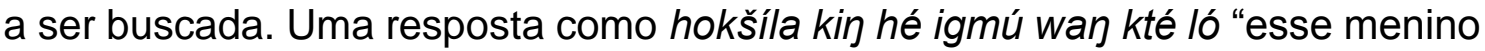
matou um gato" seria válida para esta pergunta, mas como a tendência da língua é não citar as informações subentendidas, é mais provável que se diga igmú waク kté ló "matou um gato", omitindo o tópico. É importante notar também que o lakota não possui nenhum morfema obrigatório para marcar tópico como a partícula wa do japonês ou ma do Mbyá. Assim, a interpretação da oração enquanto tópico-comentário depende do contexto em que está inserida. 
(4.2)

Kȟoškálaka yámni čhiyé-Ø-kičhi-ya-pi

čha kál Ø-thí-pi škhé.

Jovem três irmão-(3A)-REC-ter-PL ART lá (3A)-morar-PL

EVID

"Três jovens irmãos moravam lá32." (DT: 64)

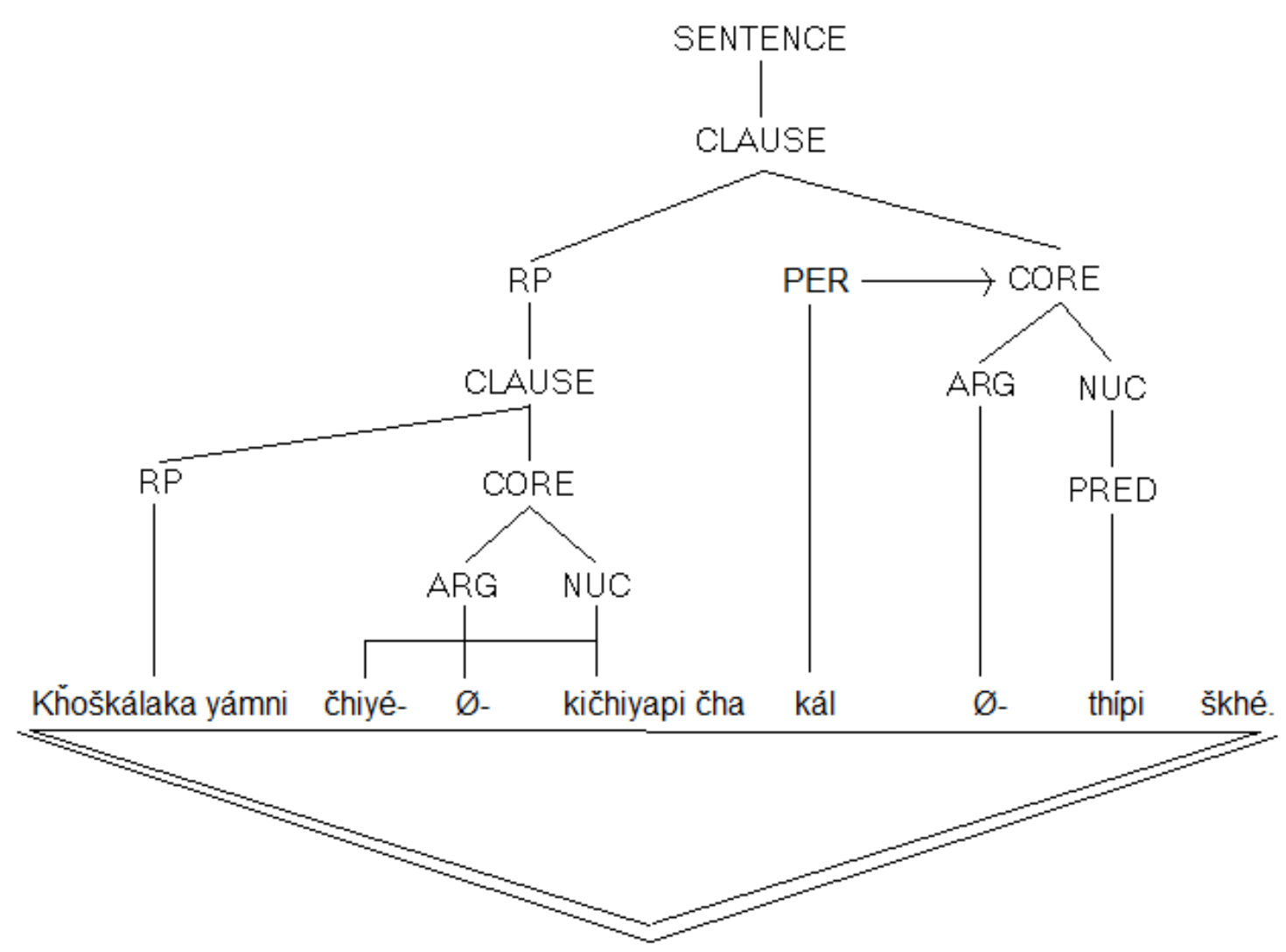

A sentença 4.2 aponta um caso de Sentence Focus. Sendo a primeira oração da narrativa "Duas Faces e os quatro irmãos", introduz três das personagens principais e contextualiza ainda o local onde a história se passa. Assim, não há nenhum pressuposição ou tópico nela, mas todas as palavras são informações novas para o ouvinte.

${ }^{32}$ Kál “lá” neste exemplo não representa um lugar específico, mas qualquer lugar distante. 
Ø-Táku

čha wan-l-áka he?

(3sgU)O que ART STEM-2sgA-ver INT

"O que foi que você viu?" (NLD: 75, čha)

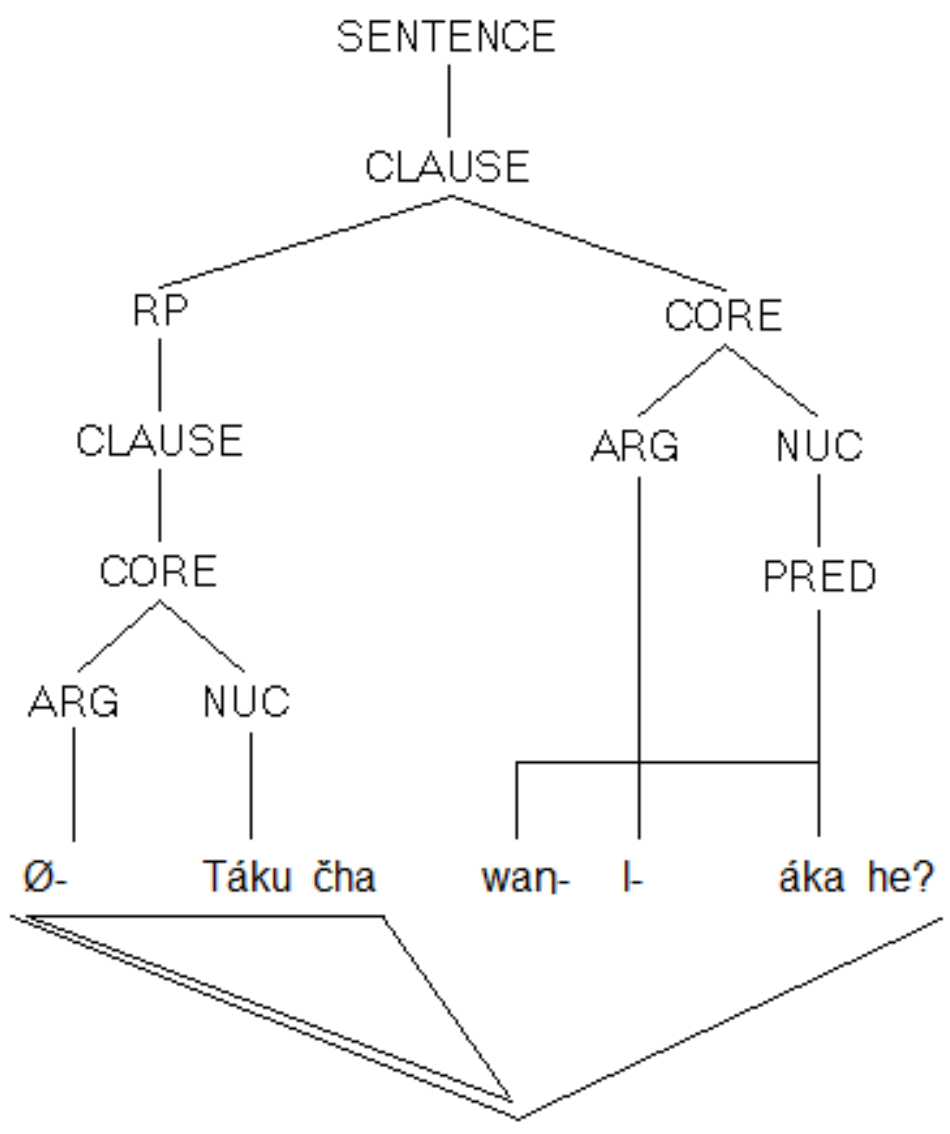

Em 4.3 temos um caso de Narrow focus. Nela o constituinte táku čha "o que é que" é a informação a ser buscada enquanto o núcleo verbal e um de seus argumentos wałláka "você vê" já são conhecidos. Uma das funções do artigo čha é justamente trazer o foco para um constituinte, como foi demonstrado com o uso pronominal de iyé e dos interrogativos (tópicos 3.3.1 e 3.4).

\subsection{Marcas de pessoa e estrutura de foco}

No capítulo dois deste trabalho foi introduzido brevemente os morfemas que se ligam as raízes para indicar pessoa. Estes morfemas podem ser divididos em dois grupos: os que indicam undergoer $(U)$ e os que indicam agent $(A)$. Como 
pode ser confirmados em sentenças como 4.4, 4.5 e 4.6, qualquer um dos dois conjuntos de morfema podem ser usados com iyé ou ínš, embora não sejam comuns no caso para se referir ao objeto de verbos transitivos.

As sentenças abaixo nos darão mais informações sobre a relação entre os morfemas pessoais e as estruturas de foco:

The-čhí-ȟila

STEM-2sgU+1sgA-amar

"Eu te amo" (NLD: theȟila, 523) kštó.

ENCL

Makȟá bl-ublú na hé Ø-ín-š

Terra 1sgA-arar e este (3sgU)-STEM-COM (3sgA)-plantar.

"Eu arei a terra e esta (pessoa) plantou." (NLD: ínš, 225)

Ø-lyé-pi čha héčh-Ø-un-pi.

(3sgU)-ser-PL DEF STEM-(3sgU)-fazer-PL.

"Eles que fizeram isso."

A sentença 4.4, composta de apenas um verbo que carrega em si o núcleo do predicado e todos os seus argumentos, é um exemplo de sentence focus. Como já foi exposto, este tipo de sentença não exige nenhuma pressuposição dentro do discurso e ela inteira é considerada uma asserção, sem que o foco caia em nenhum segmento específico. Dessa forma, os argumentos do verbo (indicados pelos morfemas pessoais) são interpretados juntos com o núcleo, no 
que se refere à estrutura de foco. A representação sintática com a estrutura de foco desta sentença é a seguinte:

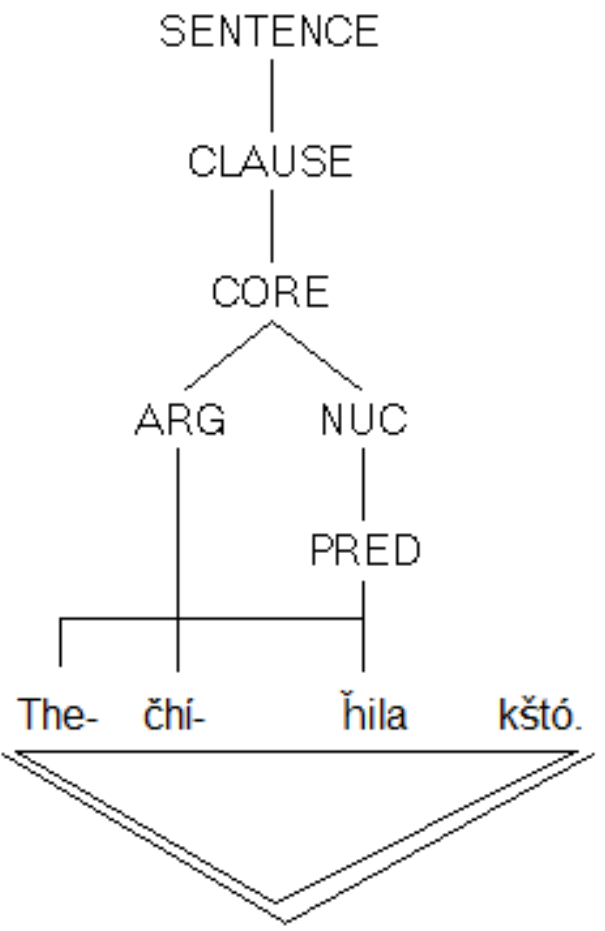

Em 4.5, temos um caso de predicate focus. o RP hé ínš é o tópico e o restante da oração é a informação nova sobre este tópico. Apesar da referência do $R P$ no verbo (indicado por $\varnothing$ ), os morfemas pessoais ligados a este possuem o mesmo foco que o resto do predicado. A árvore abaixo ilustra este caso:

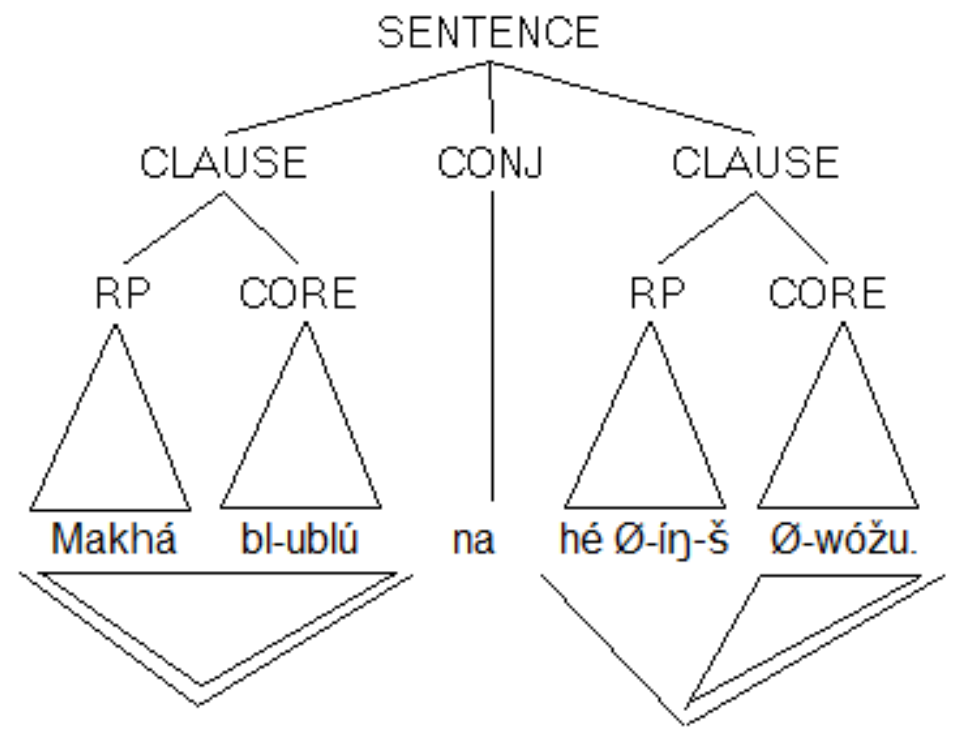


Por último, podemos ver em 4.6 um caso de narrow focus usando iyé. Nesta sentença, assim como em 4.5, um dos argumentos do verbo principal possui um $R P$ que o descreve, mas desta vez o próprio $R P$ carrega o foco da sentença.

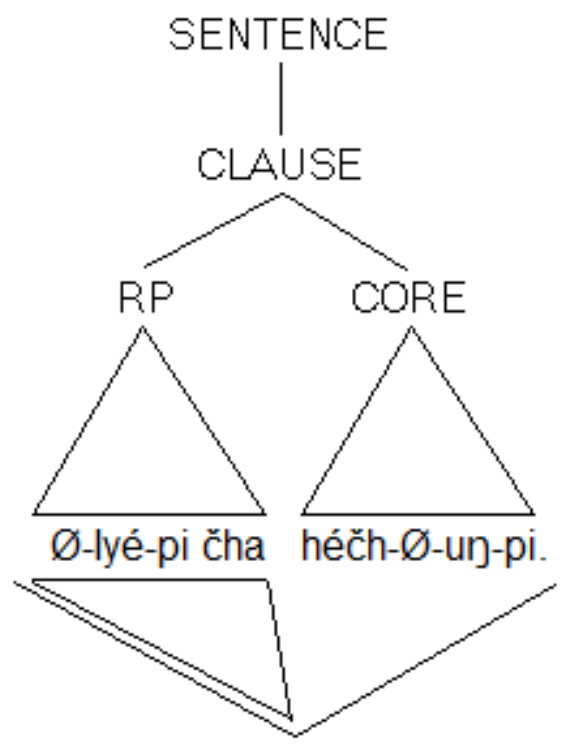

Ao comparar estas três estruturas de foco com as sentenças contendo marcas de pessoa em RP apresentadas, nota-se que as sentenças com iyé tendem a indicar Narrow Focus. Por sua vez, os RP que possuem o paradigma de ínš tendem a indicar Predicate Focus, embora não seja a única maneira: em 4.1 houve a mesma estrutura sem o uso da marca de pessoa no RP.

Pode-se constatar ainda que os morfemas acoplados aos verbos não são capazes de indicar sozinhos o foco da sentença. Enquanto no predicate focus e no sentence focus eles serão interpretados em conjunto com o núcleo verbal, no narrow focus será necessário empregar um RP para desempenhar a função, sendo uma das possibilidades o uso de iyé e suas flexões.

\subsection{Padrões derivados do narrow focus}

A partir do reconhecimento de estruturas de foco e das marcas de pessoa é possível identificar alguns padrões. Neste tópico veremos duas construções que podem ser usadas com o verbo iyé. A primeira delas, muito recorrente nos 
textos narrativos, é a associação de uma oração de identificação com a partícula čha, formando a expressão hé é čha. O trecho dado no exemplo 4.7 nos servirá para demonstrar seu uso mais comum.

Héčhel héčh- $\varnothing$-un-he ȟčehánl šúnkala wan kȟunšítku kin Assim STEM-(3sgU)-fazer enquanto cachorro IND sua avó DEF

Ø-Ø-yuhá yunkȟán hé Ø-é čha thimáhel (3sgU)-(3sgA)-ter então Esse (3sgU)-ser ART dentro da tenda

Ø-hiyú kéye.

(3sgA)-entrarEVID

"Enquanto ele estava fazendo assim, entrou na tendo um cachorrinho que sua avó possuía." (DT: 97)

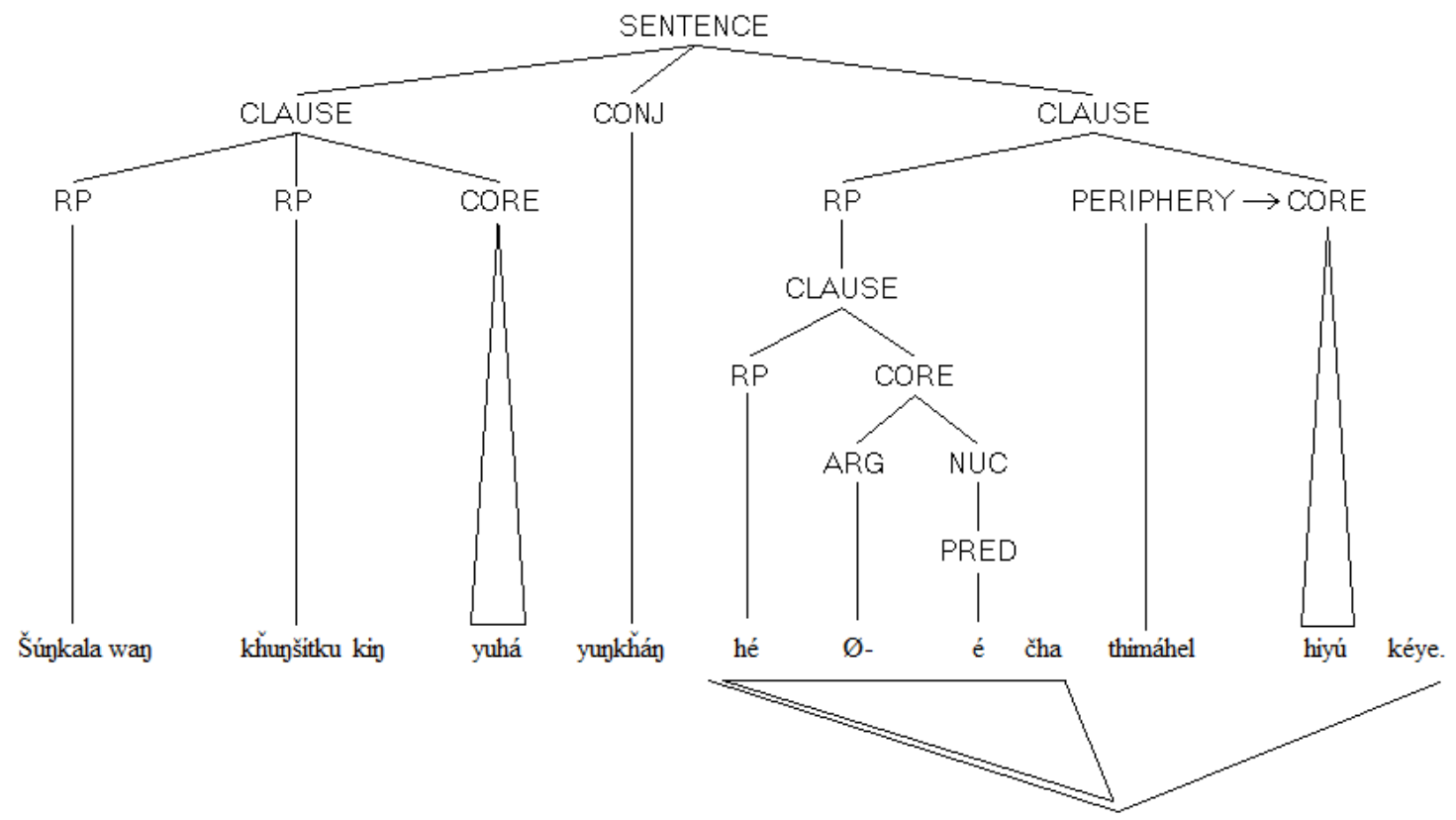

A oração šúnkala wan kȟunšitku kin yuhá, que literalmente significa "sua avó possuía um cachorrinho" seguida pela conjunção yunkȟán introduz no meio da narrativa uma nova personagem, o cachorro, que logo em seguida se torna agente e foco do verbo hiyú "entrar". O foco é marcado pela construção hé é čha, 
que dentro deste contexto pode ser entendida como "é esse (cachorro em particular) que..." e desempenha a função de RP do núcleo verbal hiyú.

Embora seja mais comum seu uso com yunkȟán, esta construção pode ser usada junto com o artigo definido k'un. Neste caso, não há introdução de uma nova personagem na narrativa, mas remete o ouvinte a algo já citado em algum momento do texto antes de colocá-lo na posição de foco. O restante da oração não sofre alteração e hé é čha continua sendo $R P$ de algum núcleo verbal.

Ektá é-Ø-tunwan yunkȟán Anúng Ité k’un hé $\varnothing$-é

LOC STEM-(3sgA)-olhar então

Duas Faces DEF Esse (3sgU)-ser

čha napé apáhaha étkiya $\varnothing$-ín-Ø-yanka kéye.

ART mão levantado DIR (3sgA)-STEM-(3sgA)-correr EVID

"Ao olhar para lá era Duas Faces que vinha correndo com as mãos levantadas." (DT: 48)

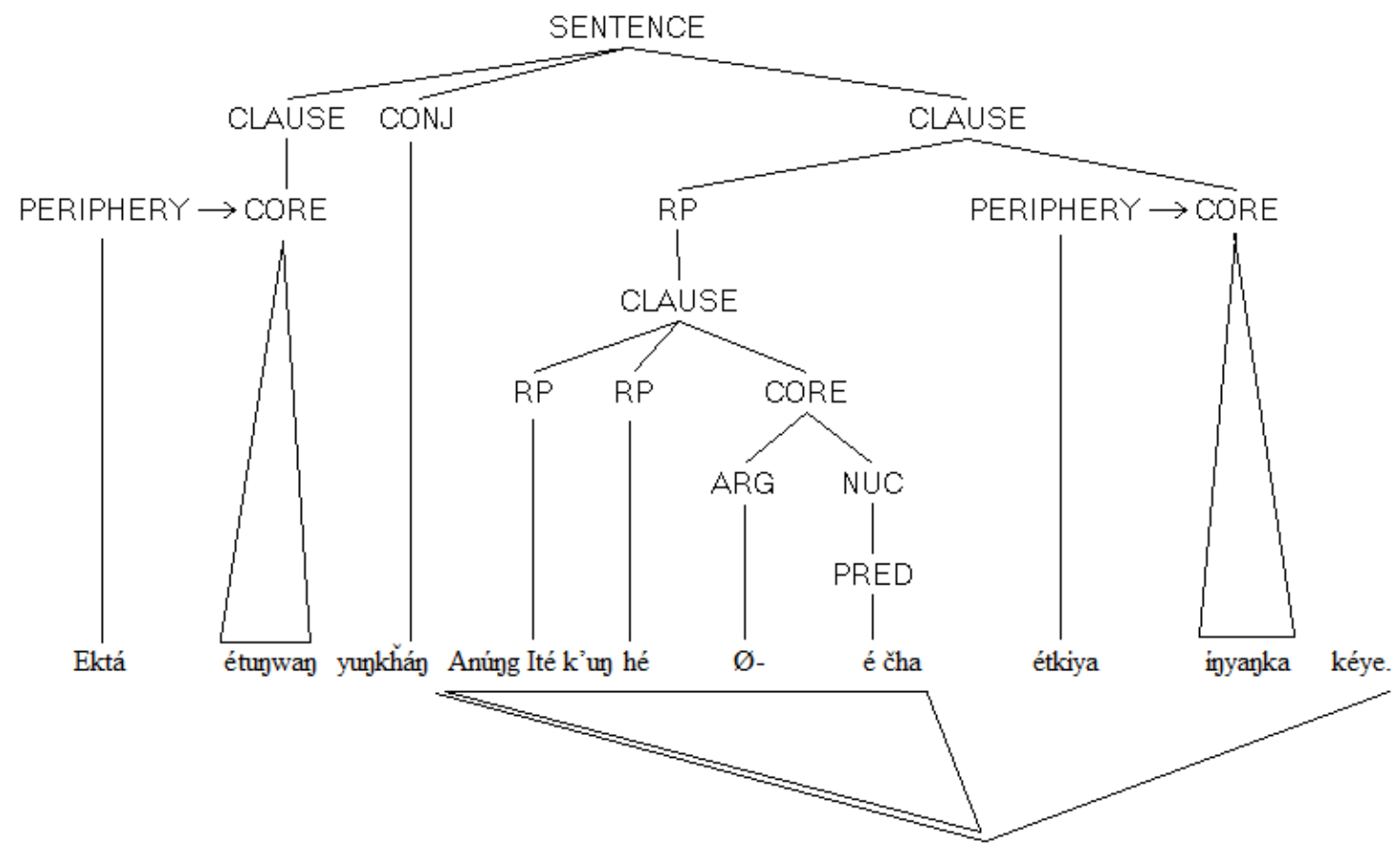


Em 4.8, há uma reintrodução da personagem Duas Faces (sua última referência no texto havia sido doze orações antes na forma de Undergoer e há dezoito orações como Actor) através do artigo k'un e logo em seguida se torna foco para o núcleo verbal ínyanka "correr".

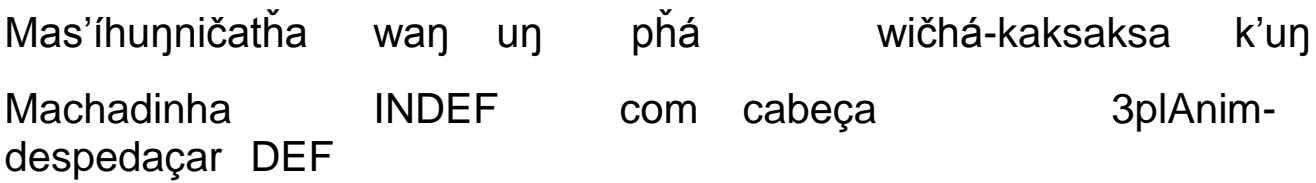

\begin{tabular}{lllllllll} 
hé & $\varnothing$-é & čha & $\varnothing-\varnothing$-ičú & na & ún & \multicolumn{2}{c}{ čhéyaya } \\
Esse & $\begin{array}{l}\text { (3sgU)-ser } \\
\text { chorando }\end{array}$ & ART & (3sgU)-(3sgA)-pegar & e & com & & ele
\end{tabular}

íš ehákela wínyan k'un Ø-Ø-kaȟúȟuğa škhé.

Ele finalmente mulher DEF (3sgU)-(3sgA)-destruir EVID

"O machado que ela havia sido usado para despedaçar a cabeça deles ele pegou e, chorando, finalmente destruiu a mulher." (DT: 88)

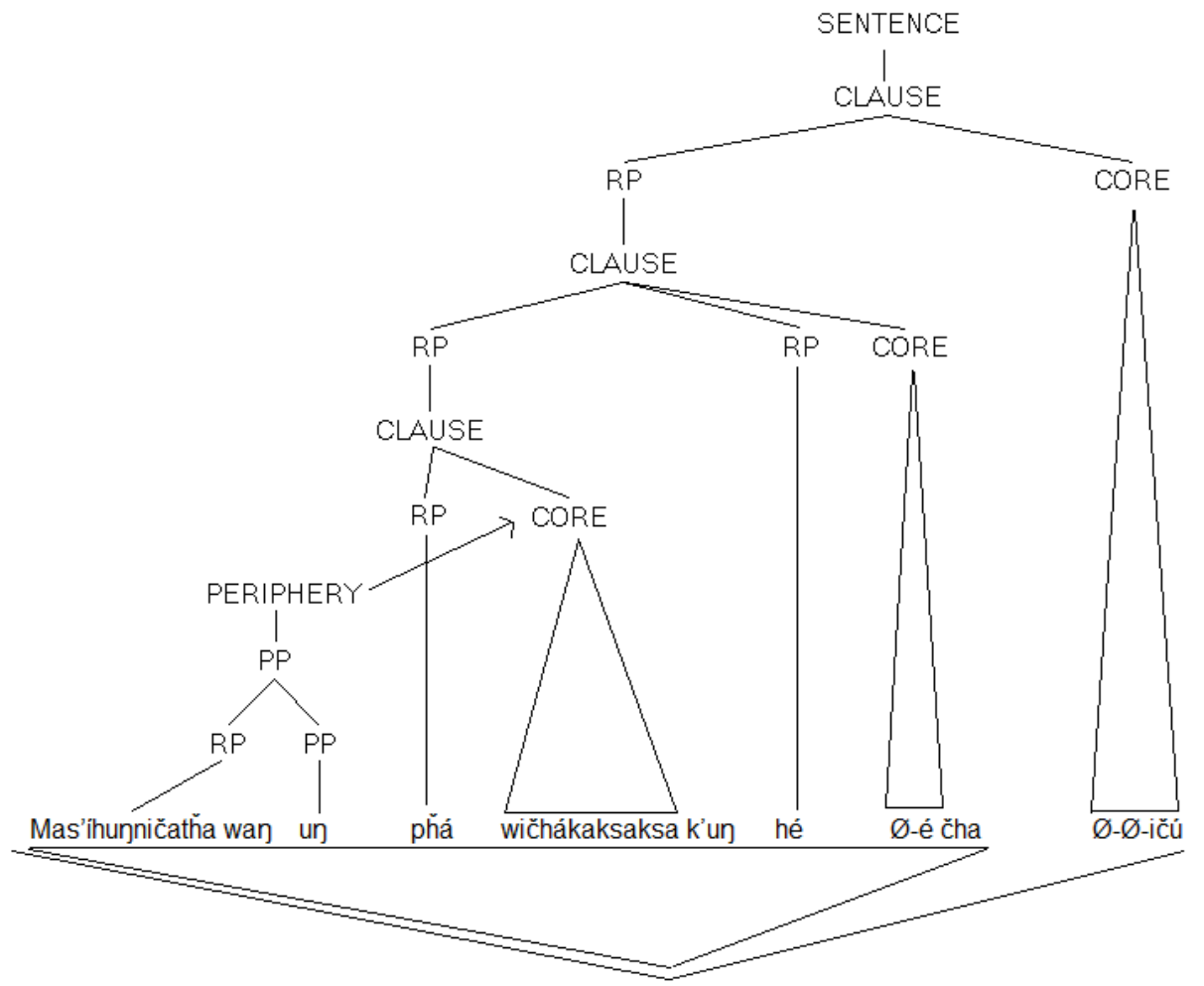


O exemplo acima nos dá duas informações novas: a primeira é que hé é čha não precisa se referir a um $R P$ da sentença anterior, mas pode também retomar uma entidade presente na Periphery, no caso, o sintagma instrumental Mas'íhunničatȟa wan un "usando um machado". De qualquer forma, trata-se de um machado em particular, portanto, não há contradição em se aplicar a raiz iyé na construção. A segunda é que, constituindo um $R P$ do núcleo verbal seguinte, pode ser usada também como undergoer.

A oração em 4.10 é um exemplo de iyé com um uso que nos serve de intermédio entre a estrutura apresentada neste tópico e o uso apresentado no tópico 3.3.1:

Išé

hé wanná akhé

Iktó Ø-é

čha $\varnothing$-ú (...)

INTERJ esse agora novamente lktó (3sgU)-ser ART (3sgA)-vir "É o lktó de novo que vem aí." (DT: 102)

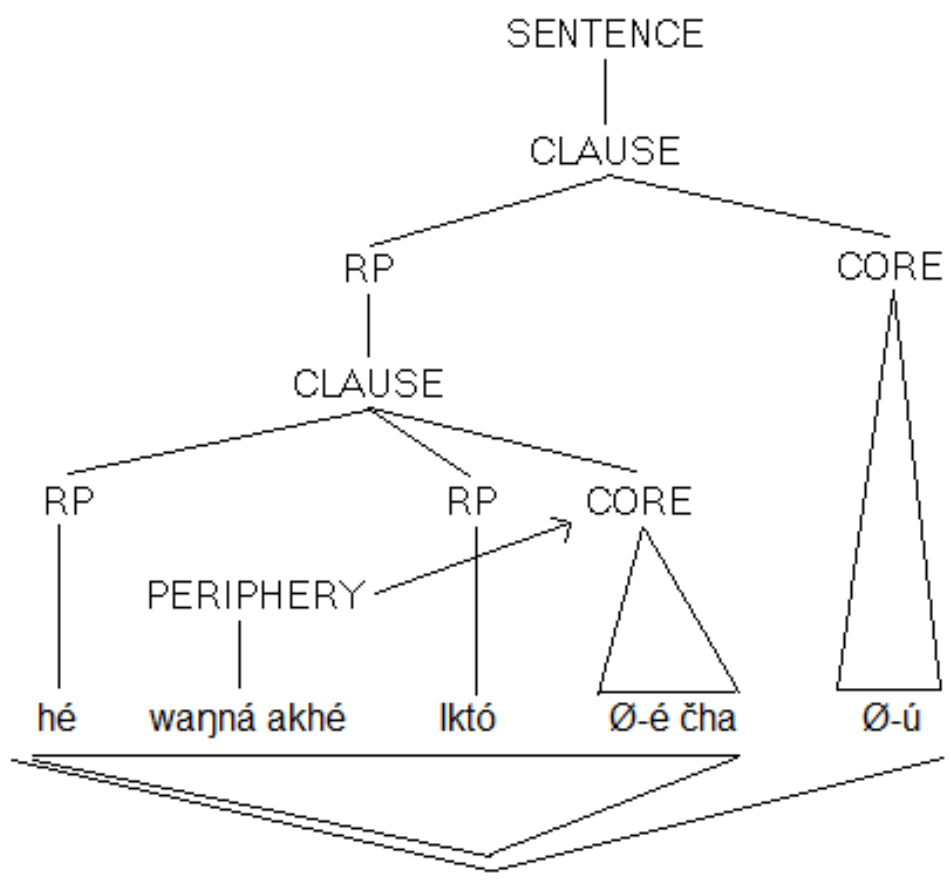

\footnotetext{
${ }^{33}$ Iktómi é um ser que pode aparecer em qualquer lugar a qualquer momento, muitas vezes disfarçado ou na forma de um coiote. Esta oração é sempre dita quando se descobre sua identidade ou quando sua presença é indesejada.
} 
Sendo o Iktómi uma personagem geralmente conhecida dentro do enredo da narrativa e que, portanto, dispensa apresentação, não há necessidade de relembrar sua existência (através de orações com yunkȟán ou k'un, como nos exemplos anteriores) e seu nome pode ser um RP do verbo iyé. Por sua vez hé wanná akhé Iktó é čha forma o RP do núcleo verbal ú, da mesma forma como hé é čha se porta nos exemplos anteriores.

Estas duas construções, junto dos demais usos de iyé e ínš, se revelam muito úteis na elaboração de uma narrativa oral. Diferente da narrativa escrita, em que o texto pode ser repensado e modificado, a narrativa oral depende da memória e da performance do falante, além da habilidade de criar tópicos e de confirmar para o ouvinte as pressuposições desses tópicos sempre que necessário. Conforme foi demonstrado neste tópico, a estrutura ...k’un hé é čha é uma das possibilidades, pois combina a função do artigo k'un, que é referir-se a algum elemento já citado anteriormente, com a estrutura de narrow focus hé é čha, cujo núcleo é a raiz iyé. Outro recurso necessário para o desenvolvimento da narrativa oral é a habilidade de introduzir repentinamente elementos que desempenharam em seguida a função de foco. Tais elementos podem ser repentinos pela intenção de criar um efeito surpresa ou talvez até pelo esquecimento do falante de tê-lo introduzido anteriormente. Uma estrutura recorrente nos textos em lakota que cumpre esta função é a combinação de yunkȟán com hé é čha.

Por fim, foi notado em uma narrativa que apresentava mais de um final possível o uso de ínš como recurso para separá-los. No texto Iktómi in a skull, após apresentar a introdução e o desenvolvimento do enredo, o narrador conta que não conhece o final verdadeiro da história:

Akšáka hetánhan tókhel Ø-h̆’an načhéče Infelizmente daí como (3sgA)-mover deve ter sido 

č'éyaš
ótakiya
na-wá-h̆'un
čhanké
mas
diversos
STEM-1sgA-ouvi
por isso

tókhetu kin tanslól-wa-ye šni.

Qual DEF STEM-1sgA-saber bem NEG

"Infelizmente ouvi diversas (versões) de como ele deve ter agido daí e por isso não sei bem qual é (a verdadeira)" (DT: 44)

Após esta proposição, ele conta cada uma das versões deixando claro que se tratam de finais diferentes. Para introduzir o segundo desfecho, o narrador usou a sentença:

Akhé léčhel o-Ø-yáka-pi: (...)

Novamente assim STEM-(3sgA)-narrar-PL

“Ainda narram assim: (...)” (DT, 45)

No último desfecho, entretanto, ínš é usado para diferenciá-lo dos demais:

Etán $\quad$ Øín-š $\quad$ h- $\varnothing$-éya-pi: (...)

Alguns (3sgU)-STEM-CON STEM-(3sgA)-dizer-PL

“E alguns dizem: (...)" (DT, 45) 
Como pode ser observado em sentenças como 3.57 e 4.13, ínš é usado para indicar contraste entre tópicos, mas não há necessidade de citá-lo mais de uma vez, podendo ocorrer apenas no último item contrastado. Nos exemplos acima, o contraste é usado não entre elementos dentro do enredo em si (personagens ou acontecimentos), mas como recurso para a estruturação da narrativa oral, em que o narrador precisa citar as fontes. Assim, o que está sendo contrastado são outros narradores e performances, criando um dinamismo dentro do gênero. A prova deste uso reside no fato do narrador não usar o enclítico de evidência škhé em nenhuma das sentenças acima, ou seja, nestes casos ele não está citando algo que ele ouviu, mas se posicionando enquanto narrador. Após cada desfecho, škhé é empregado para indicar que não é uma criação do narrador e o texto é concluído ao modo tradicional pertinente ao gênero:

Hečhékčhe oštéšteya wóyakapi kin lé o-Ø-yáka-pi

Assim estranhamente história DEF este STEM-(3sgU)-narrar-PL

s'a. Hehányela owí-Ø-hanke.

Sempre. Até aí STEM-(3sgU)-acabar.

"É assim de modo estranho que contam esta história. E aí ela acaba." 


\section{Considerações finais}

A língua lakota dispõe de dois conjuntos de palavras frequentemente classificados pela literatura como pronomes independentes. O primeiro deles, iyé, pode ser usado tanto como núcleo da sentença quanto na posição de $R P$, sendo referenciado por algum morfema pessoal no núcleo. Quando usado na posição de núcleo do predicado, a raiz assume o sentido do verbo "ser," quando usado para identificar entidades. Nos dois casos apresentados, a variação de pessoa é indicada pelo mesmo conjunto de afixos utilizado nos verbos regulares e a raiz pode ser interpretada como um verbo estativo. Daí pode-se questionar se iyé é realmente um pronome. Algumas das evidências levantadas foram a possibilidade de aparecer flexionado dentro do $R P$ e de possuir seus próprios $R P$. A estrutura sintática das sentenças com iyé e seu uso assemelham-se com a da clivagem, presente em línguas como o português.

Foram exploradas ainda outras raízes que apresentam comportamentos semelhantes, como o verbo estativo héčha "ser de determinada categoria," alguns dos pronomes interrogativos que frequentemente se referem a pessoa, como tuwá "quem" e táku "o que", e alguns termos que ora são considerados substantivos ora verbos, como hokšila "menino/ser menino" e lakh̆óta "lakota/ser lakota." Em todas estas raízes foram identificadas ocorrências no núcleo do predicado com afixação de morfemas pessoais e, com exceção dos interrogativos, a possibilidade de negá-los usando o sufixo šni.

O segundo conjunto, ínš, possui uma estrutura menos clara. Da mesma forma que iyé, é capaz de receber afixos pessoais e possivelmente originou-se como uma forma alternativa de iyé com o sufixo š. Os dois conjuntos compartilham algumas características em comum, mas ínš nunca é usado como núcleo de uma sentença. Uma maneira de analisar ínš sintaticamente é classificá-lo como núcleo do RP e os demais termos como seus sintagmas de referência. Desta forma, a estrutura de ínš e de iyé podem ser consideradas semelhantes. Outra maneira de interpretar o sintagma é entender ínš como algum tipo de modificador (ou operator) e assim o núcleo do sintagma passa a ser outro elemento. A co-ocorrência com outros termos dentro do sintagma talvez 
seja herança de alguma estrutura anterior, quando ínš possuía uma forma verbal mais clara.

Estas características tipológicas da língua lakota obscurecem os limites formais entre algumas classes gramaticais, como nome, verbo e pronome. Um estudo que visa questionar alguns dos paradigmas já hegemônicos nas teorias linguísticas precisa se atentar, no caso da língua lakota, para outras relações e possíveis semelhanças morfossintáticas, como o caso dos números e de certas posposições como etánhan "desde/ser de alguma procedência", que também podem receber os mesmos afixos dos verbos e ocupar posição de núcleo. O que possibilita uma variedade de interpretações por parte dos estudiosos é o fato do lakota não marcar a terceira pessoa através de afixos. Além disso, os morfemas que frequentemente são classificados como artigos, como kin, k’un e čha, são usados também para formar orações relativas, ou seja, um suposto nome deverbal pode ser facilmente tratado como uma oração.

De qualquer forma, ainda que iyé e ínš sejam considerados pronomes, os estudos feitos até o momento reconheceram seu uso no $R P$ para manipular a estrutura de foco dentro da sentença, atribuindo aos dois conjuntos o nome de pronome enfático. A existência de tais RPs se faz necessária já que os morfemas pessoais que são afixados ao núcleo do predicado não são capazes de criar uma estrutura de foco por si só, ou seja, o argumento do verbo só poderá desempenhar função de tópico ou de foco exclusivo, quando for referenciado em um sintagma externo. A distribuição das funções entre os dois conjuntos estudados é a seguinte: enquanto iyé é usado para indicar narrow focus, ínš é mais utilizado para indicar sentence focus. Dentro das narrativas aqui analisadas, vimos ainda que estas palavras são usadas como recurso para a estruturação do texto. Os dois casos mais recorrentes foram o emprego de iyé antecedido pela conjunção yunkh̆án "e então" para introduzir um elemento novo na narrativa que logo em seguida será posto em foco em algum acontecimento e o uso de iyé antecedido pro k’un, o artigo que retoma algum item já citado, para reintroduzi-lo na memória recente do ouvinte e usá-lo como foco. Estes usos propiciam uma fluência na performance, pois relacionam personagens e as posicionam perante os eventos narrados. Além disso, podem também servir para contextualizar as fontes que o narrador utilizou. Em uma cultura onde a oralidade 
é reconhecida como tradição e possui muitas vezes valor religioso ou artístico, a capacidade do narrador de manipular as estruturas linguísticas apresentadas se faz essencial para uma boa fluidez do texto e possivelmente até para sua legitimação, já que, apesar das inovações que a narrativa pode sofrer, ainda há a necessidade de se adequar ao estilo e forma do gênero, em especial a citação constante de que se trata de uma história ou mito ancestral. 


\section{Apêndice}

Para fins de ilustração do corpus estudado nesta dissertação, transcrevo integralmente uma das 63 narrativas pesquisadas. Nesta pequena amostra é possível encontrar parte dos fenômenos gramaticais analisados. Para facilitar a leitura dos estudantes da língua, optei por adotar a ortografia da maior parte dos livros didáticos e dicionários atuais. A versão original pode ser encontrada respectivamente na página 43 da obra Dakota Texts (DELORIA, 1932).

A narrativa será apresentada em três versões: na primeira versão, o leitor poderá apreciar o texto sem interrupção, na segunda será possível acompanhar o texto com a glossa e com uma tradução aproximada de alguns termos difíceis de serem traduzidos e, na terceira, a tradução do texto adaptada para 0 português.

\section{Primeira versão: Texto integral}

\section{Iktómi in the skull}

Iktómi kákhena ománi yá-han yunkȟán tókhiya lowánpi na akíš’api čha naȟ'ún škhé. Čhanké anáğoptan nážin kéye. Héčhena líla ínš-eyá wačhí-kiniča na sičhúha kin yašpúyaya čhanké tuktétu čha lé oíyokiphiya škánpi héčinhaniyéyewačhín kéye. Naȟ'ún nážin kin ečhél sánp hótȟanka lowánpi na wačhípi na akišs’api yunkȟán léna čhankú ičágla ptepȟá wan šéča ithímahetu čha nakéš slolyá kéye. Thimáhel iyóyanbyela ižánžanyanpi na líla okhílita čha wanyánke. Čhanké ištóȟloka kin etán éyokas'in yunkȟán hená hitȟúnkalapi čha wačhípi wan oíyokiphi tȟánka čha káğapi. Iktó thiyópa katóto na "Misún, únšimakilapi na thimá ú iyówinmakhiyapi yé. Mišs-eyá wawáčhi kte," eyá kéye. "Wán, ečéš čhiyé kiyúğanpi yé," eyápi čhanké wanná lazátanhan thiyópa kin kiyúğanpi. Yunkȟán phá kin tȟokéya pathíma hiyúkiye č'éyaš hehányela okíhi šni kéye. Yunkȟán wanží, "Hánta po, Iktó hé é yeló!" eyá čhanké tokhíyotȟan iyúha našlóg akhíyagla 
škhé. Na oíyokpaza čhanké tókhiya tȟanín šni. Héčheš Iktómi išnála tȟapȟá wan pȟóštan yín na hél čhéya-han kéye. Čhankú ičágla yankín na tuwá khiyéla hiyáya naȟ'ún čhan iyéna líla hótȟanka-kiya čhéyin na él ú šni sánp iyáyapi čhánšna akhé naȟmáh̆ma čhéya kéye.

Ho, akšáka hetánhan tókhel ȟ'án načhéče č'éyaš otákiya nawáȟun čhanké tokhétu kin tanslólwaye šni. Ínyan tȟánka wan yanká yunkȟán él i na, "Tȟunkášila, lé míčašlokin yé," eyá čhanké: Ho ečhá pȟá kin lečhétkiya kóskos hiyúya yo," eyá ayúpta škhé. Čhanké ečhún na ínyankin él iyápȟa čhanké tȟapȟá k’un átaya kabléčin na iyé pȟá kin iyówas'inyan iyápȟa čhanké natá ksúyeya škhé. Igláitomni na tónačhan owánžigži yankín na glépa-han škhé.

Akhé léčhel oyákapi. Tȟaphá kin hé mnióh̆panye šípi čhanké ečhún na mní t'eičciya škhé.

Etán íš heyápi: Čhethí na iwánkab tȟapȟá kin yúze (oyúšpe) šípi čhanké ečhún na ȟugnáȟ'ič'iya škhé. Héčhekčhe oštéšteya wóyakapi kin lé oyákapi s'a. Hehányela owíhanke.

\section{Segunda Versão: texto com glossa}

\section{Iktómi in the skull (Iktómi dentro do crânio de búfalo)}

$\begin{array}{llll}\text { Iktómi kákhena } & \text { ománi } & \varnothing \text {-yá-han } & \text { yunkȟán } \\ \text { Iktómi naquela direção } & \text { viajando } & \text { (3sgA)-ir-PROG } & \text { e então }\end{array}$

$\begin{array}{lllll}\text { tókhiya } & \varnothing \text {-lowán-pi } & \text { na } & \text { a-Ø-kišs’a-pi } & \text { čha } \\ \text { em algum lugar } & (3 s g A) \text {-cantar } & \text { e } & \text { STEM-(3sgA)-animar-PL } & \text { CONJ }\end{array}$


$\begin{array}{lll}\text { na- } \varnothing \text {-h̆'ún škhé. } & \text { Čhanké } & \text { aná- } \varnothing \text {-ğoptan } \\ \text { STEM-(3sgA)-ouvir EVID } & \text { por isso } & \text { STEM-(3sgA)-escutar }\end{array}$

$\begin{array}{lllll}\text { ná-Ø-žin } & \text { kéye. } & \text { Héčhena } & \text { líla } & \text { ínš-eyá } \\ \text { STEM-(1sgA)-levantar } & \text { EVID } & \text { Aí } & \text { muito } & \text { ele também }\end{array}$

wa-Ø-čhí-kiniča na sičhúha kin

STEM-(3sgA)-dançar-desejo e sola DEF

Ø-yašpúyaya čhanké tuktétu čha lé

(3sgA)-coçar e por isso que lugar DEF este

$\begin{array}{llll}\text { oíyokiphiya } & \varnothing \text {-škán-pi } & \text { héčinhan } & \text { i- } \varnothing \text {-yé- } \varnothing \text {-ye } \\ \text { animado } & \text { (3sgA)-mover-PL } & \text { CONJ } & \text { STEM-(3sgA)-ir }\end{array}$

$\begin{array}{llll}\text { Ø-wačhín } & \text { kéye. } & \text { Na- } \varnothing \text {-ȟ'ún } & \text { ná- } \varnothing \text {-žin } \\ (3 s g A)-q u e r e r & \text { EVID } & \text { STEM-(3sgA)-ouvir } & \text { STEM-(3sgA)-levantar }\end{array}$

kin ečhél sánp hótȟanka Ø-lowán-pi na

DEF assim mais voz alta (3sgA)-cantar-PL e
wa-Ø-čhí-pi
na $\quad a-\varnothing-k i ́ s ̌ a p i$
yunkȟán
STEM-(3sgA)-dançar-PL e STEM-(3sgA)-gritar
e então 
$\begin{array}{lllll}\text { léna } & \text { čhankú } & \text { ičágla ptephá } & \text { wan } & \varnothing \text {-šéča } \\ \text { aqueles caminho } & \text { beira crânio de búfalo um } & \text { (3sgU)-seco } \\ \text { Ø-ithímahetu } & \text { čha } & \text { nakéš } & \text { slol- } \varnothing \text {-yá } & \text { kéye. } \\ \text { (3sg)-estar dentro } & \text { DEF } & \text { finalmente } & \text { STEM-(3sgA)-saber } & \text { EVID }\end{array}$

Thimáhel iyóyanbyela ižánžan-Ø-yan-pi na líla

Dentro claramente STEM-(3sgA)-iluminar-PL e muito

o-Ø-khílita čha waク-Ø-yánke. Čhanké ištóȟloka

STEM-(3sgU)-animado DEF STEM-(3gA)-ver e por isso buracodo olho

kin etán éyo- $\varnothing$-kas’in yunkȟán hená $\varnothing$-hitȟúnkala-pi čha

DEF de STEM-(3sg)-olhar e então estes (3sgU)-rato-PL DEF

$\begin{array}{llll}\text { wačhípi wan oíyokiphithánka čha } & \varnothing \text {-káğa-pi. } \\ \text { dança } & \text { um grande felicidade } & \text { DEF } & \text { (3sgA)-fazer-PL }\end{array}$

Iktó thiyópa $\quad$-katóto na "Misún,

Iktómi porta (3sgA)-bater e meu irmão mais novo

únši-ma-Ø-kila-pi na thimá $\quad \varnothing$-ú

STEM-1sgU-(3sgA)-ter piedade-PL e dentro (3sgA)-vir 

lyówin-ma-Ø-khiya-pi
yé.
Míš-eyá
STEM-1sgU-(3sgA)-permitir-PL IMPER
Eu também

$\begin{array}{llll}\text { wa-wá-čhi } & \text { kte,” } & \varnothing \text {-eyá } & \text { kéye. } \\ \text { STEM-1sgA-dançar } & \text { FUT } & \text { (3sgA)-dizer } & \text { EVID }\end{array}$

$\begin{array}{lllll}\text { "Wán, } & \text { ečéš } & \text { čhiyé } & \varnothing \text {-kiyúğanpi } & \text { yé," } \\ \text { INTERJ } & \text { INTERJ } & \text { irmão mais velho } & (3 s g U)-(3 s g A) \text {-abrir para } & \text { IMPER }\end{array}$

$\begin{array}{lllll}\text { Ø-eyá-pi } & \text { čhanké } & \text { wanná } & \text { lazátanhan } & \text { thiyópa } \\ \text { (3sgA)-dizer-PL } & \text { e assim } & \text { agora } & \text { de trás } & \text { porta }\end{array}$

$\begin{array}{lllll}\text { kin } & \varnothing-\varnothing \text {-kiyúğanpi. } & \text { Yunkȟán } & \text { pȟ́ } & \text { kin } \\ \text { DEF } & (3 s g U)-(3 s g A) \text {-abrir para } & \text { e então } & \text { crânio } & \text { DEF }\end{array}$

$\begin{array}{cccc}\text { tȟokéya } & \text { pathíma } & \text { hiyú-Ø-khiye } & \text { č'éyaš } \\ \text { primeiro } & \text { forçando } & \text { STEM-(3sgA)-enfiar } & \text { mas }\end{array}$

$\begin{array}{lll}\text { hehányela } & \text { o-Ø-kíhi šni } & \text { kéye. } \\ \text { daí } & \text { STEM-(3sgA)-conseguir } & \text { EVID }\end{array}$

$\begin{array}{llllll}\text { Yunkhán } & \text { wajží, } & \text { "Hánta } & \text { po, } & \text { Iktó } & \text { hé } \\ \text { E então } & \text { um } & \text { Olhe } & \text { IMPER } & \text { Iktómi } & \text { este }\end{array}$




$\begin{array}{llll}\varnothing \text {-é } & \text { yeló!” } & \varnothing \text {-eyá } & \text { čhanké } \\ (3 s g U) \text {-ser } & \text { ENCL } & (3 s g A) \text {-dizer } & \text { e assim }\end{array}$

$\begin{array}{lll}\text { tokhíyotȟan } & \text { iyúha } & \text { na- } \varnothing \text {-šlóg } \\ \text { em direções } & \text { todos } & \text { STEM-(3sgA)-partir de repente }\end{array}$
a-Ø-khíyagla
škhé.
$\mathrm{Na} \quad$ o-Ø-íyokpaza
STEM-(3sgA)-ir para a própria casa
EVID
e STEM-(3sgU)-escuro

$\begin{array}{llll}\text { čhanké } & \text { tókhiya } & \varnothing \text {-tȟanín } & \text { šni. } \\ \text { E assim } & \text { onde } & \text { (3sgU)-claro } & \text { NEG }\end{array}$

$\begin{array}{lllll}\text { Héčheš } & \text { Iktómi } & \text { išnála } & \text { tȟapȟá } & \text { wan } \\ \text { Assim } & \text { Iktómi } & \text { sozinho } & \text { crânio de búfalo } & \text { um }\end{array}$

$\begin{array}{llll}\varnothing \text {-pȟóštan } & \varnothing \text {-yín } & \text { na } & \text { hél } \\ \text { (3sgA)-vestir na cabeça } & (3 s g A) \text {-ir } & \text { e } & \text { nesse lugar }\end{array}$

$\begin{array}{llll}\varnothing \text {-čhéya-han } & \text { kéye. } & \text { Čhankú } & \text { ičágla } \\ \text { (3sgA)-chorar-CONT } & \text { EVID } & \text { caminho } & \text { ao longo de }\end{array}$
$\varnothing$ Øyankín
na Ø-tuwá
khiyéla
(3sgU)-sentar-se
(3sgU)-alguém
perto 

hi-Ø-yá-Ø-ya
na-Ø-ȟ'ún
čhan
STEM-(3sgA)-STEM-(3sgA)-passar
STEM-(3sgA)-ouvir
quando

\begin{tabular}{|c|c|c|c|}
\hline iyéna & líla & hótȟankakiya & $\varnothing$-čhéyin \\
\hline /ez & muito & com voz alta & $(3 s g A)$-chorar \\
\hline
\end{tabular}

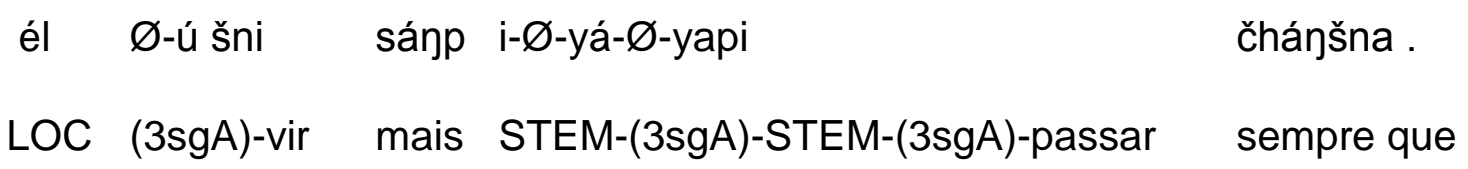

akhé naȟmáȟma Ø-čhéya kéye

novamente baixinho (3sgA)-chorar EVID

Ho, akšáka hetánhạ tókhel $\quad$-ȟ’án

INTERJ infelizmente daí como (3sgA)-mover-se

$\begin{array}{lllll}\text { načhéče } & \text { čéyaš } & \text { otákiya } & \text { na-wá-h̆'un } & \text { čhanké } \\ \text { talvez } & \text { mas } & \text { vários } & \text { STEM-1sgA-ouvir } & \text { e assim }\end{array}$

tokhétu kin tanslól-wa-ye šni.

Qual DEF STEM-1sgA-saber bem NEG

Ínyan $\quad$-th̆ánka wan $\quad$ w-yanká

Pedra (3sgU)-grande um (3sgU)-sentar-se e então 

él $\quad \varnothing-i ́$
na, "Tȟunkášila,
lé mí-Ø-čašlokin
yé,"
LOC (3sgA)-ir e meu avô
este $1 \mathrm{sgU}-(3 \mathrm{sg} \mathrm{A})$-tire
IMPER

Ø-eyá

čhanké: Ho

ečhá

pȟá

kin

(3sgA)-dizer

e assim

INTERJ

então

crânio

DEF

lečhétkiya

kóskos

hiyú-Ø-Ø-ya

yo,"

esta direção

balançando STEM-(3sgU)-(3sgA)-enviar

IMPER

$\begin{array}{llll}\text { Ø-eyá } & \text { a-Ø-yúpta } & \text { škhé. } & \text { Čhanké } \\ \text { (3sgA)-dizer } & \text { STEM-(3sgA)-responder } & \text { EVID } & \text { e assim }\end{array}$

ečh-Ø-ún

na ínyan kin él i-Ø-yápȟa

STEM-(3sgA)-fazer e pedra DEF LOC STEM-(3sgA)-bater

$\begin{array}{lllll}\text { čhanké } & \text { tȟapȟá } & \text { k'un } & \text { átaya } & \varnothing \text {-kabléčin } \\ \text { e assim } & \text { crânio } & \text { DEF } & \text { completamente } & \text { (3sgA)-quebrar }\end{array}$

$\begin{array}{llllll}\text { na } & \varnothing \text {-iyé } & \text { pȟá } & \text { kin } & \text { iyówas'inyan } & \text { i-Ø-yáph̆a } \\ \text { e } & \text { (3sgU)-ser } & \text { crânio } & \text { def } & \text { junto } & \text { STEM-(3sgA)-bater }\end{array}$

$\begin{array}{llll}\text { čhanké } & \text { natá } & \varnothing \text {-Ø-ksúyeya } & \text { škhé. } \\ \text { E assim } & \text { cabeça } & \text { (3sgU)-(3sgA)-ferir } & \text { EVID }\end{array}$




\begin{tabular}{|c|c|c|c|c|}
\hline Ø-igláitomni & na & tónačhan & \multicolumn{2}{|c|}{ owánžigži } \\
\hline (3sgU)-tonto & e & muitos dias & & \\
\hline$\varnothing$-yankín & na & $\varnothing$-glépa-haך & & škhé. \\
\hline (3sgU)-sentar-se & e & (3sgA)-vomita & NT & EVID \\
\hline
\end{tabular}

$\begin{array}{llll}\text { Akhé } & \text { léčhel } & \text { o-Ø-yáka-pi. } & \text { Tȟapȟá } \\ \text { Ainda } & \text { assim } & \text { STEM-(3sgA)-contar-PL } & \text { crânio de búfalo }\end{array}$

$\begin{array}{clll}\text { kin hé } & \text { mnióh̆pan- } \varnothing \text {-ye } & \varnothing \text {-ší-pi } & \text { čhanké } \\ \text { DEF este } & \text { STEM-(3sgA)-encharcar } & \text { (3sgA)-mandar-PL } & \text { e assim }\end{array}$

$\begin{array}{llll}\text { ečh- } \varnothing \text {-ún } & \text { na } & \text { mnít'e- } \varnothing \text {-íč'iya } & \text { škhé. } \\ \text { STEM-(3sgA)-fazer } & \text { e } & \text { STEM-(3sgU)-afogar-se } & \text { EVID }\end{array}$

$\begin{array}{llll}\text { Etán } & \text { ínš } & \text { he-Ø-yápi: } & \text { Čhe- } \varnothing \text {-thí } \\ \text { Alguns } & \text { CON } & \text { STEM-(3sgA)-dizem } & \text { STEM-(3sgA)-fazer fogo }\end{array}$

$\begin{array}{lllll}\text { na } & \text { iwánkab } & \text { thapȟá } & \text { kin } & \text { Ø-yúze } \\ \text { e } & \text { sobre } & \text { crânio } & \text { DEF } & \text { (3sgA)-segurar }\end{array}$

Ø-ší-pi čhanké ečh- $\varnothing$-ún na

(3sg)-mandar-PL e assim STEM-(3sgA)-fazer e 
$\begin{array}{lll}\text { h̆ugnáh'- } \varnothing \text {-ičilya } & \text { škhé. } & \text { Héčhekčhe } \\ \text { STEM-(3sgU)-queimar-se } & \text { EVID } & \text { dessas formas }\end{array}$

oštéšteya wóyakapi kin lé o-Ø-yáka-pi

Estranhamente história DEF este STEM-(3sgA)-contar-PL

s’a. Hehányela owí- $\varnothing$-hanke.

Sempre até aí STEM-(3sgU)-terminar.

\section{Terceira versão: Tradução}

Iktómi estava viajando e então ouviu que em algum lugar estavam cantando e gritando. Logo ele também quis dançar e sua perna começou a coçar, por isso começou a procurar onde é que se moviam com tanta animação. Ele parou para ouvir e, com a música, a dança e os gritos que ficaram mais altos, ele finalmente soube que era de dentro de um crânio de búfalo que jazia na beira da estrada. Ele viu que haviam iluminado dentro e que estava muito animado. $E$ assim, quando olhou o interior pelo buraco dos olhos, (viu que) eram ratos que faziam uma comemoração muito grande. Iktómi bateu na porta e disse: "Meus irmãozinhos, tenham piedade e me deixem entrar. Eu também vou dançar." Eles disseram "Bem, abram a porta para nosso irmão mais velho" e abriram a porta dos fundos para ele. Então ele enfiou a cabeça e não conseguiu mais mexer. $\mathrm{E}$ então um deles disse "Olhem, é o Iktómi!" e todos fugiram. Estava muito escuro e nada era visível. Assim Iktómi ficou com um Crânio em sua cabeça e começou a chorar. Sentou-se à beira da estrada e, quando ouvia alguém se aproximar, chorava alto. Quando partiam, chorava em silêncio.

Infelizmente eu ouvi esta história de várias maneiras e não posso confirmar qual é a versão verdadeira. Alguns contam que havia uma pedra e ele foi até ela, dizendo "Meu avô, tire isso de mim." E então a pedra respondeu 
"balance a cabeça nesta direção." Assim, ele o fez e bateu na pedra, quebrando o crânio completamente ao mesmo tempo em que batia e machucava sua própria cabeça. Ele ficou tonto e por muitos dias ficou sentado em silêncio vomitando.

Ainda há os que contam assim: disseram para ele enfiar o crânio na água e, fazendo isso, ele se afogou.

E alguns ainda dizem: disseram para ele fazer uma fogueira e segurar 0 crânio sobre ela e assim ele fez e se queimou. É dessas maneiras estranhas que eles sempre contam esta história. E aí ela acaba. 


\section{Referências Bibliográficas}

BOAS, Franz; DELORIA, Ella. Dakota Grammar. Washington: United States Government Printing Office, 1941.

BOAS, Franz. A mente do ser humano primitivo. 2 ed. Trad. José Carlos Pereira. Petrópolis, RJ, 2011.

BROWN, Joseph E. The Sacred Pipe: Black Elk's account of the seven rites of the Oglala Sioux. Oklahoma: University of Oklahoma Press, 1953.

CHANKU, Clifford; SIMON, Michael. The Dakota Prisoner of War Letters: Dakota Kaskapi Okicize Wowapi. Minnesota: Minnesota Historical Society Press, 2013.

ESTEBAN, Avelino C. An account of Lakota verbal affixes in transitive stative verbs. In: 16'emes Rencontres Jeunes Chercheurs (RJC 2013): Mod’eles et mod'elisation dans les sciences du langage. Paris: 2014.

CUMBERLAND. Linda A. A Grammar of Assiniboine: A Siouan Language of the Northern Plains. Indiana University, 2005.

DELORIA, Ella C. Dakota Texts. Lincoln: University of Nebraska Press,2006. Publicado originalmente em Nova lorque: American Ethnological Society, 1932.

GAGNON, Gregory O. Culture and Customs of the Sioux Indians. Greenwood: ABC-Clio, 2011.

HASSRICK, ROYAL B. The Sioux. Oklahoma: University of Oklahoma Press, 1964 
LAFONTAINE, Harlan; MCKAY, Neil. 550 Dakota Verbs. Minnesota: Minnesota Historical Society Press, 2005.

LAMBRECHT, Knud. Information Structure and Sentence Form. Cambridge: Cambridge University Press, 1994.

NETTLE, Daniel; ROMAINE, Suzanne. Vanishing Voices: The extinction of the World's Language. Oxford: Oxford University Press, 2000.

NICHOLS, Johanna. Head-Marking and Dependent-Marking Languages. In: Language, vol 62. Pag. 56-119. Washington: Linguistic Society of America, 1986.

POWERS, William K. Oglala Religion. Lincoln: University of Nebraska Press, 1982.

. Sacred Language: The Nature of Supernatural Discourse. Oklahoma: University of Oklahoma Press, 1992.

RANKIN, Robert L. Kanza Languages for Families and Communities. Kaw City: Kanza Language Project, 2007

RIGGS, Stephan R. Dakota Grammar, Texts and Ethnography. Washington: United States Government Printing Office, 1893.

SEAR, Victoria. Kanza and Osage: Language Materials, Revival and the Necessity for Phonetic Analysis. Trabalho de bacharelado. Bryn Mawr College, 2013. 
ULLRICH, Jan F. New Lakota Dictionary. Bloomington: Lakota Language Consortium, 2008.

. Lakȟótiya Wóglaka Po! Speak Lakota! Level 1 Lakota Language textbook. Bloomington, Indiana: Lakota Language Consortium, 2004a.

. Lakȟótiya Wóglaka Po! Speak Lakota! Level 2 Lakota Language textbook. Bloomington, Indiana: Lakota Language Consortium, 2004b.

- Lakhótiya Wóglaka Po! Speak Lakota! Level 3 Lakota Language textbook. Bloomington, Indiana: Lakota Language Consortium, 2010.

- Lakȟótiya Wóglaka Po! Speak Lakota! Level 4 Lakota Language textbook. Bloomington, Indiana: Lakota Language Consortium, 2012.

. Lakhótiya Wóglaka Po! Speak Lakota! Level 5 Lakota Language textbook. Bloomington, Indiana: Lakota Language Consortium, 2014.

VAN VALIN, Robert. Advances in Role and Reference Grammar. Amsterdam: John Benjamins Publishing Company, 1993.

An Introduction to Syntax. Cambridge: Cambridge University Press, 2004.

An Overview of Role and Reference Grammar. Disponível em: http://linguistics.buffalo.edu/people/faculty/vanvalin/rrg.html Acesso em: 18 de outubro de 2014. 
Aspects of Lakhota Syntax. Dissertação de pós-doutorado. Berkeley: University of California, 1977.

Exploring Syntax-Semantics Interface. Cambridge: Cambridge University Press, 2005.

. Head-Marking Languages and Linguistic Theory. Disponível em: <http://linguistics.buffalo.edu/people/faculty/vanvalin/rrg.html> Acesso: $18 \mathrm{de}$ outubro de 2014.

; LAPOLLA, Randy J. Syntax: Structure, Meaning and Function. Cambridge: Cambridge University Press, 1998.

WEST, Shannon L. Subjects and Objects in Assiniboine Nakoda. Dissertação de mestrado. University of Regina, 1988.

WHITE HAT, Sr. A. Reading and Writing Lakota Language. Salt Lake City: University of Utah Press, 1999.

WOOLFORD, Ellen. Active-Stative Agreement in Lakota: Person and Number Alignment and Portmanteau Formation. Manuscrito, University of Massachusetts, 2008.

YAMAMOTO, Akira. Endangered Languages in USA and Canada. Em: Language Diversity Endangered. Nova lorque: Walter de Gruyter GmbH \& Co, 2007. 
